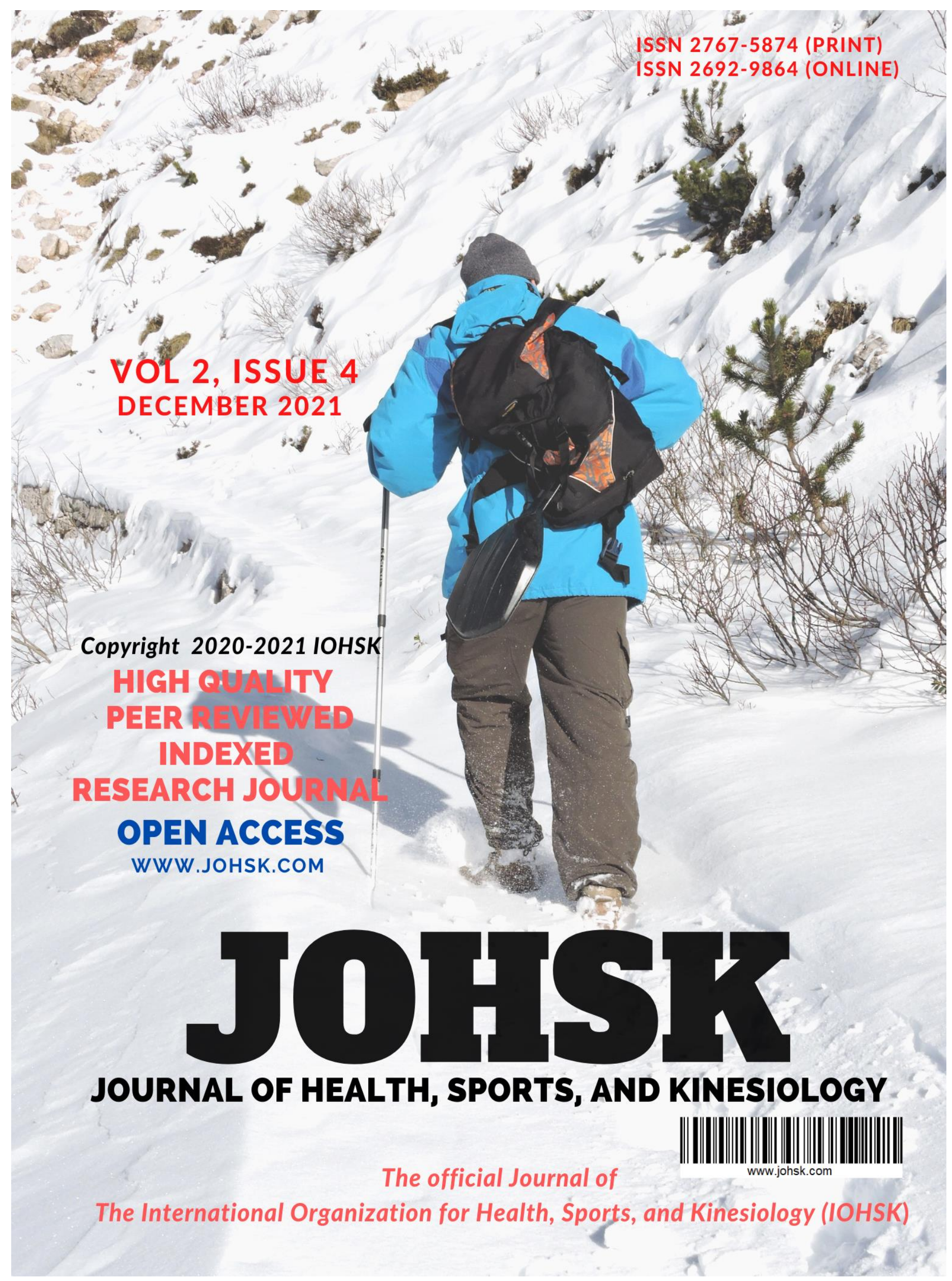




\section{JOURNAL OF HEALTH, SPORTS, \& KINESIOLOGY}

Copyright (C) 2020-2021 by the International Organization for Health, Sports, and Kinesiology (IOHSK). www.iohsk.org. The Journal of Health, Sports, and Kinesiology (JOHSK) publishes research articles in the fields of Health, Sports, and Kinesiology. JOHSK is an open access and peer-reviewed research journal that is published by the International Organization for Health, Sports, and Kinesiology (IOHSK). The Journal of Health, Sports, and Kinesiology (JOHSK) publishes four times a year. The JOHSK provides a platform for the researchers, academicians, professionals, practitioners, and students to impart and share knowledge. JOHSK welcomes and acknowledges high-quality theoretical and empirical original research papers, case studies, review papers, literature reviews, book reviews, conceptual framework, analytical and simulation models, technical notes from researchers, academicians, professionals, practitioners, and students from all over the world. Work must be of a quality and context that would be of interest to an international readership. Manuscripts for special issues and individual papers can be on any contemporary health, sports, and kinesiology topics of international interest. Research findings of high-quality research involving any discipline and methodology related to Health, Sports, and Kinesiology will be welcome. However, the journal's aim and scope are to ensure it publishes high quality research that could potentially inform research. The research findings do not have to be comparative (in the sense of comparing aspects of Health, Sports, and Kinesiology in different countries or cultures); a manuscript may report research carried out in just one regional location or sociocultural setting. Work can be drawn from any context or research paradigm. However, the Journal tends to publish empirical research studies that have clear significance to an international readership.

Editor: Dr. Young Sub Kwon, USA

Associate Editors:

Dr. Boungjin Kang, Elizabeth City State University, USA Dr. Stephen Hankil Shin, Belmont University, USA Dr. Soojin Yoo, University of Texas, Rio Grande Valley, USA
Send editorial correspondence to: Editor-in-Chief, Dr. Young Sub Kwon Department of Kinesiology \& Recreation Administration, 1 Harpst Street California Polytechnic University, Humboldt Arcata, CA 95521, USA

\author{
Send business correspondence to: \\ Publishing Editor, Dr. Hosung So \\ Department of Kinesiology, HP 202 \\ 5500 University Parkway \\ California State University, San Bernardino \\ San Bernardino, CA 92407, USA
}

\section{Editorial Board}

Junhyung Baek, Gyeongin National University of Education, Korea Joy Barros, University of Texas, Rio Grande Valley, USA Cuauhtemoc Carboni, Cuyamaca College, USA

Seung Ho Chang, San Jose State University, USA Kibum Cho, Hanyang University, Korea Soon Mi Choi, Midwestern State University, USA

Christopher Gentry, California State University, San Bernardino, USA Yu-Lun Huang, University of Wisconsin, Eau Claire, USA Christian Guerrero Juarez, University of California, Irvine, USA Sombat Karnjanakit, Chulalongkorn University, Thailand Jemin Kim, New Mexico State University, USA

Joon Young Kim, Syracuse University, USA Junhyoung Kim, Indiana University, USA MinJung Kim, University of Minnesota, USA

Yeon Kim, California State University, San Bernardino, USA Younglee Kim, California State University, San Bernardino, USA MinHyuk Kwon, California State Polytechnic University, USA Heesu Lee, Gyeongin National University of Education, Korea Julia Lee, Northwestern University Feinberg School of Medicine, USA Seonghun Lee, Flagler College, USA Seungkil Lim, Dongshin University, Korea Hasan Mavi, Eastern Illinois University, USA Emilio M. A. Millan, Autonomous University of Baja California, Mexico Junichi Nishida, Kindai University, Japan

Eung-Soo Oh, Donga University, Korea Taewoong Oh, Yongin University, Korea

Michael Olson, Midwestern State University, USA

Meungguk Park, Southern Illinois University, USA

Sitha Phongphilbool, Chulalongkorn University, Thailand

Seungmin Shin, King Fahd University of Petroleum \& Minerals, Saudi Arabia Pinar Yaprak, Gazi University, Turkey

Sung-Sang Yoo, Seoul National University, Korea
Daniel Balderson, University of Lethbridge, Canada

Elise Brown, Oakland University, USA

Chungil Chae, Kean University, Wenzhou, China

Yu-Kai Chang, National Taiwan Normal University, Taiwan

Jeongwon Choi, University of New Mexico, USA

Germina Cosma, University of Craiova, Romania

Sungchan Hong, University of Tsukuba, Japan

John A. Johnson, Keimyung University, Korea

Hoyoon Jung, Texas Tech University, USA

Doyeop Kim, Louisiana State University, Alexandria, USA

Jiho Kim, Wingate University, USA

Jun Kim, Southern Illinois University, USA

Minhyun Kim, Sam Houston State University, USA

Ji Young Kim, Sangmyung University, Korea

Youngje Kim, Chung-Ang University, Korea

Garry Kuan, Universiti Sains Malaysia, Malaysia

Don Lee, University of Houston, USA

Jihyun Lee, San Jose State University, USA

Kyoung Eun Lee, Texas A\&M University, Corpus Christi, USA

Hui Yin Ler, Tunku Abdul Rahman University College, Malaysia

Soyoun Lim, Mississippi State University, USA

Kisuk Min, University of Texas, El Paso, USA

Shannon Mulhearn, University of Nebraska, Kearney, USA

Issei Ogasawara, Osaka University, Japan

Hyun-Kyoung Oh, California State University, San Bernardino, USA

Yoonsin Oh, University of Wisconsin, Eau Claire, USA

Jinkyung Park, Georgia College and State University, USA

Sungje Park, Chung-Ang University, Korea

Wagner Prado, California State University, San Bernardino, USA

Ukje Sung, Columbia University, USA

Jae Yom, University of Illinois, Springfield, USA

\section{Publishing Editorial Board}

Taemin Ha, University of Northern Colorado, USA Jongho Moon, University of South Carolina, USA
Boram Lim, University of Nevada, Las Vegas, USA

Hyeonho Yu, Arizona State University, USA

JOSHK is a high-quality open access and peer-reviewed research journal. Work must be undertaken in an ethical manner. Research must have been undertaken in accordance with "Ethical Principles of Psychologists and Code of Conduct" provided by the American Psychological Association (APA) available at: http://www.apa.org/ethics/code/

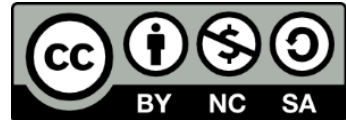

Copyright (C) 2020-2021. This work is licensed under a CC BY-NC-SA 4.0 International license. This is an open access article distributed under the Creative Commons Attribution License which permits unrestricted use, distribution, and reproduction in any medium, provided the original work is properly cited. 


\section{Journal of Health, Sports, \& Kinesiology}

\section{CONTENTS}

Acute Response of Blood Lipids and Lipoproteins to Different Intensities of

Exercise in Obese Males

Jinkyung Park \& Yunsuk Koh

Using Sport Education to Teach Wushu, a Form of Chinese Martial Arts

Peter A. Hastie, Yanhua Mo, \& Hairui Liu

Development of a Multi-Dimensional Scale to Measure

Professional Athletes as Role Model

Doyeop Kim, Giyong Koo, Minkil Kim, Stephen Shin, \& Anthony Dixon

Sex Differences in the Association Between Muscular Strength and Adiposity in Healthy Adults

Ethan W. Clark, Dorin Drignei, \& Elise C. Brown.

A Review: Effect of Rest Interval Duration on the Volume

Completed During Resistance Training

Dennis J. Hernandez \& Young Sub Kwon 


\title{
Acute Response of Blood Lipids and Lipoproteins to Different Intensities of Exercise in Obese Males
}

\author{
Jinkyung Park1 \& Yunsuk Koh² \\ ${ }^{1}$ Department of Exercise Science, Georgia College \& State University, Milledgeville, GA, USA \\ ${ }^{2}$ Department of Health, Human Performance, and Recreation, Baylor University, Waco, TX, USA \\ Received 25 August 2021 | Revised 27 November 2021 | Accepted 19 December 2021 \\ Open Access Available online at www.johsk.com
}

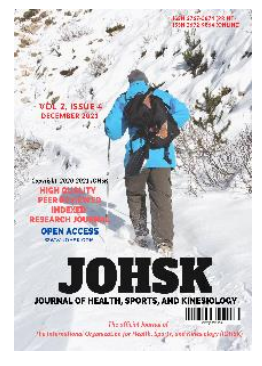

\begin{abstract}
This study aimed to examine the response of lipid and lipoprotein levels following different intensities of exercise in obese males. Fifteen obese (body mass index $>30 \mathrm{~kg} / \mathrm{m}^{2}$ ), sedentary (less than 2 days per week of physical activity) males, aged 18-30 years, participated in this randomized, cross-over study. The participants performed a single bout of cycling exercise (average energy expenditure: $\sim 300 \mathrm{kcal}$ ) at two different intensities [lower-intensity: $50 \%$ of maximal heart rate and higher-intensity: $80 \%$ of maximal heart rate] in a random order. Overnight fasting blood samples were collected at baseline, immediately post-exercise (IPE), 1-hr PE, and 24-hr PE for each intensity of exercise to determine the profile of blood lipids and lipoproteins [total cholesterol (TC), triglyceride (TG), low-density lipoprotein cholesterol (LDL-C), and high-density lipoprotein cholesterol (HDL-C)]. A 2(intensity) $\times 4$ (time) analysis of variance with repeated measures was used to examine the main and interaction differences in intensity and time on the profile of blood lipids and lipoproteins. The blood lipids and lipoproteins were not significantly altered following either lower or higher intensity exercise. There was no significant interaction between intensity and time. The results suggest that regardless of exercise intensity, an acute bout of aerobic exercise requiring $300 \mathrm{kcal}$ energy expenditure may not be enough to significantly alter blood lipids and lipoproteins in physically healthy obese males. Therefore, it is recommended that future research determine whether different intensities of chronic exercise requiring the same or higher volume of energy expenditure can positively alter the blood lipid profiles in obese males.
\end{abstract}

Keywords: Obesity, Exercise Intensity, Lipid, Cholesterol

\section{INTRODUCTION}

With the increasing prevalence of obesity in our society, a consistent correlation between obesity and the likelihood of metabolic or cardiovascular disease has become evident (Hruby \& Hu, 2015). Cardiovascular disease in particular can include high blood pressure, heart attack, stroke, heart failure, or arrhythmia. These conditions can be a byproduct of atherosclerosis-a build-up of plaque in the arteries-or blood clots in the heart or brain (Hansson, 2005; Libby, 2002). Meyers and Gokce (2007) state that increased level of body fat, as compared to the healthy recommendation, can contribute to heart disease via atrial enlargement, ventricular enlargement, and atherosclerosis (Meyers \& Gokce, 2007). Given the dangers of heart diseases and other conditions in an increasing obese population, combating obesity is crucial before it directly or indirectly leads to heart disease. A simple but extremely effective method to manage increased fat mass is exercise, specifically cardiovascular and metabolic conditioning (Fiuza-Luces et al., 2018). From years of study and abundant research to support this claim, it is known that physical exercise decreases blood pressure and body weight, while increasing high-density lipoprotein cholesterol (HDL-C) activity (Fiuza-Luces et al., 2018). In addition to these benefits, aerobic exercise improves circulation, while decreasing the lipid (Wang \& Xu, 2017) and improving lipid profile (Nystoriak \& Bhatnagar, 2018). The lipid profile test can determine the risk of plaque buildup in arteries to effectively manage diseases such as coronary artery disease. These lipid profile tests assess total cholesterol (TC), high density lipoprotein cholesterol (HDL-C), low-density lipoprotein cholesterol (LDL-C), and triglycerides (TG) (Goldberg et al., 2011). 
Previous studies on the effectiveness of high-, moderate-, and low-intensity exercise on lipid levels have reported significantly variable results (Albarrati et al., 2018; Kraus et al., 2002; Yoshida et al., 2010). Kraus et al. found that high-intensity/high-volume aerobic training seemed to elicit a statistically significant change in the LDL-C and HDL-C of the sedentary overweight participants (Kraus et al., 2002). However, Yoshida et al. suggested that the moderate-intensity aerobic exercise has a significant effect on LDL levels in subjects with dyslipidemia (Yoshida et al., 2010). Although moderate-intensity exercise may improve lipid profiles, recent evidence claims that the effects of low- and moderate-intensity aerobic exercise training on LDL levels are controversial (Albarrati et al., 2018). A main limitation of previous studies is that the previous studies (Kraus et al., 2002; Yoshida et al., 2010) did not address the diet record of the participants during the study period. This is a major factor that can significantly skew the research findings if not accounted for.

Although previous studies primarily assessed the effects of exercise training on lipid profiles, these studies did not address the role of exercise intensity in the altering of lipids and lipoproteins. In this study, we sought to better describe the influence of a single bout of exercise at different intensities on blood lipids and lipoproteins. The purpose of this study was to examine the blood lipid and lipoprotein profile changes following acute lower and higher intensity exercises in sedentary college-aged obese males.

\section{METHODS}

\section{Participants}

The study recruitment yielded 15 sedentary obese males as participants (body mass index $>30 \mathrm{~kg} / \mathrm{m}^{2}$, body fat percentage $>25 \%$ ). Participants were aged between 18 and 30 years and were physically inactive for at least 6 months prior to testing. Participants were considered physically inactive if they exercised less than twice a week. None of the participants were above the low risk of cardiovascular disease and no participant had any contraindication to exercise, as outlined by the American College of Sports Medicine exercise preparticipation health screening guidelines (Riebe et al., 2015). The study was reviewed and approved by the University Institutional Review Board for human subjects (IRB Reference No. 669721), and all subjects signed informed consent documents prior to testing. The anthropometric and body composition data of the participants are shown in Table 1.

Table 1. Anthropometric and Body Composition Data at Baseline

\begin{tabular}{cr}
\hline Variable & M SE SE \\
\hline Age (years) & $21.73 \pm .47$ \\
Height (cm) & $177.09 \pm 2.27$ \\
Body weight (kg) & $107.88 \pm 4.83$ \\
Body fat (\%) & $31.56 \pm 1.17$ \\
Lean mass (kg) & $64.62 \pm 2.37$ \\
Fat mass (kg) & $31.77 \pm 2.50$ \\
\hline
\end{tabular}

Note: $M=$ mean; $S E=$ standard error $; \mathrm{cm}=$ centimeters $; \mathrm{kg}=$ kilograms; $\%=$ percent

\section{Maximal Heart Rate Test Protocol}

The maximal heart rate (HRmax) test was conducted using a Monark cycle ergometer (Medgraphics, Monark, Ergomedic, Model No. 828E, St Paul, MN, USA) based on the protocol developed by Keytel et al. (Keytel et al., 2005) to estimate each participant's HRmax. The HRmax is defined as heart rate achieved at the point of maximal exhaustion (Keytel et al., 2005). To determine HRmax, participants warmed up on bicycle with a workload of $2 \mathrm{~W} / \mathrm{kg}$ for 2 minutes. After the warm-up session, participants maintained a speed of 70 revolutions per minute (rpm) with an intensity of $3.33 \mathrm{~W} / \mathrm{kg}$ for 150 seconds. These are the parameters of stage 1 of the HRmax test. After completion of stage 1 , workload was increased by an additional $50 \mathrm{~W}$ for another 150 seconds. After stage 2, the workload increased by $25 \mathrm{~W}$ every 150 seconds until the participants could not maintain $70 \mathrm{rpm}$ or reached maximal exertion and stopped the test on their own. The heart rate of each participant was tracked using a heart rate monitor placed around their chest (Polar Electro Inc., Lake Success, NY, USA). Heart rate was measured and recorded once each minute throughout the test duration.

\section{Study Design and Exercise Trials}

This study followed a randomized, crossover design. Exercises of two separate intensities were used, randomly assigned, and performed at least 1 week apart to ensure that the participants fully rested and returned to basal conditions. The lower-intensity (LI) trial was aimed at $50 \%$ of HRmax, while the higher intensity (HI) trial was aimed at $80 \%$ of HRmax. The participants expended the same energy expenditure $(\sim 300 \mathrm{kcal})$ on the cycle ergometer during each trial. The participants were asked to refrain from any exercise during the study period other than that involved in the study. Energy expenditure was calculated using the following equation by Keytel et al (2005): 
Energy Expenditure $=$ gender $\times(-55.0969+0.6309 \times$ heart rate $+0.1988 \times$ body weight $(\mathrm{kg})+0.2017 \times$ age $)+$

$(1-$ gender $) \times(-20.4022+0.4472 \times$ heart rate $-0.1263 \times$ body weight $(\mathrm{kg})+0.074 \times$ age $)$.

\section{Dietary Intake}

All participants recorded their food intake over 3 consecutive days (from 2 days prior to exercise to the day of exercise) for each exercise trial. Participants were instructed to maintain their usual caloric intake and diet composition.

\section{Fasting Blood Sampling}

Overnight fasting blood samples were collected at baseline (PRE), immediately post-exercise (IPE), 1-hour post-exercise (1-h PE), and 24-hour PE (24-h PE) for each exercise trial. Participants sat in a chair for 10 minutes before blood samples from the antecubital vein were collected into a serum separator tube. Blood samples were kept at room temperature for 20 minutes to ensure clotting, and then centrifuged for 20 minutes to separate the serum. Aliquots of serum samples were pipetted into 1.5 -mL tubes and frozen at $-80{ }^{\circ} \mathrm{C}$ for later analysis.

\section{Serum Lipid Profiles Analysis}

Serum samples in duplicate were assayed for TC (Kit\# R85464, Cliniqa, San Marcos, CA) and TG (Kit\# R84098, Cliniqa, San Marcos, CA) by an enzymatic colorimetric method. Serum lipoproteins, including LDL-C and HDL-C were analyzed by electrophoresis (Cat. \# 3438 SPIFE Vis Cholesterol, Helena Laboratory, Beaumont, TX) using the SPIFE 3000 electrophoresis system (Helena Laboratory, Beaumont, TX). The lipoprotein-cholesterol analysis was performed using a commercially available kit (Cat. \#3218, Helena Laboratory, Beaumont, TX) as per the manufacturer's instructions. In brief, $80 \mu \mathrm{L}$ of serum samples, in duplicate, were loaded on an agarose gel, followed by 20 minutes of electrophoresis at $16{ }^{\circ} \mathrm{C}$ with 400 volts. After applying a staining reagent (Cat. \#3438, Helena Laboratory, Beaumont, TX), additional electrophoresis was performed at $30{ }^{\circ} \mathrm{C}$ for 15 minutes. The gel was washed and then dried at $70{ }^{\circ} \mathrm{C}$ for 20 minutes, and the density of the stained lipoprotein-cholesterol bands were measured using a scanning densitometer (Epson Perfection V 700, Long beach, CA) using Quick Scan 2000 software (Helena Laboratory, Beaumont, TX). The coefficient of variation for each assay was: TC, 5.74\%; TG, 1.04\%; LDL-C, $1.86 \%$; HDL-C $3.86 \%$.

\section{Statistical Analysis}

All statistical analyses were performed using the IBM Statistical Package for the Social Sciences 20.0 (IBM SPSS, Armonk, USA) and reported as mean \pm standard error (SE) unless stated otherwise. A $2 \times 4$ (intensity x time) factorial ANOVA with repeated measures was used to test the effects of the lower and higher intensity of exercise on blood lipid and lipoprotein profiles (TC, TG, HDL-C, LDL-C) at baseline, IPE, 1-hr PE, and 24-hr PE. A p-value was set at < .05 for a statistical significance.

\section{RESULTS}

\section{Dietary Intake}

Total calories and macronutrient contents (fat, carbohydrate, and protein) between the two exercise trials were not significantly different $(p>$.05). Data for total calories, fat, carbohydrate, and protein content for each exercise trial are presented in Table 2.

Table 2. 3-Days of Dietary Intake

\begin{tabular}{|c|c|c|c|c|}
\hline Intensity & Variables & -48 Hour PRE & -24 Hour PRE & PRE \\
\hline \multirow{4}{*}{ Lower-Intensity (ㄴI) } & Total calories (kcals/day) & $1,811.89 \pm 178.72$ & $2,134.68 \pm 133.58$ & $1,690.99 \pm 196.62$ \\
\hline & Fat (kcals/day) & $637.19 \pm 126.70$ & $864.04 \pm 440.23$ & $749.71 \pm 122.21$ \\
\hline & Carbohydrate (g/day) & $257.70 \pm 32.89$ & $233.25 \pm 44.01$ & $166.35 \pm 37.66$ \\
\hline & Protein (g/day) & $86.43 \pm 13.69$ & $165.48 \pm 59.43$ & $73.38 \pm 12.48$ \\
\hline \multirow{4}{*}{ Higher-Intensity (HI) } & Total calories (kcals/day) & $1,820.48 \pm 184.99$ & $1,833.27 \pm 138.27$ & $1,739.02 \pm 203.52$ \\
\hline & Fat (kcals/day) & $1,073.56 \pm 126.70$ & $1,402.44 \pm 440.23$ & $700.32 \pm 122.21$ \\
\hline & Carbohydrate (g/day) & $217.03 \pm 32.89$ & $266.85 \pm 44.01$ & $228.56 \pm 37.66$ \\
\hline & Protein (g/day) & $109.71 \pm 13.69$ & $95.69 \pm 59.43$ & $82.81 \pm 12.48$ \\
\hline
\end{tabular}

Note: All data are presented as mean \pm standard error; $\mathrm{g}=$ grams; $\mathrm{kcals}=$ kilocalories; PRE $=$ prior to exercise. 


\section{Workload, Heart Rate, and Time}

Each exercise trial was performed at the similar exercise volume (total energy expenditure of $300 \mathrm{kcal}$ ). Significant differences were found between LI and HI in workload $(p=.001)$, heart rate $(p=.001)$, and time $(p=.001)$. Data for workload, heart rate, and time for each exercise trial are presented in Table 3.

Table 3. Workload, Heart Rate, and Time for Each Exercise Trial

\begin{tabular}{lcrr}
\hline Variable & LI (Lower-Intensity) & HI (Higher-Intensity) & $P$-value \\
\hline Workload (kp) & $1.51 \pm 0.05$ & $2.42 \pm 0.09$ & .001 \\
Heart rate (bpm) & $98.80 \pm 1.82$ & $154.20 \pm 2.76$ & .001 \\
Time (min) & $42.00 \pm 1.77$ & $19.00 \pm 0.53$ & .001 \\
\hline
\end{tabular}

Note: All data are presented as mean \pm standard error. $\mathrm{kp}=$ kilopond; $\min =$ minutes; $\mathrm{bpm}=$ beats per minute.

\section{Changes in Blood Lipid Profiles}

Changes in blood lipids and lipoproteins for each exercise intensity are presented in Table 4. There were no significant differences in any of blood lipids and lipoproteins between the exercise intensity or time.

Table 4. Changes in Blood Lipids and Lipoproteins

\begin{tabular}{|c|c|c|c|c|c|}
\hline Intensity & Variable & $\begin{array}{r}\text { Baseline } \\
(M \pm S E)\end{array}$ & $\begin{array}{c}\text { IPE } \\
(M \pm S E)\end{array}$ & $\begin{array}{c}\text { 1-Hour PE } \\
(\mathrm{M} \pm \mathrm{SE})\end{array}$ & $\begin{array}{c}\text { 24-Hour PE } \\
\text { (M } \pm \text { SE) }\end{array}$ \\
\hline \multirow{4}{*}{ Lower-Intensity (ㄴI) } & $\mathrm{TG}(\mathrm{mg} / \mathrm{dl})$ & $163.08 \pm 28.84$ & $147.35 \pm 23.52$ & $133.04 \pm 18.00$ & $139.83 \pm 21.90$ \\
\hline & $\mathrm{TC}(\mathrm{mg} / \mathrm{dl})$ & $211.70 \pm 9.02$ & $210.48 \pm 7.85$ & $210.67 \pm 8.35$ & $208.80 \pm 7.89$ \\
\hline & $\mathrm{LDL}-\mathrm{C}(\mathrm{mg} / \mathrm{dl})$ & $146.22 \pm 9.06$ & $144.79 \pm 8.50$ & $145.53 \pm 8.07$ & $143.27 \pm 8.22$ \\
\hline & HDL-C (mg/dl) & $53.51 \pm 2.95$ & $53.46 \pm 2.56$ & $52.68 \pm 2.45$ & $54.12 \pm 2.00$ \\
\hline \multirow{4}{*}{$\begin{array}{l}\text { Higher-Intensity } \\
\text { (HI) }\end{array}$} & $\mathrm{TG}(\mathrm{mg} / \mathrm{dl})$ & $128.85 \pm 28.84$ & $126.73 \pm 23.52$ & $129.77 \pm 18.00$ & $135.54 \pm 21.90$ \\
\hline & $\mathrm{TC}(\mathrm{mg} / \mathrm{dl})$ & $216.51 \pm 9.02$ & $217.80 \pm 7.85$ & $213.30 \pm 8.35$ & $209.31 \pm 7.89$ \\
\hline & $\mathrm{LDL}-\mathrm{C}(\mathrm{mg} / \mathrm{dl})$ & $151.09 \pm 9.06$ & $150.35 \pm 8.50$ & $152.25 \pm 8.07$ & $147.21 \pm 8.23$ \\
\hline & HDL-C (mg/dl) & $55.73 \pm 2.95$ & $54.87 \pm 2.56$ & $53.14 \pm 2.45$ & $54.38 \pm 2.00$ \\
\hline
\end{tabular}

Note: TG, Triglycerides; TC, total cholesterol; LDL-C, low-density lipoprotein cholesterol; HDL-C, high-density lipoprotein cholesterol; $\mathrm{IPE}$, immediate post-exercise; $\mathrm{PE}$ = post-exercise; $\mathrm{mg} / \mathrm{dl}=$ milligrams per deciliter; $\mathrm{M}$, mean; SE, standard error.

\section{DISCUSSION}

The overall objective of this study was to examine the effectiveness of a different exercise intensity (lower vs. higher) requiring the same energy expenditure in changes in the lipid and lipoprotein profiles in physically healthy obese males. Given the ever-increasing rates of obesity and cardiovascular disease in America (Capewell et al., 2010), it is important to have the most applicable knowledge and to utilize the best tools to combat this epidemic. It is unanimously agreed upon in the healthcare community that exercise can help improve body composition (Warburton et al., 2006). Exercises can also mitigate and reverse/reduce high levels of atherosclerosis, high levels of cholesterol and triglycerides, and balance the lipid profile (Warburton et al., 2006). However, it is unclear which intensity of exercise yields the most effective results. In this study, both lower and higher intensity exercises resulted in similar changes in LDL, HDL, TC, and TG, which were not statistically significant. One of the possible explanations for the lack of significant differences between the lower and higher exercise intensities in blood lipids and lipoproteins was due to the equal energy expenditure required for each exercise intensity. The participants expended $300 \mathrm{kcal}$ during lower and higher intensity exercises in this study. This would support the claim of many other studies, which have reported that changes in blood lipids and lipoproteins are based on total calories burned, not the intensity of exercise (Crouse et al, 1995; Kraus et al., 2002; Tall, 2002). Thus, it would be better to focus on increasing and accumulating caloric expenditure 
daily, which will also lead to a decrease in body weight and improve body composition. It appears that weekly caloric expenditure from exercise that meets or exceeds the range for a healthy lifestyle is more important than the intensity of exercise. An adequate volume of physical activity is more sustainable for most individuals and should be encouraged (Kannan et al., 2014).

Although many precautions were taken to ensure that the study was successful, some limitations still remained. This study was limited to the sample size that was available. In addition, there was no control session. Future studies should include a more diverse sample size, involving more variations in age, sex, and ethnicities with control setting. Also, it is recommended that future research determine whether different intensities of chronic exercise requiring the same or higher volume of energy expenditure can positively alter the blood lipid profiles in obese males.

\section{CONCLUSION}

This study suggests that regardless of exercise intensity, an acute bout of aerobic exercise requiring 300 kcal energy expenditure may not be enough to significantly alter blood lipids and lipoproteins in physically healthy obese males. Therefore, we suggest that exercise volume, instead of exercise intensity, should be considered as a key factor for positively changing the lipids and lipid profiles in obese males.

\section{REFERENCES}

Capewell, S., Ford, E. S., Croft, J. B., Critchley, J. A., Greenlund, K. J., \& Labarthe, D. R. (2010). Cardiovascular risk factor trends and potential for reducing coronary heart disease mortality in the United States of America. Bulletin of the World Health Organization, 88(2), 120-130. https://doi.org/10.2471/BLT.08.057885

Crouse, S. F., O'Brien, B. C., Rohack, J. J., Lowe, R. C., Green, J. S., Tolson, H., \& Reed, J. L. (1995). Changes in serum lipids and apolipoproteins after exercise in men with high cholesterol: Influence of intensity. Journal of Applied Physiology, 79(1), $279-286$. doi:10.1152/jappl.1995.79.1.279

Fiuza-Luces, C., Santos-Lozano, A., Joyner, M., Carrera-Bastos, P., Picazo, O., Zugaza, J. L., Izquierdo, M., Ruilope, L. M., \& Lucia, A. (2018). Exercise benefits in cardiovascular disease: beyond attenuation of traditional risk factors. Nature reviews. Cardiology, 15(12), 731-743. https://doi.org/10.1038/s41569-018-0065-1

Goldberg, A. C., Hopkins, P.N., Toch, P.P., Goldberg, A. C., Hopkins, P. N., Toth, P. P., Ballantyne, C. M., Rader, D. J., Robinson, J. G., Daniels, S. R., Gidding, S. S., de Ferranti, S. D., Ito, M. K., McGowan, M. P., Moriarty, P. M., Cromwell, W. C., Ross, J. L., Ziajka, P. E., \& National Lipid Association Expert Panel on Familial Hypercholesterolemia (2011). Familial hypercholesterolemia: Screening, diagnosis and management of pediatric and adult patients: Clinical guidance from the National Lipid Association

Expert Panel on familial hypercholesterolemia. Journal of Clinical Lipidology, 5(3), Suppl., S1-S8. 10.1016/j.jacl.2011.04.003.

Hansson, G. K. (2005). Inflammation, atherosclerosis, and coronary artery disease. The New England Journal of Medicine, 352(16), 1685-1695. doi:10.1056/NEJMra043430

Libby, P. (2002). Inflammation in atherosclerosis. Nature, 420(6917), 868-874. doi:10.1038/nature01323

Hruby, A. \& Hu, F.B. (2015). The epidemiology of obesity: A big picture. Pharmacoeconomics, 33(7), 673-689. https://doi.org/10.1007/s40273-014-0243-x

Kannan, U., Vasudevan, K., Balasubramaniam, K., Yerrabelli, D., Shanmugavel, K., \& John, N. A. (2014). Effect of exercise intensity on lipid profile in sedentary obese adults. Journal of Clinical and Diagnostic Research, 8(7), BC08-BC10 doi:10.7860/JCDR/2014/8519.4611

Keytel, L.R., Goedecke, J.H., Noakes, T.D., Hiiloskorpi, H., Laukkanen, R., van der Merwe, L., \& Lambert, E. V. (2005). Prediction of energy expenditure from heart rate monitoring during submaximal exercise. Journal of Sports Sciences, 23(3), $289-297$.

Kraus, W. E., Houmard, J. A., Duscha, B. D., Knetzger, K. J., Wharton, M. B., McCartney, J. S., Bales, C. W., Henes, S., Samsa, G. P., Otvos, J. D., Kulkarni, K. R., \& Slentz, C. A. (2002). Effects of the amount and intensity of exercise on plasma lipoproteins. The New England Journal of Medicine, 347(19), 1483-1492. https://doi.org/10.1056/NEJMoa020194

Meyers, M. R. \& Gokce, N. (2007). Endothelial dysfunction in obesity: etiological role in atherosclerosis. Current Opinion in Endocrinology, Diabetes and Obesity, 14(5), 365-369. doi: 10.1097/MED.0b013e3282be90a8.

Nystoriak, M. A., \& Bhatnagar A. (2018). Cardiovascular effects and benefits of exercise. Frontiers in Cardiovascular Medicine, 5, 135. https://doi.org/10.3389/fcvm.2018.00135

Riebe, D., Franklin, B. A., Thompson, P. D., Garber, C. E., Whitfield, G. P., Magal, M., \& Pescatello, L. S. (2015). Updating ACSM's Recommendations for Exercise Preparticipation Health Screening. Medicine and Science in Sports and Exercise, 47(11), 24732479. https://doi.org/10.1249/MSS.0000000000000664

Tall A. R. (2002). Exercise to reduce cardiovascular risk--how much is enough?. The New England Journal of Medicine, 347(19), 15221524. https://doi.org/10.1056/NEJMe020117

Wang, Y., \& Xu, D. (2017). Effects of aerobic exercise on lipids and lipoproteins. Lipids in Health and Disease, $16(1), 132$. doi:10.1186/s12944-017-0515-5

Albarrati, A. M., Alghamdi, M. S. M., Nazer, R. I., Alkorashy, M. M., Alshowier, N., \& Gale, N. (2018). Effectiveness of Low to Moderate Physical Exercise Training on the Level of Low-Density Lipoproteins: A Systematic Review. BioMed Research International, 5982980. https://doi.org/10.1155/2018/5982980 
Warburton, D. E. R., Nicol, C. W., \& Bredin, S. S. D. (2006). Health benefits of physical activity: The evidence. CMAJ: Canadian Medical Association Journal, 174(6), 801-809. https://doi.org/10.1503/cmaj.051351

Yoshida, H., Ishikawa, T., Suto, M., Kurosawa, H., Hirowatari, Y., Ito, K., Yanai, H., Tada, N., \& Suzuki, M. (2010). Effects of supervised aerobic exercise training on serum adiponectin and parameters of lipid and glucose metabolism in subjects with moderate dyslipidemia. Journal of Atherosclerosis and Thrombosis, 17(11), 1160-1166. https://doi.org/10.5551/jat.4358

\section{Author Information}

Jinkyung Park, Ph.D., Corresponding Author (D) https://orcid.org/0000-0003-4888-8881

Assistant Professor, Department of Exercise Science School of Health and Human Performance

Georgia College \& State University, Milledgeville, GA, USA.

@ijinkyung.park@gcsu.edu

\section{Yunsuk Koh, Ph.D.}

(D https://orcid.org/0000-0001-9280-5786

Associate Professor \& Director of Exercise Physiology

Department of Health, Human Performance, and Recreation

College of Health and Human Sciences

Baylor University, Waco, TX, USA.

직u﹎koh@baylor.edu

Conflict of Interest: The authors declare that the research was conducted in the absence of any commercial or financial relationship that could be constructed as a potential conflict of interest.

Publisher's Note: All claims expressed in this article are solely those of the authors and do not necessarily represent those of their affiliated organizations, or those of the publisher, the editors and reviewers. Any product that may be evaluated in this article, or claim that may be made by its manufacturer, is not guaranteed or endorsed by the publisher.

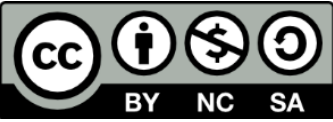

Copyright (C) 2020-2021. This work is licensed under a CC BY-NC-SA 4.0 International license. This is an open access article distributed under the Creative Commons Attribution License which permits unrestricted use, distribution, and reproduction in any medium, provided the original work is properly cited. 


\title{
ORIGINAL RESEARCH
}

\section{Using Sport Education to Teach Wushu, a Form of Chinese Martial Arts}

\author{
Peter A. Hastie', Yanhua Mo2, \& Hairui Liu ${ }^{3}$ \\ ${ }^{1}$ School of Kinesiology, Auburn University, AL, USA \\ ${ }^{2}$ Guangxi Normal University, China \\ ${ }^{3}$ University of Winnipeg, Manitoba, Canada
}

Received 11 August 2021 | Revised 3 December 2021 | Accepted 7 December 2021

Open Access Available online at www.johsk.com

\begin{abstract}
This study examined the veracity of the commonly held notion that 'there is only one way to teach Chinese martial arts.' To achieve this, a cohort of Chinese physical education majors and their teacher participated in a semester-long season of Wushu taught using Sport Education (SE). Data were collected from the teacher in the form of weekly logs and interviews and students participated in small-group interviews throughout the program. Student grades were also analyzed. Student and teacher generated data were analyzed using analytic induction and constant comparison techniques. There was a high consistency among teacher's log entries, her interviews, and comments made by students during interviews. Nevertheless, one topic that occupied significant discussion in the final interview was the teacher's sense of professional renewal as a result of the SE project. Analysis of student interviews generated six themes, most which reflected student responses about SE (e.g., teams, competition, roles) but which also expressed a preference for the instructional climate of classes. Further, participation during the season did not compromise knowledge or skill performance of these students. Rather, SE led to higher levels of enthusiasm and engagement than in students' previous martial arts courses.
\end{abstract}

Key words: Wushu, Teacher Education, China, Engagement, Motivation

\section{INTRODUCTION}

The practice of martial arts in China has a long and storied history, tracing back as early as the Shang dynasty (1600-1066BC) (Li \& Du, 1991). Currently, it is estimated that over 70 million Chinese citizens practice martial arts as part of their lifestyles, with a focus on the fighting, health, or cultural elements (Zheng \& Yuan, 2013). Originally there was not a single martial arts style, but a number of schools and variations (Wang, 2010). However, in the 1950s all different forms of martial arts were standardized by the central party (Lorge, 2012). The term adopted was "Wushu".

There are two disciplines in modern Wushu competition: routines (taolu), consisting of sets of connecting stylized movements (with or without traditional weapons), and free sparring (sanda) that includes kicking, punching, grappling, and throwing techniques (Chinese Wushu Association, 2008). However, within school and university physical education, only the taolu discipline is taught.

In Chinese universities, physical education is a compulsory requirement for graduation for students in all degree programs. Instruction in Wushu itself appears in three formats (I) as an optional physical education class for all students, (ii) as a required component of physical education degrees, and (iii) as a specialty study area within physical education. Nonetheless, the instruction of Wushu is not without its critics. Some of these are philosophical, while others focus on pedagogy. From a philosophical perspective, the content of courses is seen as somewhat superficial, leading to what Tan (2009) describes as a curriculum that is "broad but not deep, substantive but not refined", and where students' learning of martial arts techniques and martial arts culture mostly stays at the level of "initial experience". Further, Chai and Sun (2020) suggest that the focus on technique fails to include the spiritual/theory behind the practice of Wushu.

More frequent than philosophical discussions about Wushu content, however, are criticisms about how Wushu instruction is delivered (Du et al., 2018). In essence, the teaching of Wushu follows a very controlling form of teaching where the teacher is seen as the 
exclusive source of knowledge, and students practice rote movements in specific orders in order to develop mastery of individual techniques (Wang, 2018).

Together, these features of rote learning within Wushu instruction have been critiqued from two perspectives. The first is that is many students see it as boring, particularly given the emergence of new physical spaces and digital cultures that play a significant role in Chinese society today (Frangville \& Affric, 2019). Second, given the lack of Wushu instruction in primary and secondary schools, college students are not familiar with, do not understand, do not respect Wushu, and generally lack interest in learning Wushu (Li \& Lu, 2018). Within the abundance of theoretical papers recommending an overhaul of the practice of Wushu instruction, there are those who present the Sport Education (SE) model (Siedentop et al, 2020) as a way of changing the paradigm (Tan, 2009; Yang \& Yang, 2012). The central tenet of these papers is that through the repositioning of the status of students and teachers, in which cooperative learning is promoted through various roles and responsibilities, students would gain a more complete understanding of the content of Wushu.

The use of SE in Chinese physical education is not new, and there have been reports of successful forays reported in both Chinese and English journals. Examples include increases in students' intrinsic motivation and task orientation (Xiong \& Ma, 2013), enhanced student enthusiasm and initiative, and well as improved interest in learning and participation (Wu, 2018), and increases in motor skills (Liu, 2015; Liu et al., 2020).

Despite this evidence, the notion of SE being a suitable vehicle for the instruction of Wushu has met significant resistance. Arguments include that students do not have sufficient content knowledge or technical skill to carry out the roles that are transferred to students during the model. In particular, the main concerns relate to the capacity of apprentice Wushu participants to teach/coach peers or to adequately and accurately officiate during competitions. Ancillary concerns include the time taken to train students in these roles takes time away from performance training. The primary aim of this paper was to explore whether participation in a season of SE would compromise the learning of Wushu technical skills, which is the fundamental goal of the traditionalists. A second aim was to examine the experiences of the participants within SE classes (teacher and students) in terms of their motivation and attitudes toward Wushu.

\section{METHODS}

\section{Participants}

Participants in this study were 54 male physical education students enrolled in two second-year level Wushu classes at a university in southern China. Twenty-eight students participated in a class using the SE model and 26 students in a second class following traditional, teacher-directed Wushu instruction. At the end of the first class, students were asked to answer three questions with respect to their experience with Wushu. These were answered using a 7-point semantic differential scale. Questions included "How would you rate your skill level of Wushu?, How much do you enjoy practicing Wushu?, and How confident are you in your ability to teach Wushu to students in school?" Both cohorts were very similar, with students reporting low levels of perceived competence $(<1.5)$, mediocre levels of enjoyment $(<4.4)$ and low levels of instructional competence $(<3.5)$.

The female teacher in this study had been a faculty member in the college of physical education for the past 11 years. She had been teaching Wushu for 10 of those years to both the regular student population in elective physical education classes, as well as to physical education majors. The teacher had also participated in three Wushu specific professional development programs at both regional and national levels. Her annual teaching evaluations average $93+$ on a 100 -point scale.

\section{Wushu Instruction}

Students in both classes participated in two, 90-minute lessons per week over 16 weeks that were conducted in a large indoor sports hall. The Wushu content for all students consisted of three parts (a) fundamental body movement skills - punch, (b) skills with a knife, and (c) skills with a stick. Punch, knife, and stick parts involved learning 32, 18, 17 movements respectively. All skills were learned in a set order. In this study, traditional and SE cohorts followed some content progressions, with only the format of delivery being different. Table 1 shows the traditional presentation of Wushu content.

\section{Table 1. Traditional Wushu Class Schedule}

\begin{tabular}{clll}
\hline Week & \multicolumn{1}{c}{ Content } & Week & Content \\
\hline & & 10 & Knife movements 13-18 \\
\hline 2 & Introduction of syllabus and skills & 11 & Test: Knife movements 1-18; Stick movements 1-8 \\
\hline 3 & Review fundamental movements; First 14 punch movements & 12 & Stick movement 9-17 \\
\hline 4 & Practice individual and paired 14 punch movements; Test & 13 & Stick movement review \\
\hline 5 & Introduce and practice second 18 movements & 14 & Test: Stick movements 1-17 \\
\hline 6 & Practice individual \& paired 18 punch movements & 15 & Practice: punch, knife, and stick \\
\hline 7 & Test: individual \& paired 18 punch movements & 16 & Practice: punch, knife, and stick \\
\hline 8 & Fundamental knife movements; Knife movements 1-6 & 17 & External skill testing for grade \\
\hline 9 & Knife movements 7-12 & &
\end{tabular}




\section{Traditional Format}

The focus of instruction for the traditional class was exclusively on learning the fundamental technical skills of Wushu and then demonstrating the correct form. Lessons consisted of $25 \mathrm{~min}$ of warm-up, followed by 40-50 min of teacher demonstration, and $15 \mathrm{~min}$ of individual skill practice. The time spent on the various disciplines (punch, knife, and stick) was approximately six, four, and three weeks respectively, with the final three weeks allocated to theory learning and practice for the final exam.

\section{Sport Education}

Table 2 shows the plan for the Wushu season. Central to the plan were four competitions interspersed with formal instruction from the teacher as well as team practices. Students were also given opportunities to learn the officiating process of Wushu. The first three competitions focused on the development of skills relating to (a) fundamental body movements - punch, (b) skills with a knife, and (c) skills with a stick. These skills were repeated during the fourth competition (the culminating event) where teams presented choreographed routines.

The competitions were central to the season. During these competitions, a randomly selected student from each team was required to demonstrate a random sequence of four moves (e.g., 4-7 or 13-16) before a judging panel consisting of the teacher and two representatives from each of the other teams. Scoring for each competitor was on a 1-5 rating scale that focused on posture, quality of movements, smoothness, and the correctness of the sequence. The grade from the teacher counted towards the performing team, while the score for the officiating team was derived from the extent to which the judges matched the teacher's score.

\section{Table 2. Wushu Sport Education Season Plan}

\begin{tabular}{|c|c|c|}
\hline Week & Content & SE Tasks \\
\hline 1 & Introduction of syllabus, Explanation of the season, Introduction of skills & Place students in teams \\
\hline 2 & $\begin{array}{l}\text { First } 14 \text { movements, Teacher directed learning (whole class), Some partner } \\
\text { checking of easy skills to check }\end{array}$ & $\begin{array}{l}\text { Partner checking of easy skills (Teacher to choose from the } \\
\text { list of 14) }\end{array}$ \\
\hline 3 & $\begin{array}{l}\text { Team training First } 14 \text { movements, Teacher rotate through teams } \\
\text { Offer voluntary T led training camp for students struggling }\end{array}$ & $\begin{array}{l}\text { Students have random numbers of cards with skills listed } \\
\text { Test teammates knowledge of moves, Check for form } \\
\text { Can be led by a student leader or in pairs (small groups) }\end{array}$ \\
\hline 4 & $\begin{array}{l}\text { Second } 18 \text { movements, Teacher directed learning (whole class) } \\
\text { Some partner checking of easy skills to check }\end{array}$ & As per week 2 \\
\hline 5 & $\begin{array}{l}\text { Team training Second } 18 \text { movements, Teacher rotate through teams } \\
\text { Offer voluntary T led training camp for students struggling }\end{array}$ & As per week 3 \\
\hline 6 & $\begin{array}{l}\text { Introduce competition 1, Random sequence of } 4 \text { moves }(4.5 .6 .7 \text { or } \\
14,15,16,17) \text { etc., Explain scoring system }\end{array}$ & $\begin{array}{l}\text { Practice with } 2 \text { teams to show how the whole competition } \\
\text { works (Practice), Second lesson of the week do the } \\
\text { competition, Scoring is by T and } 2 \text { representatives. }\end{array}$ \\
\hline $7-8$ & Repeat lessons 2 \& 3 with knife movements & \\
\hline 8 & Knife competition as per lesson 6 & \\
\hline 9 & Repeat lessons $2 \& 3$ with stick movements & \\
\hline 10 & Stick competition as per lesson 6 & \\
\hline 11 & Revisit punch movements & \\
\hline 12 & Revisit knife/stick & \\
\hline 13 & Team practice and allocation of presentation within team & \\
\hline 14 & $\begin{array}{l}\text { Presentation competition (round 1): punch competition, knife competition, } \\
\text { stick competition }\end{array}$ & Team Avs Team B \\
\hline 15 & Presentation competition & Round 2 - semis and finals \\
\hline 16 & Practice for final assessment by external teachers & \\
\hline 17 & External skill testing for grade & \\
\hline
\end{tabular}

\section{Fidelity of the Instructional Conditions}

In terms of validation, videos and photographs taken during the course showed students participating in student-led team practices, officiating, and record keeping. To account for constraints that may have resulted in a possible misapplication of the model, the teacher sent a weekly review of events in which any problems or misunderstandings were outlined. The teacher received a response within 24 hours. All these strategies served to confirm that students did receive a well-founded version of SE as intended by its creators. 


\section{Data Collection}

Student grades: Students' scores for the three components of the course, (a) class performance (10\%), final skill examination $(60 \%)$, and theory test (30\%), as well as the overall grade were recorded. Class performance was awarded by the teacher based on attendance, effort, and commitment to learning. The final skill examination was conducted in week 17, in which students from all classes reported to the indoor sports hall. Students rotated through three stations (punch, knife, stick) and performed the complete set of Wushu skills before college faculty and senior students certified as Wushu referees. The final evaluation was based on five perspectives: (a) postures (correct) - 20\%, (b) movement (standardized) - 20\%, (c) power or strength of the movement -20\%, (d) coordination (hand-eye) - 20\%, (e) presentation/performance/spirit - 20\%. Punch accounted for $40 \%$ of the total score, while knife and stick were $30 \%$.

Data were collected from the two classes of the instructor in this study as well as two other classes from other Wushu instructors during the same semester. Having grades from other Wushu instructors provided a large sample of data from the traditional format.

Teacher logs and interviews: Each week, the teacher wrote a reflective log (ranging between 1000 and 1500 words) to describe particular incidents and interactions that happened during the lessons and how these were particularly meaningful to her. These were emailed to the research team weekly.

Two interviews were held between the teacher and the third author. Following the second competition, the teacher was asked to compare her experiences of the two classes, particularly in terms of skill development, motivation, and behavioral and cognitive engagement. The teacher was also asked to comment on her confidence to deliver SE. At the completion of the course, the teacher was asked to provide an overall summary statement about her experiences in the project, referencing both classes. Follow up questions focused on her pedagogy, the abilities and responses of students, as well as any difficulties and challenges faced when implementing SE. Both interviews lasted one hour.

Student interviews: At three time points during the course, two students representing each of the teams participated in smallgroup interviews, also with the third author. The first interview (conducted following the first competition), focused on the design of the class, students' ideas of team training and the taking of roles, as well as their greatest and least concerns about their potential success in the course. These questions were also posed after the second competition, with particular interest being placed on any changes of perceptions with added experience in the SE format. Following the grand presentation at the end of the course, students were asked to reflect on the season as a whole, the development of their Wushu skills, and for comparisons between this format of instruction and those they had previously experienced in the training as prospective teachers. Interview time was one hour per interview for the first two, and two hours for the final interview.

\section{Data Analysis}

Student grades: Four separate analyses of variance (ANOVA) were conducted to compare the scores for the three components of the course and the overall grade for students participating in either SE or traditional instruction. An alpha level of 0.0125 was used based on a Bonferroni adjustment.

Logs and interview data: All logs and interview transcripts underwent a line-by-line analysis by two members of the author team. Each record was identified by class (SE or traditional) and week. Analytic induction and constant comparison techniques (Goetz \& LeCompte, 1984) were to reduce the data to meaningful themes. Specifically, participant responses were coded, categorized, and then collated into themes. Specific quotes and terms were then selected to represent each theme.

\section{RESULTS}

\section{Student Grades}

Table 3 compares the performance of students in the two teaching conditions. For the three most critical elements (skill exam, theory tests, and overall score) there were no significant differences between the classes. These data allow us to reject the idea that learning Wushu through SE would compromise student learning and performance. The one difference between groups was for class performance. While accounting for only $10 \%$ of a student's grade, it is notable that students in SE significantly outperformed their peers in terms of attendance, effort, and commitment. 
Table 3. Comparisons of Student Performance Across Teaching Conditions

\begin{tabular}{rccccc}
\hline \multicolumn{1}{c}{ Component } & $\begin{array}{c}\text { Sport Education } \\
\text { M (SD) }\end{array}$ & $\begin{array}{c}\text { Traditional Instruction } \\
\text { M (SD) }\end{array}$ & $\boldsymbol{F ( 1 , 1 0 6 )}$ & $p$ & $\eta^{2}$ \\
\hline Skill exam (60\%) & $81.5(8.7)$ & $79.3(7.6)$ & 1.88 & .176 & .034 \\
Theory tests (30\%) & $91.9(5.1)$ & $94.4(7.8)$ & 2.38 & .126 & .022 \\
Class performance (10\%) & $96.7(2.9)$ & $87.8(14.6)$ & 9.49 & .003 & .152 \\
\hline Overall score & $86.2(5.2)$ & $85.2(8.1)$ & 0.26 & .530 & .004 \\
\hline
\end{tabular}

\section{Student Perceptions}

Analysis of interviews with SE students generated six themes (see Table 4). Within these themes, certain comments or ideas were repeated by a number of students across all three interviews. These were categorized as "predominant". "Reoccurring" topics appeared across more than one interview, although were expressed less often. Those terms or topics relating to the theme that appeared as single cases or within one interview were considered "incidental." However, these incidental cases still related to the central theme and add to our understanding of the students' perspectives. In fact, some of these incidental comments were negative cases of the theme.

Climate: The students were unanimous in their view that the practice of Wushu in the past had been particularly boring, to the point of being tedious. In essence, they described their previous lessons as "skill instruction, then practice, practice, practice." In contrast, the SE format was given many labels, including "motivating," "fun" and even "innovative." This led to it being described by most students with the phrase "this form is not boring." While many students suggested they were prepared to undergo skill instruction followed by practice, they expressed the major pedagogical challenge of a traditional teacher was "how to keep the student-focused is the most critical issue .... they are focused in the first half, but the second half is the challenging part." What was attractive about SE was that it was "more than teaching and practice." Practice was accompanied by competitions, learning how to referee, and leading team and class events such as warm-ups. In essence "the structure makes every student have to participate and be involved."

Competitions: The competitions (referred to as "games" by the students), were seen as central to the positive climate of the class. They were seen as fun and meaningful, leading students to be more enthusiastic about Wushu, "rather than just practice-practice-practice forever." The competitions were seen as serving a dual pedagogical purpose. First, as "Wushu needs a lot of time to practice, the competition encourages students to practice with a specific purpose." Practices thereby assumed a degree of seriousness, as "preparation for the game can encourage students to review/go over the movements we learned in the past lessons." Second, the feedback given to students in terms of scores "helped them keep improving the movement quality."

The one negative case discussed by students was that there were too many competitions during the course. Students were required to participate in a college-wide competition in addition to those in the course, and two students commented that this extra demand "detracted from the time students spent practicing," given the time needed to learn how to officiate associated with the games.

Teams: The most common point made by students concerning persisting teams is that they "created a peer support mechanism." In essence, "every student in the team can ask questions or seek help if they need it." Others commented that having teammates will help you to "not be intimidated by your lack of confidence in Wushu skills."

Some students focused on the pedagogical advantage of teams. As one noted, "compare this to a class without divided students into a fixed team, and I can imagine the teaching will be hard to organize. You will have to miss part of students who needs the teacher to help them with additional instruction. The structure of the team (3-4 people) can solve this problem." Others reinforced this idea that having peer instruction allowed the teacher to "move more freely to assist students most in need."

Roles: Across teams and time, students noted that the roles of team coach and warm-up leader provided "an opportunity for the student to practice their leadership". As a coach it was "important to get the respect of your teammates", while leading the class in warmups required you to be "responsible to plan carefully." Nonetheless, not all roles were seen as essential. Aside from the coach, the team roles of strength and conditioning specialist and team manager were seen as somewhat "superfluous." The students mentioned that these roles were rarely incorporated during classes and at times, the responsibilities associated with them were "unclear."

Referee: The role of referee was seen by students as a positive aspect. First, they noted that "experiencing both player and referee help me learn better. Knowing the criteria will help you learn Wushu." More specifically, "you notice a lot of the wrong movements when you are a referee... you will pay attention to your own practice and recall these wrong movements and postures, then avoid making those mistakes." The students also agreed that their officiating judgments became more accurate with time. Indeed, by the third interview, students commented that "most are getting close to matching the teacher's score. It is impressive." 
New learning style: The final theme had a future focus in that it did not relate to the specific elements of the season. Rather it was a holistic assessment of how the structural features of SE "all help prepare me (as a pre-service teacher) for my future career." Examples included "learning how to lead a warm-up," and "how to organize class (teaching)." The learning enhancement provided by persisting teams and the motivating feature of competitions were also seen by the students as "providing more elements and opportunities for students in their learning."

Table 4. Prevalence of Themes from Student Interviews

\begin{tabular}{|c|c|c|c|}
\hline Theme & Predominant & Reoccurring & Incidental \\
\hline Climate & $\begin{array}{l}\text { - Traditional Wushu is boring/tedious } \\
\text { - This form of Wushu is not boring }\end{array}$ & $\begin{array}{l}\text { - Motivating } \\
\text { - Fun }\end{array}$ & $\begin{array}{l}\text { - New } \\
\text { • Innovative Exciting }\end{array}$ \\
\hline Teams & - Peer support mechanism & $\begin{array}{l}\text { - Frees teacher to attend to specific } \\
\text { students }\end{array}$ & $\begin{array}{l}\text { - Small teams benefit practice } \\
\text { - Element of seriousness }\end{array}$ \\
\hline Competitions & $\begin{array}{l}\text { - Encourage focused practice (prior to) } \\
\text { - Help learning by providing feedback } \\
\text { (following) }\end{array}$ & $\begin{array}{l}\text { - Fun to compete } \\
\text { - Meaningful learning } \\
\text { - More enthusiastic about Wushu }\end{array}$ & $\begin{array}{l}\text { - Nervousness } \\
\text { (though decreases with time) } \\
\text { - Too many detract from practice time }\end{array}$ \\
\hline Roles & - Practice leadership & - Some roles are superfluous & - Unclear responsibilities \\
\hline Refereeing & $\begin{array}{l}\text { - Enhances one's own learning } \\
\text { - Improves with practice }\end{array}$ & - Learn more than just skills & - Another angle to experience Wushu \\
\hline New learning style & $\begin{array}{l}\text { - Learned skills I can apply in future } \\
\text { teaching }\end{array}$ & $\begin{array}{l}\text { - Allows all students to participate } \\
\text { - Good way to learn skills }\end{array}$ & \\
\hline
\end{tabular}

\section{Teacher's Perceptions}

The teacher's interviews served as a form of triangulation between her more extensive log entries and the comments made by students during their interviews. Analysis of these led to the generation of five themes.

Differences in time: The teacher commented that she was spending significantly more time in planning during SE than in previous iterations of Wushu instruction. In essence, "in the SE class, especially during the competitions. I have to train referees, prepare tables, assign students to the right place to take their duty (referee or players), and manage the whole performance. This is new." In contrast, "the traditional class is easy. I don't need to prepare anything for them. I can use 5-10 minutes to think about how to teach when I am on the way to campus (in the bus). Then I am ready for teaching."

Teaching leadership: The teacher also mentioned in the first interview how some students were struggling with their leadership roles, perhaps because "they are not super confident to comment or correct their teammates' movements." Of interest, however, is that she also suggested their leadership was "not strong," which ran counter to the point made by the students that having roles gave them an opportunity to develop these skills. Where the teacher and her students were in alignment was with respect to those roles the students described as superfluous, describing some as "just a title without meaning for students."

Differences in motivation: The teacher noted a marked difference between the levels of motivation shown by the students in the two classes was also mentioned. In particular, the teacher believed that "I can teach more [in SE] because students are paying attention to what I am saying. I can feel students want to learn." Control students were described as “disengaged" and "lazy"

The benefits of teams: Consistent with the views of the students, it was the persisting team that was the catalyst that "significantly impacted the effect of team practice," an effect the teacher described as "amazing." Small teams allowed for "efficient peer support," and allowed the teacher more freedom to check individual student's progression. It was not only that students were in teams that generated this focused engagement. The teacher recognized the value of the competitions. She commented:

Another part is the games, where students were required to be both referee and player. They built a sense of ownership for my students in the class. Combined with the team training, I thought the organization of the games shifted the power from teacher 
to students. Students are more independent to learn in the classroom. We always mentioned that learning should be studentcentered. The teaching reform advocated learning should be help students to develop in multiple perspectives. I think this is how this model is functioning well to meet those education goals.

A breakthrough in my professional development: One topic that occupied significant discussion in the final interview was the teacher's sense of professional renewal as a result of the SE project, and particularly the students' responses to it. She began by commenting that "I always thought that students' learning motivation could impact teachers' motivation and effort in teaching. And it also caused me to believe that the highly motivated students/class will improve performance better." This belief was reinforced during this class, as this "new concept forced me to think about how to teach PE differently." Indeed, she believed that "my teaching ability has improved a lot after this semester. I am more confident in the teaching (of Wushu) because I have to think about how to organize my teaching, class management, and routine...It pushes you to think about how to provide a better PE."

\section{DISCUSSION}

The number one take-home message from this study was that participation in a season of SE did not compromise the learning or performance of Chinese physical education majors during a course of Wushu. As predicted by skeptics, there were instances where the teacher needed to spend time helping students become competent at providing feedback and instructing them to officiate competently in class competitions. However, the key finding is that participation in these aspects of the course did not negatively affect the students' grades. As such, the results of this one intervention provide a small chink in the armor of the belief that 'there is only one way to learn Wushu - using a highly trained performer as instructor and students undertaking rigorous repetition of movements.'

\section{Motivation Led to Engagement}

The structure of Wushu learning follows a process of numerically mandated movements (either with or without weapons) in a repetitive learning environment. All participants who were interviewed noted that irrespective of their depth of prior learning, that the elements of SE served to make Wushu practice "not boring", but motivated them in several ways. We argue that the hallmarks of the SE model placed students in situations where they experienced all the dimensions of "situational interest". Within physical education, Chen and Darst (2001) list these as novelty (e.g. 'What we did was new'), instant enjoyment (e.g. 'What we did was enjoyable'), exploration intention (e.g. 'I wanted to analyze and have a better grasp of what we were learning today'), attention demand (e.g. 'What we were learning demanded a high level of attention'), and challenge (e.g. 'What we were learning was hard to learn'). A meta-analysis of motivational constructs related to student engagement in physical education has found that situational interest is a primary motivator (Chen et al., 2012). Of particular significance is the finding that situational interest is directly related to student engagement (at least behavioral engagement), and engagement seems to be a significant determinant of skill outcomes.

We suggest that the curricular and instructional aspects of SE served to motivate students, which then had a positive impact on their engagement in class. Further, this increased engagement more than compensated for the lower amounts of time spent in teacher-directed skill practice.

\section{Engaged Learners}

"Engagement" is an active, effortful, goal-directed interaction with one's learning environment (Hastie et al., 2020). Engagement is a multidimensional construct involving behavioral (effort and active involvement), cognitive (self-regulation and investment), and emotional (positive attitude and interest) aspects (Appleton et al., 2008). In addition, Reeve and Tseng (2011) have noted that some students become so deeply involved during instruction that they contribute to the evolution and growth of the lesson, a concept they labeled as "agentic engagement."

Behavioral engagement of students: Behavioral engagement is a student's effort, persistence, and on-task behavior demonstrated in learning (Xiang et al., 2017). The teacher's logs and interviews were replete with examples of SE students arriving early to class, giving full effort during lessons, and being highly self-disciplined. Compared to the students in the traditional format, the teacher reported these students positively using movement cards and e-books to explore and organize their learning/practice.

From the students' perspective, the structure of the season (with intermittent competition and practice) "encouraged students to practice with a specific purpose." Given that "Wushu needs a lot of time to practice," the model provided a level of "content-embedded accountability" (Hastie, 2000). Accountability refers to being held responsible and answerable for specified results or outcomes of an activity over which one has control. Because the competitions "counted" toward a season outcome, team practices were taken more seriously.

Cognitive engagement: The cognitive aspect of engagement refers to mental effort students spend on learning tasks (Chapman, 2003). Through her logs and interviews, the teacher used the terms "serious," "organized" and "having an active learner attitude" to describe how students projected their approach to the content. She saw them "positively using movement cards and e-books to explore and organize their learning/practice". Comments from students add to the validity of the teacher's perceptions. They reported "learning 
the rules of referring very seriously" and having to "think carefully about preparing lesson plans." Students reported that the "game pulls students' attention to their learning, and even cases where when a student was absent from class, "he will be asking me (coach) or the team captain to teach him the lesson he missed."

Emotional engagement: Emotional engagement is reflected by students' attitudes toward and interest and values in learning (Xiang et al., 2017). Evidence of this came from the teacher's log where she wrote that some students suggested using music to invigorate the atmosphere of the competitions. As a result, the whole process of the competition was videotaped, and each team was specifically recorded with a mobile phone. Students also took photos of themselves in preparation and during the competition to share on social media. During interviews, the students all claimed that the format of practice and competitions "kept everyone motivated and excited about Wushu."

Agentic engagement: Agentic engagement is evident when students proactively attempt to learn and contribute to the flow of instruction their teachers provide (Reeve \& Tseng, 2011). It is different from the other dimensions of engagement in that it is exhibited in student-initiated, action. Agentic engagement is a uniquely proactive and transactional type of engagement, as students try to create a more motivationally supportive learning environment for themselves. Surface-level examples of this engagement were offered by students when they mentioned that they "also ask our teacher because she is available during team training. It will help us learn fast and efficiently." However, more substantive cases were when the students and the teacher met to modify the scoring process planned by the teachers. Here they suggested that they use the average referee score (two referees) first, and then compare these with the teacher's score to decide whether they win or not win the referee points.

\section{CONCLUSIONS}

In the first paper reporting the outcomes of the adoption of SE, Alexander, Taggart, and Thorpe (1996, p. 36) made the following conclusion:

"Skill development is one area in which sceptical teachers are often quick to criticise the sport education concept. However, through a combination of longer units of work, increased motivation amongst students as they learn to work effectively in persisting groups, the relevance offered by competition and the removal of the need for teachers to always be organisers and disciplinarians, significant improvements in skill development have been reported, especially for lower skilled students."

Twenty-five years later, we could make the same statement. The data from this report show that both teachers and students developed "a spring in their steps", providing them with a degree of professional renewal, at no cost to the quality of performance of Wushu techniques. For the teacher, new opportunities to be "off center-stage" provided her with the time and energy to more frequently ask how she could do it even better. For the students, the structure of SE introduced them to pedagogies that would help them in their future careers and provided them with a structure of teaching that provides more elements and opportunities for students in their learning.

\section{FUTURE RESEARCH}

The primary goal of this study was to determine whether a new method of teaching Wushu would negatively affect student achievement. As such, it was centered on the performance and experiences by the key players who participated in Sport Education. Given the results, future research on SE and Wushu would be enhanced by having more quantitative measures of student engagement during classes. These could include behavioral measures such as time in practice (both teacher-directed and independent), as well as motivational inventories by participation in a curriculum model where the students were given more autonomy, and where the teacher was less of a director. In that way, factors such as situational motivation, enjoyment or perceived physical literacy could be used to differentiate the experiences of students in both SE and traditional wushu instruction.

\section{REFERENCES}

Alexander, K., Taggart, A., \& Thorpe, S. (1996). A spring in their steps? Possibilities for professional renewal through sport education in Australian schools. Sport, Education, and Society, 1(1), 23-46. https://doi.org/10.1080/1357332960010102

Appleton, J. J., Christenson, S. L., \& Furlong, M. J. (2008). Student engagement with school: Critical conceptual and methodological issues of the construct. Psychology in the Schools, 45(5), 369-386. https://doi.org/10.1002/pits.20303

Chai, G., \& Sun, Y. (2020). Effective teaching strategies of Wushu in primary and secondary schools aiming at core accomplishment of martial arts. Journal of Wuhan Institute of Physical Education, 54(4), 87-92.

Chapman, E. (2003). Alternative approaches to assessing student engagement rates. Practical Assessment, Research, and Evaluation, 8(13), 1-10. https://doi.org/10.7275/3e6e-8353 
Chen, S., Chen, A., \& Zhu, X. (2012). Are K-12 learners motivated in physical education? A meta-analysis. Research Quarterly for Exercise and Sport, 83(1), 36-48. https://doi.org/10.1080/02701367.2012.10599823

Chen, A., \& Darst, P. W. (2001). Situational interest in physical education: A function of learning task design. Research Quarterly for Exercise and Sport, 72(2), 150-164. https://doi.org/10.1080/02701367.2001.10608945

Chinese Wushu Association (2008). Chinese Wushu rules and regulations for competition (3 ${ }^{\text {rd }}$ ed.). Beijing: The Peoples' Sport Publisher.

Du, X., Chen, Y., Li, B., \& Han, J. (2018). The present situation and predicament of wushu compulsory courses for physical education majors in universities. Journal of Beijing Sport University, 41(3), 95-102.

Frangville, V., \& Gaffric, G. (2019). China's youth cultures and collective spaces: Creativity, sociality, identity and resistance. London: Routledge.

Goetz, J. P., \& LeCompte, M. D. (1984) Ethnography and qualitative design in educational research. San Diego, CA: Academic Press.

Hastie, P. A., Stringfellow, A., Johnson, J. L., Dixon, C. E., Hollett, N., \& Ward, K. (2020). Examining the concept of engagement in physical education. Physical Education and Sport Pedagogy, 27(1), 1-18. https://doi.org/10.1080/17408989.2020.1861231

Li, T., \& Du, X. (1991). A guide to Chinese martial arts. Foreign Languages Press.

Li, L., \& Lu, J. (2018). Research on the construction of learning resource module of Wushu online course in colleges and universities. Wushu Studies, 3(9), 94-96.

Liu, J. (2015). Research on the application of sport education model in college basketball teaching. Contemporary Sports Science and Technology, 2015(9), 54-57.

Liu, H., Shen, W., \& Hastie, P. A. (2020). Responses of Chinese university students and their teacher to a season of Sport Education. International Sports Studies, 42(2), 5-20. https://doi.org/10.30819/iss.42-2.02

Lorge, P. A. (2012). Chinese martial arts: From antiquity to the twenty-first century. Cambridge: Cambridge University Press.

Reeve, J., \& Tseng, C. M. (2011). Agency as a fourth aspect of students' engagement during learning activities. Contemporary Educational Psychology, 36(4), 257-267. https://doi.org/10.1016/j.cedpsych.2011.05.002

Siedentop, D., Hastie, P., \& van der Mars, H. (2019). Complete guide to sport education. Human Kinetics.

Tan, X. (2009). To construct a curriculum model in wushu education from theories of sport education. Journal of Sports and Science, $30(2), 82-86$.

Wang, G. (2010). Chinese Kungfu: Masters, schools and combats. Intercontinental Press.

Wang, J. (2018). Problems and countermeasures of college sports wushu teaching in college education field. Journal of Huangshan University, 20(3), 87-91.

$\mathrm{Wu}, \mathrm{W}$. (2018). Experimental research on sports education model in physical education of colleges and universities. Journal of Beijing Sport University, 2018(12), 1682-1685.

Xiang, P., Ağbuğa, B., Liu, J., \& McBride, R. E. (2017). Relatedness need satisfaction, intrinsic motivation, and engagement in secondary school physical education. Journal of Teaching in Physical Education, 36(3), 340-352. https://doi.org/10.1123/jtpe.2017-0034

Xiong, Y., \& Ma, H. (2013). The influence of 'sports education model' on students' motivation. Journal of Nanjing Sport Institute (Social Science), 2013(6), 82-90.

Yang, Y., \& Yang, F. (2012). The application of sports education model in the teaching of wushu specialized courses in colleges. Fighting Martial Arts Science, 9(8), 63-64.

Zheng, Z., \& Yuan, M. J. (2013). The population of Wushu for health purposes is over 70 million. Xinhuanet, 6 August. Available at: http://news.xinhuanet.com/sports/2013-08/06/c_125126851.htm 


\section{Author Information}

Peter A. Hastie, Ph.D., Corresponding Author

(1) https://orcid.org/0000-0002-3727-6006

School of Kinesiology

Auburn University, Auburn, AL, USA

ㄱastipe@auburn.edu

Hairui Liu, Ph.D.

(1) https://orcid.org/0000-0002-0497-3622

Department of Kinesiology and Applied Health

University of Winnipeg, Manitoba, Canada

직.liu@uwinnipeg.ca

\section{Yanhua Mo, Ph.D.}

College of Physical Education \& Health Science

Guangxi Normal University, China

(2) yanhua_mo@foxmail.com

IRB Approval \#GNU20200036

Conflict of Interest: The authors declare that the research was conducted in the absence of any commercial or financial relationship that could be constructed as a potential conflict of interest.

Publisher's Note: All claims expressed in this article are solely those of the authors and do not necessarily represent those of their affiliated organizations, or those of the publisher, the editors and reviewers. Any product that may be evaluated in this article, or claim that may be made by its manufacturer, is not guaranteed or endorsed by the publisher. 


\title{
Development of a Multi-Dimensional Scale to Measure Professional Athletes as Role Models
}

\author{
Doyeop Kim', Giyong Koo², Minkil Kim², \\ Stephen Shin ${ }^{3}, \&$ Anthony Dixon' \\ ${ }^{1}$ Louisiana State University, Alexandria, LA, USA \\ ${ }^{2}$ Troy University, $A L, U S A$ \\ ${ }^{3}$ Belmont University, TN, USA
}

Received 3 July 2021 | Revised 4 September 2021 | Accepted 22 November 2021

Open Access Available online at www.johsk.com

\begin{abstract}
Previous studies have indicated that young students who play sports look up to professional athletes and perceive these athletes as their role models. However, empirical studies that examine such perceptions comprehensively have not been conducted. In order to fill this gap in the literature, the current study developed a multi-dimensional scale to measure college student athletes' attitudes toward professional athlete role models. The eight-factor sports role model scale has 40 items. The results of this study indicate that student athletes observe and emulate the eight dimensions of their sports role model's behavior on and off the court in order to become like that role model. Such findings support social learning theory in the sport management discipline.
\end{abstract}

Key words: Sport Role Model, Professional Athlete, Student Athlete, Scale Development

\section{INTRODUCTION}

With the growing popularity of professional athletes under the spotlight, many students who participate in sporting activities choose professional athletes as their role models (Kohlstrung, 2016). "When I take my kid out and hit him ground balls at shortstop, he wants to be Derek Jeter. He does not want to be me. So any professional athlete who tells you he is not a role model is full of baloney" (Pulley, 2001, p. 131). In the highly commercialized sport industry, professional athletes who receive high salaries and media attention have become role models for the younger generation (Adair, 2015). Professional athletes are expected to play an important public role due to their prominence and visibility in the media (Guest \& Cox, 2009). Leading sports stars are celebrities, and society expects them to be a public role model (Coakley, 2001; Rojek, 2006). Regarding the status of sports role models, a former NBA star, Tim Duncan, mentioned that professional athletes as role models should be careful of their behavior on and off the court (Feezell, 2005). An American Olympic gold medalist, Cheryl Miller also said, "When you reach a certain level of visibility, you are a role model whether you like it or not" (Globus, 1998, p. 28).

Journalists argue that sports role models' behavior on and off the court strongly influences college students' life in various ways (Smoll, 2015; Williams, 2017). Scholars also indicated that sports role models play an important role in helping young students develop viable self-concept (Bricheno \& Thornton, 2007; Guest \& Cox, 2009). Early adults are likely to be independent of their parents while defining and developing their self-concept (Gibson, 2003). Therefore, these young individuals seek external role models, such as highprofile athletes, through the media who can help them formulate self-concept (Strudler, 2000). These young people observe and emulate various aspects of their ideal sports role model (May, 2009). Therefore, they can become similar to their sports role model (Neemann \& Harter, 2012). Furthermore, marketing researchers indicated that as a way of becoming similar to their sports role models, college students use the same sportswear, sports shoes and products which the role models endorse (Bush, Martin, \& Bush, 2004). Marketing managers who target these young college students utilized these professional sports role models in television commercials (Clark, Martin, \& Bush, 2001).

The phenomenon of professional athletes being regarded as role models for collegiate student athletes can be explained by social 
learning theory (Bandura, 1977). Social learning theory indicates that individuals tend to observe others while formulating their own beliefs and attitudes. People learn a new skill or behavior by watching another prominent person, who thus plays an essential role in this learning and socialization process (Bandura, 1977). Such a process can be indirect, such as observing external role models through the mass media, because individuals' learning of a specific behavior is not necessarily related to the direct experience of that action (Bandura, 1977). Young students learn new skills, behaviors, or values by observing and following these vicarious role models presented by the media and reproduce them if these attributes and values become more critical to their life (Bandura, 1977).

Previous studies (Burch \& Murray, 1999; Feezell, 2005; Globus, 1998; Harris, 1994; Kellner, 1996; Simons, 1997; Wilson \& Sparks, 1996) have identified key attributes that define the concept of sports role models. The attributes include clothing styles, athletic footwear, fame, wealth, high social status, perceived positive value to society, supreme athleticism on the court, desire to win, championship, greatness throughout a career, charismatic play style, good personality, confidence, sportsmanship, fair play, community service, strong family ties, moral behaviors, hard work toward reaching a goal, dedication, commitment, love and respect for the game, and charitable work. Additionally, other studies represented several attributes of athletic role models, such as physical skills, moral behavior on and off the court, personal characteristics, interpersonal and intellectual abilities, self-actualization, giving back to society, physical characteristics, and socio-economic status (Assibey-Mensah, 1997; Bricheno \& Thornton, 2007; Fleming, Hardman, Jones, \& Sheridan, 2005; Giuliano, Turner, Lundquist, \& Knight, 2007; Guest \& Cox, 2009; May, 2009; Vescio, Wilde, \& Crosswhite, 2005). However, there has been no scientific scale to comprehensively measure all these attributes of professional sports role model.

Some existing sports role model scales have been used to measure the relationship between a general sports role model concept and sport consumer behavior. For example, Rich's (1997) five-item general role model scale, developed in the management field, has been used in sport marketing research (Bush, Martin, \& Bush, 2004). These previous studies found that sports role models influence young consumers' purchase intention and behavior. In addition, a three-item sports role model factor as part of the sports interest inventory scale (Funk, Mahony, Nakazawa, \& Hirakawa, 2001) was used in several sport consumer behavior studies (Funk, Ridinger, \& Moorman, 2003; Kim \& Trail, 2010). These findings indicated the positive relationship between sports role models and consumers' interest in and attendance at sporting events. Also, Arai, Ko, and Kaplanidou (2013) included the three-item sports role model factor in their athlete brand image scale. They found that for consumers, sports role model is positively related to athlete brand image.

However, these existing scales failed to adequately capture various dimensions of the sports role model construct, such as athletic performance, professionalism, physical appearance, personality, fame/fortune, community service, and morality. Therefore, little is empirically known about the several domains which are demonstrated by sports role models and their relationships with the learning behavior of the young admirers. Therefore, the purpose of this study was to develop and validate a valid and reliable instrument to measure various aspects of the sports role model construct for college student athletes. In order to achieve the aim of the study, this study developed a multidimensional measurement tool of the sports role model scale.

\section{METHODS}

\section{Participants}

The researchers recruited 716 student athletes from universities in the northern region of South Korea who perceive professional athletes as their role models. The researcher provided those student athletes with the information on the research purpose, the requirement for study participation, and the informed consent letter. These students participated in the study by answering the Korean version of the questionnaire. All data were analyzed as a group and stored in the password-protected computer of the primary researcher. As a way of protecting the confidentiality of the research participants, the survey questionnaire did not contain any information that personally identifies them. The results of this study are used for scholarly purposes only and shared with other researchers of the study. There were no known physical or psychological risks, inconveniences, and discomforts that the participants might experience while completing the survey questionnaire. However, if any respondent felt uncomfortable with participating in the study, he or she was able to withdraw from completing the survey at any time.

\section{Procedures}

The English version of questionnaire items was generated and developed following a comprehensive literature review of methods for measuring attributes of sports role models. In order to examine the criterion validity of this newly-developed scale (DeVellis, 2012), the questionnaire included a self-concept measure. The study adapted the self-perception scale (Neemann \& Harter, 2012), which is composed of various domains (i.e., scholastic competence, athletic competence, physical appearance, and social acceptance).

To evaluate the content validity of the sports role model scale, the questionnaire items were reviewed by a panel of five experts from departments of sport management, education, and psychology in the United States (DeVellis, 2012). Some overlapping items in terms of the athletic performance (i.e., my sports role model is a superior athlete) were removed. For the face validity of the instrument, 50 college students reviewed and responded to the items (Netemeyer, Bearden, \& Sharma, 2003).

Next, two bilingual experts translated the English version of the questionnaire into Korean. Another panel of two experts interpreted the translated Korean questionnaire back to English to verify the instrument's reliability and clarify it for the eventual survey respondents. Therefore, the initial questionnaire consisted of seven factors: athletic performance ( 8 items), professionalism (22 items), physical appearance ( 7 items), personality (12 items), community service ( 7 items), morality ( 7 items), and fame/fortune (7 items). 


\section{Data Analysis}

Next, the researcher randomly split this dataset into two groups, utilizing the Statistical Package for the Social Sciences (SPSS) computer program. Gorsuch (1983) asserted that at least 200 people are needed to conduct a factor analysis. An Exploratory Factor Analysis (EFA) was conducted on the 355 respondents of the first dataset to develop the initial factor structure for the sports role model scale. A Confirmatory Factor Analysis (CFA) was conducted on the 361 participant responses of the second dataset to see if any changes to this original model should be made. Such modifications of the model were based on a combination of statistical results (i.e., model fit indices) and theoretical senses. For example, the original sports role model scale was examined and revised by model fit indices, such as RMSEA, CFI, and SRMR, which are the most rigorous measures, and theoretical interpretability of items in each factor (Schumacker \& Lomax, 2010). This study utilized RMSEA, CFI, and SRMR because those fit indices that are the least influenced by sample size and parameter number. The cut-off value of RMSEA for good fit is .08; the cut-off value of CFI for good fit is .90; and the cut-off value of SRMR for good fit is .08 (Hu \& Bentler, 1999). The reliability of the modified sports role model scale was examined by the internal consistency test (i.e., Cronbach's alpha).

\section{RESULTS}

Of the 716 respondents, $72 \%$ were male and $28 \%$ were female. Ages ranged between 19 and 25 . Study participants were considered to have positive perceptions of their sport role models' behavior on and off the court due to their mean score which was higher than 3.5 (the half-way point of a 7-point Likert scale) for all questionnaire items.

\section{Exploratory Factor Analysis (EFA)}

For the EFA of the first sample of 355 participants, the 70 questionnaire items were analyzed to establish an initial factor structure of the sports role model scale. The study utilized a principal-components analysis with oblique rotation, a promax rotation technique. The KMO measure for sampling adequacy was 0.96 , and the BTS value was 18,124.76 $(p<0.001)$. These figures indicate that the sample is appropriate for factor analysis. The principal-components analysis identified eight factors with 67 items, explaining $66.76 \%$ of the total variance. After careful examination of the pattern matrix, 13 of the EFA items were discarded (AP3, AP4, PRO12, PRO21, PER2, PER5, COM1, COM2, M4, M5, M6, M7, and FF1), due to the critical issue of inappropriate theoretical justification. For example, AP3 and AP4 items were supposed to be a part of the athletic performance factor. However, they belonged to another factor (i.e., professionalism). Consequently, an eight-factor model with 54 items emerged for conducting a further CFA. As stated in Table 1, the eight factors which emerged from the EFA were professionalism (18 items, $\alpha=0.95)$, personality (10 items, $\alpha=0.91$ ), fame and fortune ( 6 items, $\alpha=0.88$ ), athletic performance ( 6 items, $\alpha=0.90$ ), community service ( 5 items, $\alpha=0.91$ ), game outfit ( 3 items, $\alpha=0.87$ ), physical strength ( 3 items, $\alpha=0.82$ ), and morality (3 items, $\alpha=0.90$ ). This factor structure of the sports role model is almost consistent with the conceptual approaches. Six factors (i.e., professionalism, personality, fame and fortune, athletic performance, community service, and morality) were equivalent between the two models. However, physical appearance, which had been implemented, was divided into the two dimensions, game outfit and physical strength.

\section{Confirmatory Factor Analysis (CFA)}

The study used the second group of 361 participants to conduct the CFA for confirming and revising the eight-factor structure, using the 54 items of the sports role model scale established by the EFA. This study examined the initial measurement model on the basis of multiple model fit indices (i.e., chi-square fit index, RMSEA, CFI, and SRMR). The results indicated that the initial eight-factor with 54-item model did not statistically fit the current data. For example, the chi-square fit index was statistically significant $\left(X^{2}=3964.88, p<0.001\right)$ indicating that the measurement model does not fit the data. Furthermore, the CFI fit index was 0.83, which is below the cutoff value (0.90). On the other hand, the RMSEA fit index was 0.07, which is in the acceptable model fit range (0.08). Also, the SRMR fit index was 0.06 , which is deemed acceptable.

On the basis of the model fit indices results, the study modified the initial measurement model in order to obtain reasonable model fit. As a way of respecifying the current model, the study examined whether the model had low factor loading items. After careful investigation, this study deleted 10 indicators (AP1, PRO2, PRO5, PRO8, PRO13, PRO14, PRO15, PER3, PER12, and FF4) whose factor loading was less than 0.71 . This approach is likely to increase the convergent validity of the model (Anderson \& Gerbing, 1988). Next, the CFA was conducted again; it showed that the fit indices of the modified measurement model had improved. For instance, the chi-square fit index decreased $\left(\chi^{2}=2443.16, p<0.001\right)$. Also, the CFI fit index increased to 0.88. The RMSEA fit index was the same, at 0.07. The SRMR fit index was the same, at 0.06. In spite of the respecification, the measurement model still had four indicators (AP7, PRO1, FF3, and FF5) that had a low factor loading. Therefore, those four items were deleted. The chi-square fit index decreased $\left(\chi^{2}=1906.13, p<0.001\right)$. Also, the CFI fit index increased to 0.90, which meets the recommended threshold. The RMSEA fit index was the same, at 0.07. The SRMR fit index was the same, at 0.06 . However, the factor loading of the Fame and Fortune item $2(0.70)$ was lower than the criterion. This indicator was retained, because of its theoretical meaning, in order to create the focal construct, which should comprise at least three items. 
Table 1. Rotated Factor Pattern Matrix for Sports Role Model Dimensions $(n=355)$

\begin{tabular}{|c|c|c|c|c|c|c|c|c|}
\hline FACTOR & 1 & 2 & 3 & 4 & 5 & 6 & 7 & 8 \\
\hline \multicolumn{9}{|l|}{ Professionalism } \\
\hline Set example (PRO1) & 0.61 & & & & & & & \\
\hline Inspire me (PRO2) & 0.47 & & & & & & & \\
\hline Work hard (PRO3) & 0.82 & & & & & & & \\
\hline Determined person (PRO4) & 0.90 & & & & & & & \\
\hline Disciplined person (PRO5) & 0.87 & & & & & & & \\
\hline Tough (PRO7) & 0.69 & & & & & & & \\
\hline Passionate (PRO8) & 0.57 & & & & & & & \\
\hline Leadership (PRO9) & 0.88 & & & & & & & \\
\hline Never give up (PRO10) & 0.75 & & & & & & & \\
\hline Brave (PRO13) & 0.40 & & & & & & & \\
\hline Fair player (PRO14) & 0.54 & & & & & & & \\
\hline Sportsmanship (PRO15) & 0.51 & & & & & & & \\
\hline Desire to win (PRO16) & 0.80 & & & & & & & \\
\hline Dedicated athlete (PRO17) & 0.80 & & & & & & & \\
\hline Love for game (PRO18) & 0.79 & & & & & & & \\
\hline Competitive (PRO19) & 0.54 & & & & & & & \\
\hline Strong work ethic (PRO20) & 0.61 & & & & & & & \\
\hline Successful player (PRO22) & 0.45 & & & & & & & \\
\hline \multicolumn{9}{|l|}{ Personality } \\
\hline Good person (PER1) & & 0.66 & & & & & & \\
\hline Personable (PER3) & & 0.53 & & & & & & \\
\hline Loving (PER4) & & 0.72 & & & & & & \\
\hline Friendly (PER6) & & 0.69 & & & & & & \\
\hline Kind (PER7) & & 0.61 & & & & & & \\
\hline Generous (PER8) & & 0.61 & & & & & & \\
\hline Trustworthy (PER9) & & 0.63 & & & & & & \\
\hline Humble (PER10) & & 0.86 & & & & & & \\
\hline Responsive to fans (PER11) & & 0.63 & & & & & & \\
\hline \multicolumn{9}{|l|}{ Fame and Fortune } \\
\hline High salary (FF2) & & & 0.84 & & & & & \\
\hline High social status (FF3) & & & 0.61 & & & & & \\
\hline Famous (FF4) & & & 0.54 & & & & & \\
\hline Affluent (FF5) & & & 0.56 & & & & & \\
\hline Luxurious home (FF6) & & & 0.93 & & & & & \\
\hline Expensive car (FF7) & & & 0.88 & & & & & \\
\hline \multicolumn{9}{|l|}{ Athletic Performance } \\
\hline Excellent player (AP1) & & & & 0.62 & & & & \\
\hline High-level performer (AP2) & & & & 0.55 & & & & \\
\hline Best player (AP5) & & & & 0.89 & & & & \\
\hline Dominate competition (AP6) & & & & 0.79 & & & & \\
\hline Charismatic play (AP7) & & & & 0.51 & & & & \\
\hline Exemplary performance (AP8) & & & & 0.61 & & & & \\
\hline \multicolumn{9}{|l|}{ Community Service } \\
\hline Giving back (COM3) & & & & & 0.53 & & & \\
\hline Help people (COM4) & & & & & 0.67 & & & \\
\hline Charitable work (COM5) & & & & & 0.75 & & & \\
\hline Donate money (COM6) & & & & & 0.78 & & & \\
\hline Community service (COM7) & & & & & 0.62 & & & \\
\hline \multicolumn{9}{|l|}{ Game Outfit } \\
\hline Clothing style (PA1) & & & & & & 0.78 & & \\
\hline Athletic apparel (PA2) & & & & & & 0.90 & & \\
\hline Athletic footwear (PA3) & & & & & & 0.90 & & \\
\hline \multicolumn{9}{|l|}{ Physical Strength } \\
\hline Physically strong (PA4) & & & & & & & 0.78 & \\
\hline Physically fit (PA6) & & & & & & & 0.53 & \\
\hline Powerful (PA7) & & & & & & & 0.62 & \\
\hline \multicolumn{9}{|l|}{ Morality } \\
\hline Honest (M1) & & & & & & & & 0.58 \\
\hline Integrity (M2) & & & & & & & & 0.57 \\
\hline Honorable (M3) & & & & & & & & 0.56 \\
\hline
\end{tabular}

The study investigated the criterion validity of the modified sports role model scale. It examined the correlation coefficients between the eight factors of the sports role model construct and the four factors of the self-concept construct (i.e., scholastic competence, athletic competence, physical appearance, and social acceptance). The results indicated that these eight factors of the sports role model construct 
are significantly correlated with the four factors of the self-concept construct. The correlation coefficients ranged from 0.20 to 0.37 .

In order to verify the convergent validity of the scale, this study examined the Average Variance Explained (AVE) values of each dimension. The AVE values ranged from 0.57 to 0.74 , which meet the recommended threshold (0.50). In order to verify the discriminant validity of the scale, this study tested to see if the square root of every AVE value belonging to each sub-construct is larger than any correlation among any pair of sub-constructs. The square root of all the AVE values were larger than all the correlation values among the sub-constructs, except that the correlation value between the professionalism sub-construct and the morality sub-construct was larger than the square root of the AVE value belonging to the professionalism sub-construct. The Cronbach's alpha values of all the eight factors ranged from 0.80 to 0.94 , which are above the recommended threshold $(0.70)$.

Table 2. Revised Model's $(n=361$ ) Factor Loading $(\lambda)$, Cronbach's Alpha $(\alpha)$, and Average Variance Explained (AVE)

\begin{tabular}{|c|c|c|c|}
\hline FACTOR & $\lambda$ & $\alpha$ & AVE \\
\hline Professionalism & & .94 & .61 \\
\hline Work hard (PRO3) & .82 & & \\
\hline Determined person (PRO4) & .73 & & \\
\hline Tough (PRO7) & .72 & & \\
\hline Leadership (PRO9) & .80 & & \\
\hline Never give up (PRO10) & .71 & & \\
\hline Desire to win (PRO16) & .83 & & \\
\hline Dedicated athlete (PRO17) & .79 & & \\
\hline Love for game (PRO18) & .82 & & \\
\hline Competitive (PRO19) & .83 & & \\
\hline Strong work ethic (PRO20) & .77 & & \\
\hline Successful player (PRO22) & .76 & & \\
\hline Personality & & .93 & .64 \\
\hline Good person (PER1) & .78 & & \\
\hline Loving (PER4) & .80 & & \\
\hline Friendly (PER6) & .85 & & \\
\hline Kind (PER7) & .87 & & \\
\hline Generous (PER8) & .81 & & \\
\hline Trustworthy (PER9) & .78 & & \\
\hline Humble (PER10) & .72 & & \\
\hline Responsive to fans (PER11) & .74 & & \\
\hline Fame and Fortune & & .88 & .74 \\
\hline High salary (FF2) & .70 & & \\
\hline Luxurious home (FF6) & .93 & & \\
\hline Expensive car (FF7) & .93 & & \\
\hline Athletic Performance & & .84 & .58 \\
\hline Best player (AP5) & .78 & & \\
\hline Dominate competition (AP6) & .78 & & \\
\hline Exemplary performance (AP8) & .76 & & \\
\hline Community Service & & .92 & .72 \\
\hline Giving back (COM3) & .82 & & \\
\hline Help people (COM4) & .87 & & \\
\hline Charitable work (COM5) & .91 & & \\
\hline Donate money (COM6) & .85 & & \\
\hline Community service (COM7) & .77 & & \\
\hline Game Outfit & & .88 & .72 \\
\hline Clothing style (PA1) & .78 & & \\
\hline Athletic apparel (PA2) & .87 & & \\
\hline Athletic footwear (PA3) & .89 & & \\
\hline Physical Strength & & .80 & .57 \\
\hline Physically strong (PA4) & .74 & & \\
\hline Physically fit (PA6) & .75 & & \\
\hline Powerful (PA7) & .77 & & \\
\hline Morality & & .89 & .74 \\
\hline Honest (M1) & .83 & & \\
\hline Integrity (M2) & .89 & & \\
\hline Honorable (M3) & .86 & & \\
\hline
\end{tabular}




\section{DISCUSSION}

This current sport role model scale has comprehensively established the eight dimensions of the sports role model construct, such as athletic performance, professionalism, game outfit, physical strength, personality, fame/fortune, community service, and morality on the basis of the rigorous scale development procedure. Therefore, this multidimensional measurement tool can be used to scientifically examine scores of the eight domains which are demonstrated by sports role models and their relationships with the learning and patronage behavior of the young admirers. On the basis of the study findings, sport role model can be defined as the construct which is composed of the eight sub-constructs and positively influences admirers' self-concept development.

Consistent with social learning theory, Korean college student athletes who participated in this study seemed to perceive and learn various on- and off-court behavior of their own professional sports role model. Furthermore, the findings of this study indicated that such perception on the multiple aspects of the sports role models can help these young college students develop the several domains of their self-concept (i.e., scholastic competence, athletic competence, physical appearance, and social acceptance) and become similar to their own sports role model who exemplifies the eight dimensions. Based on these findings, it is suggested that administrators, coaches, and athletes in the professional sport organizations acknowledge this significant role of professional sports role models on college student athletes' life.

The descriptive statistics of the preliminary factor model indicated that athletic performance had the highest mean score $(\mathrm{M}=6.36$; $\mathrm{SD}=0.73)$, whereas community service had the lowest mean score $(\mathrm{M}=5.50 ; \mathrm{SD}=1.09)$ in the Korean sample. In other words, the highest score of athletic performance might be attributable to learning by heart just for scores in Korean society. On the other hand, the possible reason for the lowest score of community service in the sample was that Korean professional athletes are little involved in the community service. Based on these findings, it is suggested that coaches and administrators in the Korean sports associations help college student athletes balance their school work and athletics, while encouraging professional athletes to give back to the community and establishing more community service programs.

The factor analysis revealed eight dimensions: professionalism, personality, fame and fortune, athletic performance, community service, morality, game outfit, and physical strength. Athletic performance was the most significant aspect that makes high-profile athletes role models. Student athletes watch and learn superior on-court performance of their sport role models to master certain sports skills and improve their athletic performance. Previous research also regarded athletic performance as one of the important domains that sports role models exhibit (Biskup \& Pfister, 1999; Bricheno \& Thornton, 2007; Feezell, 2005; Fleming et al., 2005; Freedman-Doan \& Eccles, 1996; Funk, et al., 2002; Giuliano et al., 2003; Guest \& Cox, 2009; Harris, 1994; May, 2009; Vescio et al., 2005; Wilson \& Sparks, 1996). Recently, Stephen Curry, who is widely known as the best 3-point shooter in the NBA history, has totally changed the paradigm of the modern basketball (Abbott, 2016). Many young basketball players imitate and practice Curry's prominent three-point shooting technique which led his team to the three-time championships (Abbott, 2016).

Professionalism was also regarded as one of the important dimensions. Professional athletes who work very hard every single day are perceived as good role models for the young generation. The literature supported the importance of professional athletes' professionalism (Biskup \& Pfister, 1999; Bricheno \& Thornton, 2007; Bush et al., 2004; Feezell, 2005; Fleming et al., 2005; Giuliano et al., 2003; Globus, 1998; Guest \& Cox, 2009; Strudler, 2000; Vescio et al., 2005; Wilson \& Sparks, 1996). Regardless of winning the championships, hard work and discipline which professional athletes exhibit on a daily basis can have a positive impact on young people's life. For example, Chanho Park, a former Major League Baseball (MLB) player, never gave up, continued to improve himself in spite of a series of injuries, and consequently broke the record for the most wins by an Asian pitcher with 124 (Terrill, 2012). Such self-discipline and incredible work ethic which he showed throughout his MLB career encouraged young Korean baseball players and college students to work hard (Kim, 2009).

Personality also played an important role in representing sport role models. Professional athletes who have a good personality are perceived to be good role models for young learners. Superior athletes who possess a good personality are loved and praised by many fans and the media (Eisenband, 2010). These findings were consistent with the previous studies (Bricheno \& Thornton, 2007; Fleming et al., 2005; Giuliano et al., 2003; McInerney \& McInerney, 1998; Rich, 1997; Wescio et al., 2005; Wright et al., 1997). Good relationships with family members, teammates, coaches, fans, and opponents should be one of the crucial aspects for public sports role models. On the contrary, professional athletes who show rude or violent behavior toward opposing players, coaches, and fans cannot become a good role model for young admirers in our society (Mclendon, 2016).

Engaging in community service has been established as one of the crucial qualifications for sport role models. Professional athletes pay attention to and speak up on community issues while helping people in trouble because they receive substantial media attention and arouse public interest. The literature also supported this social responsibility aspect of sports role models (Burch \& Murray, 1999; Bricheno \& Thornton, 2007; Feezell, 2005; Fleming et al., 2005; Globus, 1998; Guest \& Cox, 2009; May, 2009). Kevin Durant, an NBA superstar, recently donated $\$ 10$ million to support public schools and local students who are in need (Ellis, 2018). As such, the successful professional sports role model who contributes to the community is likely to positively influence their young admirers to work hard and succeed in their field in order to become like their role model.

Morality was also one of the essential aspects of being a good sports role model. These public sports role models should be responsible for living a moral life for their admirers. This moral aspect of sports role models is supported by the literature (Bricheno \& Thornton, 2007; Feezell, 2005; Guest \& Cox, 2009; Miller Brewing Company, 1983; Vande Berg \& Trujille, 1989; Wright, Wong, \& Newill, 1997). The media severely blame the immoral behavior of professional athletes due to their public figure status in society. For example, an NBA legend, Kobe Bryant who is the husband and father in his family was criticized by the media and lost several endorsement contracts when he committed adultery and was prosecuted for sexual assault (Tuchman \& Cabell, 2003). He apologized in public and made every effort to perform on and off the court in an excellent manner. In result, he redeemed his previous immature behavior and regained the fame as the 
superstar basketball player (Stern, 2016). Professional sports role models who live a moral life can positively influence immature admirers to become an upright and moral citizen.

Fame and fortune were identified as another significant domain. Professional athletes who earn millions of dollars receive the media spotlight and keep their celebrity status. This result was consistent with the sports literature (Assibey-Mensah, 1997; Bricheno \& Thornton, 2007; Clark et al., 2001; Fleming et al., 2005; Giuliano et al, 2003; MacCallum \& Beltman, 2002; Sinclair, 1997; Strudler, 2000; Vande Berg \& Trujille, 1989; Wilson \& Sparks, 1996). The media frequently reveal the enormous salaries, luxurious house, and expensive cars of high-profile athletes which ordinary people cannot afford to purchase in their lifetime (Badenhausen, 2018). Furthermore, professional athletes and their games are always at the center of media attention, while highly praising the superior performance in the clutches (Kell, 2016). Observing a successful career and life which their own sports role model enjoys can strongly motivate college student athletes to work hard and obtain their dream job.

However, the hypothesized physical appearance factor was further divided into two dimensions; game outfit and physical strength. This finding seems understandable. On one hand, many high-profile athletes wear their own shoes and uniform with their back number and name. College student athletes are likely to imitate the game outfit of their favorite athlete. For example, basketball players all over the world emulated Michael Jordan's long and wide shorts and jersey with an elbow band and calf sleeve, while wearing Air Jordan basketball shoes (O'Brien, 2015). Furthermore, the NBA has recently changed its basketball shoes policy which allows players to wear colorful sneakers during the game as a way of expressing their individuality (Flores, 2015). On the other hand, professional athletes show off a muscular body and tremendous power on the court. For instance, the NBA superstar, LeBron James is widely known for his incredible workout and physical strength in spite of his old age as a player (Davis, 2018). College student athletes who have their own sports role model are likely to envy such a strong physique and train the body in order to make it strong.

This newly-developed sports role model scale can help both scholars and practitioners comprehensively understand and assess the eight dimensions of the sports role model instrument. For example, sport marketing researchers can utilize the instrument to examine how each dimension influences admirers' purchase intentions for their own sports role model's merchandise and endorsement products, as well as for attendance at (or watching) games. Furthermore, the comprehensive sports role model instrument can allow professional sport league administrators to investigate which aspects of sports role models are perceived to be good or bad by collegiate student athletes. Based on the scores measured by the sports role model scale, administrators could educate and improve upon athletes' weak points. Such systematic evaluation and education on the multiple domains of sports role model behavior can help professional athletes become better role models, while improving the reputation of professional sport leagues.

Professional sport league administrators and sporting goods company marketers have utilized professional athletes for various purposes, such as regular/playoff season promotion videos, back-to-school campaigns, community service events, fan meetings, sports clinics, public service announcements, and endorsement commercials, etc. However, the selection of an appropriate athlete seems to be made intuitively rather than scientifically. This multi-dimensional sports role model instrument can provide the practitioners with scientific evidence to help them choose the most effective sports role models on the basis of relevant dimension scores. For example, it is suggested that league administrators refer to professionalism dimension scores in order to select a proper sports role model when they make films to promote a good work ethic as a way of encouraging young student athletes to study and work hard. It is also suggested that practitioners consider personality dimension scores when they plan to hold fan meeting events. Furthermore, this study suggests that the athletic performance dimension scores be used when choosing athletes who appear in promotional videos for regular season/playoff games. The community service sub-scale could be a good measure for league administrators looking for a sports role model who is eligible to conduct a campaign of community service in order to inspire social consciousness among young people.

Additionally, the current study suggests that sporting goods company marketers who target a young fashion-conscious group could consider game outfit dimension scores as a way of finding an appealing endorser. Moreover, sports drink or supplement company marketers who plan to sell their products to young consumers who want to build up a strong physique could refer to physical strength dimension scores. Finally, administrators creating public service advertisements to educate and prevent immature student athletes from engaging in immoral/criminal activities, such as premarital sex, abortion, smoking, drunk-driving, drug use, and domestic violence, could pay attention to athletes who receive high scores on the morality dimension.

Although this study's findings are significant, it has a limitation. Due to the logistical difficulty of using a random sampling technique for data collection, convenience sampling was used for the sample of South Korean university student athletes. Therefore, the samples utilized may not be representative of the larger population. Thus, the results obtained from the study should be interpreted with caution. In order to enhance external validity, a probability sampling method should be planned and implemented that would increase the sample size in broader geographic regions and other countries.

\section{REFERENCES}

Adair, D. (2015, December 18). Athletes of influence. Bounce of the ball. Retrieved from https://theconversation.com/athletes-ofinfluence-the-role-model-refrain-in-sport-52569

Addis, A. (1996). Role models and the politics of recognition. University of Pennsylvania Law Review, 144(4), 1377-1468.

Arai, A, Ko, Y, \& Kaplanidou, K. (2013). Athlete brand image: scale development and model test. European Sport Management, 13(4), 383-403.

Assibey-Mensah, G. O. (1997). Role models and youth development: Evidence and lessons from the perceptions of African-American male youth. The Western Journal of Black Studies, 21(4), 242-251. 
Badenhausen, K. (2018, June 5). The world's 100 highest-paid athletes 2018. Forbes. Retrieved from https://www.forbes.com/sites/kurtbadenhausen/2018/06/05/the-worlds-100-highest-paid-athletes-2018-behind-thenumbers/\#10caceab4dd0

Bandura, A. (1977). Social learning theory. Englewood Cliffs, N.J.: Prentice Hall.

Biskup, C., \& Pfister, G. (1999). I would like to be like her/him: Are athletes role-models for boys and girls? European Physical Education Review, 5(3), 199-218.

Bricheno, P., \& Thornton, M. (2007). Role model, hero or champion? Children's views about role models. Educational Research, 49(4), 383-396.

Burch, H. M., \& Murray, J. B. (1999). An essay on athletes role models, their involvement in charities, and considerations in starting a private foundation. Sports Lawyers Journal, 6, 249-271.

Bush, A. J., Martin, C. A., \& Bush, V. D. (2004). Sports celebrity influence on the behavioral intentions of generation Y. Journal of Advertising Research, 44(1), 108-118.

Clark, P. W., Martin, C. A., \& Bush, A. J. (2001). The effect of role model influence on adolescents' materialism and marketplace knowledge. Journal of Marketing Theory and Practice, 9(4), 27-36.

Coakley, J. J. (2001). Sport in society: Issues and controversies. New York: McGraw-Hill.

Davis, S. (2018, June 3). LeBron James takes immaculate care of his body, and the NBA world is in awe of it. Business Insider. Retrieved from https://www.businessinsider.com/lebron-james-body-care-workouts-diet-insane-2017-10

DeVellis, F. (2012). Scale development: Theory and applications. Thousand Oaks, CA: Sage.

Eisenband, J. (2010, September 3). 2010's Most Loved Athletes. Bleacher Report. Retrieved from https://bleacherreport.com/articles/450276-2010s-most-loved-athletes\#slide0

Ellis, C. (2018, February 23). Kevin Durant commits $\$ 10$ million to Prince George's County public schools. NBC Sports. Retrieved from https://www.nbcsports.com/washington/wizards/kevin-durant-commits-10-million-prince-georges-county-public-schools

Feezell, R. (2005). Celebrated athletes, moral exemplars, and lusory objects. Journal of the Philosophy of Sport, 32(1), 20-35.

Fleming, S., Hardman, A., Jones, C., \& Sheridan, H. (2005). Role models among elite young male rugby league players in Britain. European Physical Education Review, 11(1), 51-70.

Flores, G. (2015, February 23). New rules: breaking down the NBA's sneaker policy. Sole Collector. Retrieved from https://solecollector.com/news/2015/02/new-rules-breaking-down-the-nba-s-sneaker-policy

Freedman-Doan, C., \& Eccles, J. S. (1996). Where have you gone Joe Dimaggio? An examination of adolescent's heroes and identity formation. Paper presented at the Sixth Society for Research on Adolescence, Boston, MA.

Funk, D.C., Ridinger, L. L., \& Moorman, A. M. (2003). Understanding consumer support: Extending the sport interest inventory (SII) to examine individual differences among women’s professional sport consumers. Sport Management Review, 6, 1-32.

Giuliano, T. A. Turner, K. L., Lundquist, J. C., \& Knight, J. L. (2007). Gender and the selection of public athletic role models. Journal of Sport Behavior, 30(2), 161-198.

Globus, S. (1998). Athletes as role models. Current Health, 24(6), 25-28.

Guest, A. M., \& Cox, S. (2009). Using athletes as role models? Conceptual and empirical perspectives from a sample of elite women soccer players. International Journal of Sports Science \& Coaching, 4(4), 567-581.

Gorsuch, R. L. (1983). Factor analysis. Hillsdale, NJ: Erlbaum.

Harris, J. (1994). Athletes and the American hero dilemma. Champaign, IL: Human Kinetics.

$\mathrm{Hu}, \mathrm{L} .$, \& Bentler, P. (1999). Cutoff criteria for fit indexes in covariance structure analysis: Conventional criteria versus new alternatives. Structural Equation Modeling, 6(1), 1-55.

Kell, J. (2016, March 19). Why Nike, Adidas are turning to celebrities in 2016. Fortune. Retrieved from http://fortune.com/2016/03/19/nike-adidas-kevin-hart-kanye

Kellner, D. (1996). Sports, media culture, and race: Some reflections on Michael Jordan. Sociology of Sport Journal, 13, $458-467$.

Kim, Y., \& Trail, G. (2010). Constraint and motivators: A new model to explain sport consumer behavior. Journal of Sport Management, 24(2), 190-210.

Kohlstrung, L. (2016). Characteristics of good role models in sports and social life. Retrieved from https://essay.utwente.nl/69918/1/Kohlstrung_BA_BMS.pdf

May, B. (2009). The good and bad of it all: Professional black male basketball players as role models for young black male basketball players. Sociology of Sport Journal, 26, 443-461.

Mclendon, S. (2016, January 3). Top 10 worst sports role models of 2015. Movie TV Tech Geeks. Retrieved from https://movietvtechgeeks.com/top-10-worst-sports-role-models-of-2015

Neemann, J., \& Harter, S. (2012). Self-perception profile for college. Department of Psychology. University of Denver.

Netemeyer, R. G., Bearden, W. O., \& Sughash, S. (2003). Scaling procedures: Issues and applications. Thousand Oaks, CA: Sage.

O'Brien, G. (2015, March 4). Young Michael Jordan. GQ. Retrieved from https://www.gq.com/story/michael-jordan

Pulley, B. (2001, March 19). Top of the lineup. Derek Jeter is must-see TV. Forbes. Retrieved from https://www.forbes.com/forbes/2001/0319/130.html\#75c062d3586c

Rich, G. A. (1997). The sales manager as a role model: Effects on trust, job satisfaction, and performance of salespeople. Journal of the Academy of Marketing Science, 25(4), 319-328.

Rojek, C. (2006). Sports celebrity and the civilizing process. Sport in Society, 9, 674-690.

Schumacker, R. E., \& Lomax, R. G. (2010). A Beginner's Guide to Structural Equation Modeling (3 ${ }^{\text {rd }}$ ed.). Mahwah, NJ: Lawrence Erbaum Associates. 
Smoll, F. (2015, April 20). Are athletes good role models? Psychology Today.

Retrieved from https://www.psychologytoday.com/us/blog/coaching-and-parenting-young-athletes/201504/are-athletes-goodrole-models

Stern, M. (2016). Kobe Bryant's disturbing rape case. Daily Beast. Retrieved from https://www.thedailybeast.com/kobe-bryantsdisturbing-rape-case-the-dna-evidence-the-accusers-story-and-the-half-confession

Strudler, K. A. (2000). The mass mediated sports hero as a role model for adolescent males: Measuring self-concept congruity with perceived image of the hero to predict role

Terrill, M. (2012, November 30). Chanho Park holds mark for most wins by Asian pitcher in MLB history. Rant Sports. Retrieved from http://www.rantsports.com/mlb/2012/11/30/chan-ho-park-holds-mark-for-most-wins-by-asian-pitcher-in-mlb-history/

Tuchman, G., \& Cabell, B. (2003, December 16). Kobe Bryant charged with sexual assault. CNN.com. Retrieved from http://www.cnn.com/2003/LAW/07/18/kobe.bryant

Vescio, J., Wilde, K., \& Crosswhite, J. J. (2005). Profiling sport role models to enhance initiatives for adolescent girls in physical education and sport. European Physical Education Review, 11(2), 153-170.

Williams, L. (2017, September 11). Why do athletes make good role models? Live Strong.

Retrieved from https://www.livestrong.com/article/374758-why-do-athletes-make-good-role-models

Wilson, B., \& Sparks, R. (1996). It's gotta be the shoes: Youth, race, and sneaker commercials. Sociology of Sport Journal, 13(4), 398427.

\section{Author Information}

Doyeop Kim, Ph.D., Corresponding Author

(D https://orcid.org/0000-0002-7933-9183

Assistant Professor

Department of Education

Louisiana State University, Alexandria, LA, USA

징okim1976@gmail.com

Minkil Kim, Ph.D.

(D https://orcid.org/0000-0002-5619-5412

Associate Professor

School of Hospitality, Sport \& Tourism Management

College of Business, Troy University, AL, USA

지kim95145@troy.edu

Anthony Dixon, Ph.D.

(D https://orcid.org/0000-0003-3556-8678

Professor \& Director

School of Hospitality, Sport \& Tourism Management

College of Business, Troy University, AL, USA

ㅈawdixon@troy.edu
Giyong Koo, Ph.D.

(D https://orcid.org/0000-0001-5411-9662

Professor \& Sport Management Doctoral Coordinator

School of Hospitality, Sport \& Tourism Management

College of Business, Troy University, AL, USA

ㅈkoo@troy.edu

Stephen Shin, Ph.D.

(D https://orcid.org/0000-0002-9647-5208

Associate Professor, Department of Sport Administration

College of Liberal Arts \& Social Sciences

Belmont University, TN, USA

จ Stephen.shin@belmont.edu

Conflict of Interest: The authors declare that the research was conducted in the absence of any commercial or financial relationship that could be constructed as a potential conflict of interest.

Publisher's Note: All claims expressed in this article are solely those of the authors and do not necessarily represent those of their affiliated organizations, or those of the publisher, the editors and reviewers. Any product that may be evaluated in this article, or claim that may be made by its manufacturer, is not guaranteed or endorsed by the publisher.

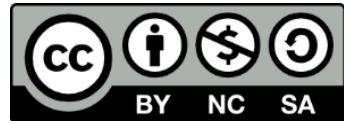

Copyright (C) 2020-2021. This work is licensed under a CC BY-NC-SA 4.0 International license. This is an open access article distributed under the Creative Commons Attribution License which permits unrestricted use, distribution, and reproduction in any medium, provided the original work is properly cited. 


\title{
ORIGINAL RESEARCH
}

\section{Sex Differences in the Association Between Muscular Strength and Adiposity in Healthy Adults}

\author{
Ethan W. Clark, Dorin Drignei, \& Elise C. Brown \\ Oakland University, Rochester, MI, USA
}

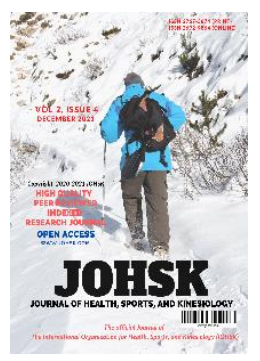

Received 13 September 2021 | Revised 30 November 2021 | Accepted 1 December 2021

Open Access Available online at www.johsk.com

\begin{abstract}
Although sex differences in body composition are well established, differences in the relationship between adiposity and muscular strength remain elusive. Thus, the aim of this study was to determine sex differences in the relationship between muscular strength and adiposity in adults. Body mass index (BMI), waist circumference (WC), waist-toheight ratio (WtHR), skinfold, and bench press were assessed on 140 males and females aged 18-40 years. Normalized strength (NS) was determined by dividing bench press one-repetition maximum by body mass. Using linear regression, positive associations between NS and BMI were found in males $[p=0.003$, parameter estimate $(\mathrm{PE})=0.051]$ and females $(p=0.010, \mathrm{PE}=0.021)$; inverse associations between $\mathrm{NS}$ and body fat percentage were found in males $(p<0.001, \mathrm{PE}=-0.035)$ and females $(p=0.015, \mathrm{PE}=-0.008)$; an inverse association between NS and WC was observed only amongst females $(p=0.037, \mathrm{PE}=-0.011)$; and no significant associations were found between NS and (WtHR) for either sex. Although the current study design does not permit determining causality, the findings suggest that resistance training may be more effective in reducing abdominal adiposity in females.
\end{abstract}

Key words: Bench Press, Body Composition, Muscle Strength, Resistance Training, Waist Circumference

\section{INTRODUCTION}

Over the previous two decades, the prevalence of age-adjusted obesity has increased linearly among United States adults, with similar increases in males and females (Hales et al., 2020). Comorbidities commonly associated with obesity include type 2 diabetes (Daousi et al., 2006), musculoskeletal pain (Melissas et al., 2003), and impaired quality of life (Pimenta et al., 2015). Obesity has also been linked to limitations in skeletal muscle performance (Tomlinson et al., 2016). The damaging effects to skeletal muscle are partly a consequence of increased pro-inflammatory cytokines which are released from accumulated adipocytes (Pellegrinelli et al., 2015) and anabolic hormone reduction that is also linked to excessive adipose tissue (Galli et al., 2012). Furthermore, compared to subcutaneous adipose tissue, visceral adipose tissue (VAT) is exceptionally harmful to skeletal muscle development, indicating site-specific cross talk exists between adipocytes and skeletal muscle (Pellegrinelli et al., 2015).

Sex differences in body composition (Bredella, 2017), and the response of skeletal muscle to resistance training (Roberts et al., 2020), are well established. However, findings from studies are mixed in terms of the relationship of muscular strength with adiposity measures (Hardy et al., 2013; Keevil et al., 2015; Pasdar et al., 2019), especially when sex differences are considered. For example, a meta-analysis conducted on 16,444 adults aged 50-90+ years found that handgrip strength was positively associated with body mass index (BMI) among males only (Hardy et al., 2013). Conversely, in a cross-sectional study conducted on British adults aged 48-92 years by Keevil et al. (2015), handgrip strength was positively correlated with BMI, yet inversely related to waist circumference (WC) in both males and females (after adjustment for BMI). Additionally, most of the research conducted on the relationship between muscular strength and adiposity has focused on older or unhealthy populations, leaving the associations among healthy, young adults to be underreported. 
Muscular strength (Grgic et al., 2020; Hamilton et al., 1992) and adiposity (Madden \& Smith, 2016; Tran et al., 2018; Witt \& Bush, 2005) can be assessed using a variety of instruments or tests. While BMI is a commonly used marker of obesity, it does not distinguish fat mass from fat-free mass and can be a poor predictor of body fat distribution and mass (Witt \& Bush, 2005). Measurements such as WC and waist-to-height ratio (WHtR) are used to evaluate patterns of body mass distribution, specifically around the abdominal region, serving as proxy measures of VAT (Ashtary-Larky et al., 2018; Tran et al., 2018). Skinfold measurements similarly evaluate adiposity at different sites of the body (Madden \& Smith, 2016). For muscular strength assessment, one-repetition maximum (1RM) testing is considered the gold standard (Grgic et al., 2020). However, this technique of measuring muscular strength is not as accessible as a handgrip dynamometer, which many researchers choose to measure muscular strength (Hardy et al., 2013; Keevil et al., 2015; Pasdar et al., 2019). The many techniques of assessing muscular strength and adiposity may contribute to the divergent findings from studies investigating associations between these two measurements. Using various total and abdominal adiposity measures to better understand mechanisms that influence sex differences in determinants of muscular strength will help inform intervention design for health and performance improvement. Thus, the purpose of this study was to determine sex differences in associations of muscular strength with adiposity measures in healthy, young adults.

\section{METHODS}

\section{Participants}

A cross-sectional study design was used to determine sex differences in the association between normalized strength (NS) using bench press $1 \mathrm{RM}$ and various measures of adiposity (WHtR, WC, BMI, and body fat percentage [BF\%]). NS was calculated by dividing the subject's $1 \mathrm{RM}$ by their body mass (Hurd et al., 2011). The study used a convenience sample of adults recruited from a university and the surrounding area. Participants were recruited through word of mouth and class announcements. Each subject completed two data collection sessions separated by at least 48 hours. On the day of the $1 \mathrm{RM}$ testing, subjects were asked to refrain from caffeine ingestion prior to the test, refrain from vigorous exercise 24 hours prior to the test, and to eat a light meal 2 hours before the testing session.

One hundred forty subjects aged 18-40 years, including 66 males (mean $\pm S D$ : age: $21.59 \pm 3.23$ years; body mass: $80.57 \pm 15.79 \mathrm{~kg}$; height: $178.77 \pm 6.45 \mathrm{~cm}$ ) and 74 females (age: $20.95 \pm 3.14$ years; body mass: $67.79 \pm 15.57 \mathrm{~kg}$; height: $164.76 \pm 6.59 \mathrm{~cm})$ from a southeast Michigan university and the surrounding area, participated in this study. In this sample, $83.3 \%$ of males (49.92 \pm 49.47 months, $\mathrm{N}=63)$ and $55.4 \%$ of females (32.50 \pm 72.82 months, $\mathrm{N}=70)$ reported previous weight training experience. Recruiting materials included flyers displayed around the university campus, class announcements, and word of mouth. Subjects were excluded from the study if they were currently taking blood pressure medications, had high blood pressure, a muscular, bone, or joint injury, a contraindication to exercise, were pregnant, or had an uncontrolled medical condition or known balance impairment. This study was approved through the Oakland University Institutional Review Board (approval \# 1328081-8), and informed consent was obtained from all subjects prior to study involvement.

\section{Procedure}

Subjects attended two separate data collection sessions. In the first session, subjects arrived at the university's strength lab where their age and sex were recorded. They also completed the Physical Activity Readiness Questionnaire Plus and a health history questionnaire to determine if it was safe for them to exercise (Bredin et al., 2013). Subjects reported their activity level by answering two questions in accordance with Kwon et al. (2018): “Do you lift weights?” and “How long have you been lifting weights?”. Additionally, anthropometrics were assessed, and a bench press familiarization session took place. Personnel trained by the principal investigator taught the bench press movement to subjects, as described by Rippetoe and Kilgore (2007).

During the second data collection session, which occurred at least 48 hours after the first session, subjects arrived at the strength lab or university's recreation facility. Free weight testing equipment within both facilities was similar and allowed for reliable testing conditions. During this session, subjects completed a 1RM test for the bench press exercise following the National Strength and Conditioning Association (2015) testing protocol. NS was calculated by dividing the subject's 1RM by their body mass, developing a relative strength value (Hurd et al., 2011).

Subjects were instructed to perform the bench press through a full range of motion so that the bar touched the chest in the down phase, and elbows were fully extended in the up phase. They could self-select open or closed grip, and the grip width was determined by ensuring that the forearms were vertical in the down phase of the lift (Rippetoe and Kilgore, 2007). There was a minimum of one spotter present for this session to ensure that the weight was lifted in a safe manner. Subjects achieved a moderate intensity of five repetitions which was then used to predict $1 \mathrm{RM}$.

The bench press $1 \mathrm{RM}$ test was administered by trained personnel with at least two spotters present to ensure that the exercises were conducted safely. Subjects were required to lift 10 repetitions at $50 \%$ of predicted $1 \mathrm{RM}, 5$ repetitions at $70 \%$ of predicted $1 \mathrm{RM}, 3$ repetitions at $80 \%$ of predicted $1 \mathrm{RM}$, and 1 repetition at $90 \%$ of predicted $1 \mathrm{RM}$, followed by up to five attempts to determine the subjects' actual 1RM (National Strength and Conditioning Association, 2015). Subjects were given three minutes of rest between 1RM attempts and after their last warm-up set.

Height was measured to the nearest $0.1 \mathrm{~cm}$ using a stadiometer, and body mass to the nearest $0.1 \mathrm{lb}$ using a beam balance scale, which was converted to $\mathrm{kg}$. BMI was calculated as weight in $\mathrm{kg}$ divided by height in meters squared. WC was measured to the nearest $0.1 \mathrm{~cm}$ using a Gulick tape measure (Gulick II; Country Technology, Inc., Gays Mills, WI) and following National Institute of Health (2000) 
protocol. Skinfold measurements were taken using a Lange skinfold caliper to estimate density. For men, the sites included the chest, abdominal, and thigh, while the sites for females included the tricep, suprailiac, and thigh following American College of Sports Medicine protocols (2018). BF\% was estimated from body density using the Jackson Pollock nomogram method (Jackson \& Pollock, 1978).

\section{Data Analysis}

Males and females were analyzed separately. Descriptive statistics included the subjects' mean age, WC, height, weight, BMI, WHtR, BF\%, bench press $1 \mathrm{RM}, \mathrm{NS}$, and weight training experience. Independent sample t-tests were computed to determine sex differences across measures using IBM SPSS Statistics for Windows, Version 26.0 (IBM Corp., Armonk, N.Y., USA). The relationship between NS and adiposity was explored using linear regression and examined how NS values were associated with BMI, WC, BF\%, and WHtR values. BMI, $\mathrm{WC}, \mathrm{BF} \%$, age, and weight training experience in months were controlled. Linear regression was performed using SAS, version 9.4. Statistical significance was determined at $p<0.05$.

\section{RESULTS}

When examining subject characteristics, significant sex differences were evident for height, body mass, and weight lifting experience, such that males had higher values for height [95\% confidence interval, $\mathrm{CI}=(11.83,16.20) ; p<0.001]$, body mass $[95 \% \mathrm{CI}=(7.54,18.03) ; p$ $<0.001$ ], and a higher percentage of individuals who had weight lifting experience [95\% CI $=(-0.43,-0.13), p<0.001]$. Subject characteristics for muscular strength and adiposity data are shown in Table 1, including significant sex differences in BF\%, bench press $1 \mathrm{RM}$, and NS.

Table 1. Adiposity and Strength Measurements of Subjects

\begin{tabular}{|c|c|c|c|c|c|}
\hline \multirow[t]{2}{*}{ Variables } & \multirow{2}{*}{$\begin{array}{l}\text { Males } \\
(n=66)\end{array}$} & \multirow{2}{*}{$\begin{array}{c}\text { Females } \\
(n=74)\end{array}$} & \multirow{2}{*}{$\begin{array}{c}\text { Sig } \\
\text { (2-Tailed) }\end{array}$} & \multicolumn{2}{|c|}{$95 \% \mathrm{Cl}$ of the Difference } \\
\hline & & & & Lower & Upper \\
\hline BMI $\left(\mathrm{kg} / \mathrm{m}^{2}\right)$ & $25.15 \pm 4.28$ & $24.89 \pm 5.21$ & 0.751 & -1.346 & 1.862 \\
\hline Body Fat (\%) & $13.91 \pm 5.93$ & $25.94 \pm 6.17$ & $0.001^{* *}$ & -14.053 & -9.997 \\
\hline$W C(\mathrm{~cm})$ & $86.86 \pm 11.50$ & $82.89 \pm 12.44$ & 0.053 & -0.050 & 7.990 \\
\hline WHtR & $0.49 \pm 0.06$ & $0.50 \pm 0.07$ & 0.131 & -0.041 & 0.005 \\
\hline Bench Press 1RM (kg) & $78.57 \pm 23.85$ & $32.25 \pm 11.64$ & $0.001^{* *}$ & 40.148 & 52.486 \\
\hline Normalized Strength & $0.98 \pm 0.27$ & $0.48 \pm 0.16$ & $0.001^{* *}$ & 0.426 & 0.571 \\
\hline
\end{tabular}

Note: Values are presented as mean \pm standard deviation.

CI, confidence interval; WC, waist circumference; BMI, body mass index; WHtR, waist-to-height ratio; 1RM, one-repetition maximum

***Indicates significant difference between groups with $\mathrm{p}$-value $<0.001$

Table 2 presents parameter estimates (PE) of the regression between NS and adiposity measures. A significant positive association between NS and BMI was found in both males and females when controlling for BF\%, WC, WHtR, age, and weight training experience. This relationship was stronger in males $(p=0.003, \mathrm{PE}=0.051)$ than in females $(p=0.010, \mathrm{PE}=0.021)$. Except for the potential outlier participant having a BMI close to $45 \mathrm{~kg} / \mathrm{m}^{2}$, the scatterplot in Figure 1A shows a perceptible increasing trend for each sex, in agreement with the above findings.

Table 2. Parameter Estimates of the Regression Between Normalized Strength and Adiposity Measures

\begin{tabular}{|c|c|c|c|c|c|c|}
\hline & & $\begin{array}{l}\text { Males } \\
(n=66)\end{array}$ & & & $\begin{array}{c}\text { Females } \\
(n=74)\end{array}$ & \\
\hline Measure of Adiposity & $\begin{array}{c}\text { Parameter } \\
\text { Estimate }\end{array}$ & $\begin{array}{c}\text { Standard } \\
\text { Error }\end{array}$ & $p$-value & $\begin{array}{c}\text { Parameter } \\
\text { Estimate }\end{array}$ & $\begin{array}{c}\text { Standard } \\
\text { Error }\end{array}$ & $p$-value \\
\hline $\mathrm{BMI}\left(\mathrm{kg} / \mathrm{m}^{2}\right)$ & 0.051 & 0.017 & $0.003^{*}$ & 0.021 & 0.008 & $0.010^{*}$ \\
\hline Body Fat (\%) & -0.035 & 0.007 & $0.001^{* *}$ & -0.008 & 0.003 & $0.015^{*}$ \\
\hline$W C(\mathrm{~cm})$ & -0.005 & 0.009 & 0.591 & -0.011 & 0.005 & $0.037^{*}$ \\
\hline WHtR & -0.289 & 1.805 & 0.873 & 0.531 & 0.763 & 0.488 \\
\hline
\end{tabular}

Note: BMI, body mass index; WC, waist circumference; WHtR, waist-to-height-ratio

*Indicates significant difference between groups with p-value $<0.05$

${ }^{* * *}$ Indicates significant difference between groups with p-value $<0.001$

A significant inverse association was found between NS and BF\% in both males $(p=<0.001, \mathrm{PE}=-0.035)$ and females $(p=0.015, \mathrm{PE}=$ -0.008) when controlling for BMI, WC, WHtR, age, and weight training experience. Figure 1B shows a decreasing trend for each sex, in agreement with these negative associations. 
Table 2 also shows the results for the association between NS and WC in both males and females when controlling for BMI, BF\%, WHtR, age, and weight training experience. No significant association between these variables was observed among males ( $p=0.591, \mathrm{PE}$ $=-0.005)$; however, females exhibited a significant, but relatively weak inverse association between NS and WC $(p=0.037, \mathrm{PE}=-0.011)$. The scatterplot in Figure 1C also indicates a weak linear relationship between NS and WC for each sex. No significant association was found between NS and WHtR for either sex.

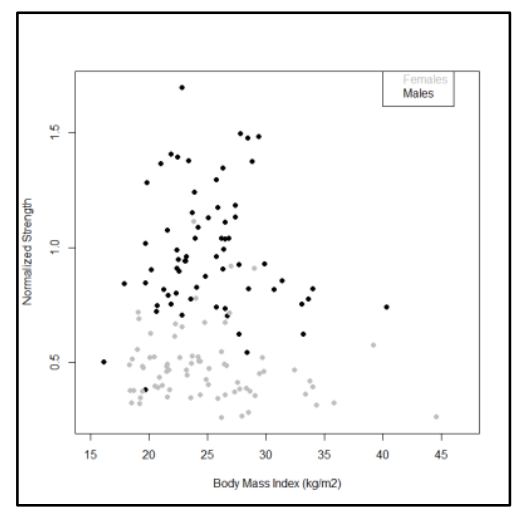

A

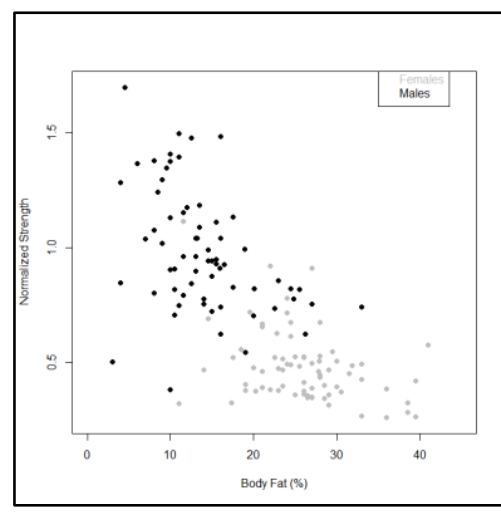

B

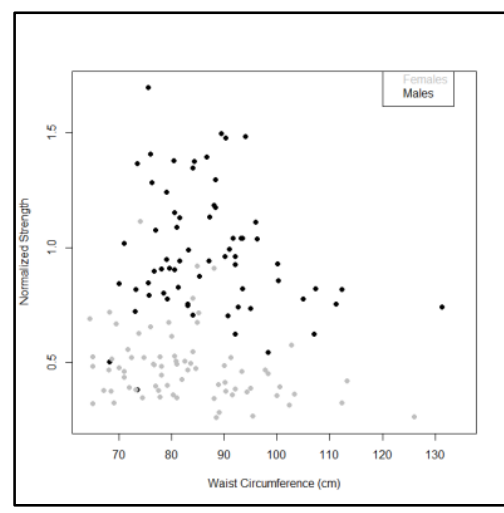

C

Figure 1. Associations between normalized strength and adiposity in males and females. In (A), Normalized Strength vs Body Mass Index $\left(\mathrm{kg} / \mathrm{m}^{2}\right)$ in females and males is depicted. In (B), Normalized Strength vs Body Fat (\%) in females and males is depicted. In (C), Normalized Strength vs Waist Circumference $(\mathrm{cm})$ in females and males is depicted.

\section{DISCUSSION}

The purpose of this study was to determine sex differences in the relationship between muscular strength and adiposity in healthy United States adults. To the knowledge of the authors, this was the first study to examine associations between muscular strength and adiposity in healthy young United States adults using gold standard strength testing and both regional and total body fat measurements. In both males and females, a high NS was associated with a high BMI and low BF\%. Conversely, a high NS was associated with a low WC only in females.

The first key finding was the positive association between NS and BMI in both sexes, which was congruent with previous literature that investigated this relationship (Pasdar et al., 2019). Other authors (Keevil et al., 2015) have acknowledged that BMI may not be the most appropriate obesity marker when investigating relationships between adiposity and muscular strength, as it does not distinguish between fat-free mass (a predictor of muscle strength) and fat mass. While this association was significant in both sexes, it was stronger in males than in females. Pasdar et al. (2019) similarly found this association to be stronger among males than females. Sex differences in body composition may explain this. Lafortuna et al. (2005) determined that as males gain mass, they increase proportional amounts of fatfree mass and fat mass, while females tend to exhibit increases in fat mass nearly three times more than fat-free mass when body mass is increased. Thus, it may be that males on average have greater amounts of fat-free mass to produce more force than females at any given BMI.

Next, consistent with other studies (Jackson et al., 2010), NS and BF\% were found to be inversely associated among males and females. While Jackson et al. (2010) suggested muscular strength acts as a protective mechanism against excessive body fat accumulation, it is also apparent that increased body fat is deleterious to skeletal muscle. Obese adipocytes induce atrophy by diminishing the expression of contractile proteins in myotubes and increasing secretion of cytokines and chemokines, most notably interleukin (IL)- 6 and IL-1 $\beta$ (Pellegrinelli et al., 2015). Therefore, adipose tissue may cause muscle wasting, and the results from the present study concurred by demonstrating increases in $\mathrm{BF} \%$ were associated with decreases in NS.

In addition to investigating relationships between whole-body measurements of adiposity (BMI and BF\%) with NS, this relationship was evaluated using regional measurements of adiposity, including WC and WHtR. Only the females had a significant inverse association between NS and WC. Previous reports on this association have been inconsistent. In a study by Pasdar et al. (2019), handgrip strength was positively associated with WC among Iranian males and females. Conversely, Keevil et al. (2015) determined that handgrip strength was inversely associated with WC among both sexes. Possible explanations for this disparity include differences in subject characteristics, such as age, nationality, and health-status. VAT, which can be estimated using WC measurements, has shown to be more toxic to skeletal muscle than subcutaneous adipose tissue (Pellegrinelli et al., 2015), explaining why NS values decreased as WC increased. Studies have shown while males tend to have larger amounts of VAT than females, VAT has a stronger association with cardiometabolic risk factors in females than males (Schorr et al., 2018). It is possible that the damaging effects of VAT on muscle cells are also heightened in females, thus explaining the inverse association found between NS and WC. 
Finally, no significant association was found between NS and WHtR for either sex. This relationship is not one that has been thoroughly studied. WHtR is often used as an effective measurement for predicting diseases, such as hypertension (Rezende et al., 2018), but does not appear to be significantly linked to NS.

Some limitations to this study should be considered. A small sample size limited the analyses the authors initially performed on the data collected. In accordance with Keevil et al. (2015) and Pasdar et al. (2019), a larger sample size would have permitted the subjects to be grouped into sex-specific BMI quartiles, where their strength and WC could be further analyzed. Next, BMI does not distinguish between fat mass and fat-free mass, and, therefore, limits the distinction between the association of fat mass and muscular strength. Additionally, the age range of the study was $18-40$ years, but the mean age of the male subjects was $21.59 \pm 3.23$ years, and the mean age of the female subjects was $20.95 \pm 3.14$ years. Thus, these findings may be more generalizable to younger adults closer to college age. Finally, only one measure on muscular strength was evaluated in this study. Incorporating measures of upper and lower body muscular strength would allow for a better indication of the relationship between adiposity and overall strength.

The strengths of this study include multiple measurements of total and abdominal adiposity. Total body fat evaluations were included, such as BMI and BF\%, as well as regional body fat evaluations, WC and WHtR. This study was unique, as few studies have assessed NS and adiposity associations using a variety of adiposity measurements. Additionally, the gold standard of strength testing, 1RM testing (Grgic et al., 2020), was used in this study to determine NS, whereas other studies have relied on handgrip strength, a surrogate measure of total strength (Hardy et al., 2013; Keevil et al., 2015; Pasdar et al., 2019). In the future, similar studies evaluating muscular strength and adiposity associations may benefit from using multiple strength tests, including upper and lower body tests.

\section{CONCLUSION}

Sex differences in the relationship between muscular strength and adiposity are apparent. Clinicians and trainers alike may use the findings of this study to inform program design for health enhancement and sport performance. Understanding sex differences in muscular strength and adiposity associations may aid clinicians in writing exercise prescriptions for decreased health risk in patients following tenants of precision medicine, while trainers may use these findings to increase performance of athletes. While larger BMI values are associated with increased NS, increases in BF\% are associated with lower NS values. Thus, these findings suggest that athletes who hope to increase their muscular strength may need to monitor their dietary intake closely as improvements in fat-free mass likely promote strength gains but increases in fat-mass may be deleterious to muscular strength. Given that abdominal adiposity was inversely associated with NS only in females, resistance training may have a more profound effect on VAT in females compared to males. However, longitudinal studies are necessary to determine sex differences in changes to VAT following regular resistance training.

\section{REFERENCES}

American College of Sports Medicine. (2018). Body composition. In G. Liguori (Ed.), ACSM's health-related physical fitness assessment manual (pp. 53-76). Wolters Kluwer.

Ashtary-Larky, D., Daneghian, S., Alipour, M., Rafiei, H., Ghanavati, M., Mohammadpour, R., Kooti, W., Ashtary-Larky, P., \& Afrisham, R. (2018). Waist circumference to height ratio: Better correlation with fat mass than other anthropometric indices during dietary weight loss in different rates. International Journal of Endocrinology and Metabolism, 16(4), e55023.

Bredella, M. A. (2017). Sex differences in body composition. Advances in Experimental Medicine and Biology, 1043, 9-27.

Bredin, S. S., Gledhill, N., Jamnik, V. K., \& Warburton, D. E. (2013). PAR-Q+ and ePARmed-X+: New risk stratification and physical activity clearance strategy for physicians and patients alike. Canadian Family Physician Medecin de Famille Canadien, 59(3), 273277.

Daousi, C., Casson, I. F., Gill, G. V., MacFarlane, I. A., Wilding, J. P., \& Pinkney, J. H. (2006). Prevalence of obesity in type 2 diabetes in secondary care: Association with cardiovascular risk factors. Postgraduate Medical Journal, 82(966), 280-284.

Galli, G., Pinchera, A., Piaggi, P., Fierabracci, P., Giannetti, M., Querci, G., Scartabelli, G., Manetti, L., Ceccarini, G., Martinelli, S., Di Salvo, C., Anselmino, M., Bogazzi, F., Landi, A., Vitti, P., Maffei, M., \& Santini, F. (2012). Serum insulin-like growth factor-1 concentrations are reduced in severely obese women and raise after weight loss induced by laparoscopic adjustable gastric banding. Obesity Surgery, 22(8), 1276-1280.

Grgic, J., Lazinica, B., Schoenfeld, B. J., \& Pedisic, Z. (2020). Test-retest reliability of the one-repetition maximum (1RM) strength assessment: A systematic review. Sports Medicine - Open, 6(1), 31.

Hales, C. M., Carroll, M. D., Fryar, C. D., \& Ogden, C. L. (2020). Prevalence of obesity and severe obesity among adults: United States, 2017-2018. National Center for Health Statistics Data Brief, 360, 1-8.

Hamilton, G. F., McDonald, C., \& Chenier, T. C. (1992). Measurement of grip strength: Validity and reliability of the sphygmomanometer and jamar grip dynamometer. The Journal of Orthopaedic and Sports Physical Therapy, 16(5), 215-219.

Hardy, R., Cooper, R., Aihie Sayer, A., Ben-Shlomo, Y., Cooper, C., Deary, I. J., Demakakos, P., Gallacher, J., Martin, R. M., McNeill, G., Starr, J. M., Steptoe, A., Syddall, H., Kuh, D., \& HALCyon study team. (2013). Body mass index, muscle strength and physical performance in older adults from eight cohort studies: The HALCyon programme. Public Library of Science One, 8(2), e56483.

Hurd, W. J., Morrey, B. F., \& Kaufman, K. R. (2011). The effects of anthropometric scaling parameters on normalized muscle strength in uninjured baseball pitchers. Journal of Sport Rehabilitation, 20(3), 311-320. 
Jackson, A. S., \& Pollock, M. L. (1978). Generalized equations for predicting body density of men. The British Journal of Nutrition, 40(3), 497-504.

Jackson, A. W., Lee, D. C., Sui, X., Morrow, J. R., Jr, Church, T. S., Maslow, A. L., \& Blair, S. N. (2010). Muscular strength is inversely related to prevalence and incidence of obesity in adult men. Obesity (Silver Spring), 18(10), 1988-1995.

Keevil, V. L., Luben, R., Dalzell, N., Hayat, S., Sayer, A. A., Wareham, N. J., \& Khaw, K. T. (2015). Cross-sectional associations between different measures of obesity and muscle strength in men and women in a British cohort study. The Journal of Nutrition, Health and Aging, 19(1), 3-11.

Kwon, Y. S., Robergs, R., So, H. \& Mermier, C. M. (2018) Free weight bench press muscular fitness normative data for adults aged 20-29 years. Medicine and Science in Sports and Exercise, 50(5S), 613-614.

Lafortuna, C. L., Maffiuletti, N. A., Agosti, F., \& Sartorio, A. (2005). Gender variations of body composition, muscle strength and power output in morbid obesity. International Journal of Obesity, 29(7), 833-841.

Madden, A. M., \& Smith, S. (2016). Body composition and morphological assessment of nutritional status in adults: A review of anthropometric variables. Journal of Human Nutrition and Dietetics: The Official Journal of the British Dietetic Association, 29(1), $7-25$.

Melissas, J., Volakakis, E., \& Hadjipavlou, A. (2003). Low-back pain in morbidly obese patients and the effect of weight loss following surgery. Obesity Surgery, 13(3), 389-393.

National Institute of Health. (2000). Treatment guidelines. In F. X. Pi-Sunyer, (Ed.), The practical guide: Identification, evaluation, and treatment of overweight and obesity in adults (pp. 7-24). National Heart, Lung, and Blood Institute.

National Strength and Conditioning Association. (2015) Administration, scoring, and interpretation of selected tests. In G. G. Haff \& N. T. Triplett, (Eds.) Essentials of strength training and conditioning (pp. 259-316). Human Kinetics.

Pasdar, Y., Darbandi, M., Mirtaher, E., Rezaeian, S., Najafi, F., \& Hamzeh, B. (2019). Associations between muscle strength with different measures of obesity and lipid profiles in men and women: Results from RaNCD cohort study. Clinical Nutrition Research, 8(2), 148158.

Pellegrinelli, V., Rouault, C., Rodriguez-Cuenca, S., Albert, V., Edom-Vovard, F., Vidal-Puig, A., Clément, K., Butler-Browne, G. S., \& Lacasa, D. (2015). Human adipocytes induce inflammation and atrophy in muscle cells during obesity. Diabetes, 64(9), 3121-3134.

Pimenta, F. B., Bertrand, E., Mograbi, D. C., Shinohara, H., \& Landeira-Fernandez, J. (2015). The relationship between obesity and quality of life in Brazilian adults. Frontiers in Psychology, 6, 966.

Rezende, A. C., Souza, L. G., Jardim, T. V., Perillo, N. B., Araújo, Y., de Souza, S. G., Sousa, A., Moreira, H. G., de Souza, W., do Rosário Gondim Peixoto, M., \& Jardim, P. (2018). Is waist-to-height ratio the best predictive indicator of hypertension incidence? A cohort study. BioMed Central Public Health, 18(1), 281.

Rippetoe, M., \& Kilgore, L. (2007) The bench press. In S. Bradford (Ed.) Starting strength: Basic barbell training (pp. 65-102). The Aasgaard Company.

Roberts, B. M., Nuckols, G., \& Krieger, J. W. (2020). Sex differences in resistance training: A systematic review and metaanalysis. Journal of Strength and Conditioning Research, 34(5), 1448-1460.

Schorr, M., Dichtel, L. E., Gerweck, A. V., Valera, R. D., Torriani, M., Miller, K. K., \& Bredella, M. A. (2018). Sex differences in body composition and association with cardiometabolic risk. Biology of Sex Differences, 9(1), 28.

Tomlinson, D. J., Erskine, R. M., Morse, C. I., Winwood, K., \& Onambélé-Pearson, G. (2016). The impact of obesity on skeletal muscle strength and structure through adolescence to old age. Biogerontology, 17(3), 467-483.

Tran, N., Blizzard, C. L., Luong, K. N., Truong, N., Tran, B. Q., Otahal, P., Nelson, M., Magnussen, C., Gall, S., Bui, T. V., Srikanth, V., Au, T. B., Ha, S. T., Phung, H. N., Tran, M. H., \& Callisaya, M. (2018). The importance of waist circumference and body mass index in cross-sectional relationships with risk of cardiovascular disease in Vietnam. Public Library of Science One, $13(5), \mathrm{e} 0198202$.

Witt, K. A., \& Bush, E. A. (2005). College athletes with an elevated body mass index often have a high upper arm muscle area, but not elevated triceps and subscapular skinfolds. Journal of the American Dietetic Association, 105(4), 599-602. 


\section{Author Information}

Ethan W. Clark, M.S.

(1) https://orcid.org/0000-0001-5790-7277

Department of Human Movement Science

School of Health Sciences

Oakland University, Rochester, MI, USA

@ ethanclark@oakland.edu

\section{Dorin Drignei, Ph.D.}

(1) https://orcid.org/0000-0002-7649-6618

Professor \& Department of Mathematics and Statistics

College of Arts and Sciences

Oakland University, Rochester, MI, USA

@ drignei@oakland.edu

Elise C. Brown, Ph.D., Corresponding Author

(D) https://orcid.org/0000-0002-2584-0052

Associate Professor, Wellness \& Health Promotion

Department of Public and Environmental Wellness

School of Health Sciences

Oakland University, Rochester, MI, USA

จ elisebrown@oakland.edu

Conflict of Interest: The authors declare that the research was conducted in the absence of any commercial or financial relationship that could be constructed as a potential conflict of interest.

Publisher's Note: All claims expressed in this article are solely those of the authors and do not necessarily represent those of their affiliated organizations, or those of the publisher, the editors and reviewers. Any product that may be evaluated in this article, or claim that may be made by its manufacturer, is not guaranteed or endorsed by the publisher. open access article distributed under the Creative Commons Attribution License which permits unrestricted use, distribution, and reproduction in any medium, provided the original work is properly cited. 


\title{
A Review: Effect of Rest Interval Duration on the Volume Completed During Resistance Training
}

\author{
Dennis J. Hernandez' \& Young Sub Kwon ${ }^{2}$ \\ ${ }^{1}$ D'Youville College, Buffalo, NY, USA \\ ${ }^{2}$ California Polytechnic University, Humboldt, Arcata, CA, USA \\ Received 20 September 2021 | Revised 15 December 2021 | Accepted 26 December 2021 \\ Open Access Available online at www.johsk.com
}

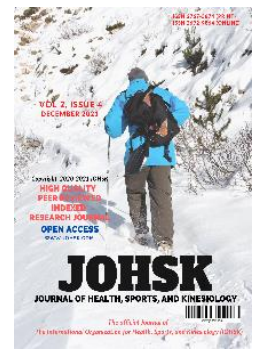

\begin{abstract}
The rest duration between sets is one of the most essential resistance training variables; however, research on the effects of rest intervals between sets has shown inconsistencies on whether short or long rest intervals significantly increase overall performance during resistance training. This literature review aimed to investigate how different rest intervals between sets affect the maintenance of repetitions, training volume, and overall strength gains from resistance exercises in both trained and non-trained individuals. Fifteen original investigations and three textbooks involving the effect of between set rest intervals during resistance training are summarized in this review. The results for the studies interested in repetition maintenance suggested longer rest intervals significantly increased the number of repetitions and helped repetitions stay more consistent throughout sets. Longer rest intervals were also determined to increase training volume but had no significant effect on overall strength gains. Biochemical substrates that provide the catalyst for energy creation can take up to eight minutes to fully resynthesize; therefore, more research is needed on longer rest intervals to see if there are further increases in resistance training performance.
\end{abstract}

Key words: Resistance Training, Training Load, Training Volume, Rest Periods

\section{INTRODUCTION}

Resistance training is commonly associated with sports and the enhancement of sport performance (Kraemer et al., 2002). Furthermore, resistance training can be used for injury prevention, rehabilitation, and in preparation for high-risk jobs such as law enforcement, firefighting, or military service (Jan, Lin, Liau \& Lin, 2008; Weiss, 1991; Willardson, 2006). With a large demographic heavily reliant on training benefits, the understanding of resistance training is imperative to prevent any incidental adverse effects such as a training plateau (Kraemer \& Fleck, 2007). The training plateau is caused by muscular adaptations (obtained from an invariable resistance training program) and impedes further improvements in muscular size, power, and strength. The progressive overload principle can be applied to inhibit or rectify a training plateau by introducing variation that enables further muscular growth and absolute strength (Kraemer \& Fleck, 2007). The progressive overload principle states that in order for a muscle to grow and strength to be increased, the training stimulus must be progressively increased to force the body to adapt to a tension it has never experienced (Kenny, Wilmore, \& Costil, 2015). This principle is essential to acquire further gains in muscular strength and power because it manipulates specific training variables to provide variation in an otherwise invariable training program (Kraemer \& Fleck, 2007). According to the American College of Sports Medicine (2009), training variables include exercise intensity, order of exercise, movement velocity, training frequency, training volume (sets $\times$ repetitions $\times$ load), and the duration of rest between sets. Prior research demonstrates the rest duration between sets as one of the most important variables affecting the repetitions, training volume, and muscular strength (Larson \& Potteiger, 1997; Miranda et al., 2009; Mirzaei, Arazi, \& Saberi, 2008; Willardson, 2006).

The duration of rest between sets, or rest interval (RI), is dependent on the resistance training goals, which include muscular endurance, hypertrophy, power, and strength. The National Strength and Conditioning Association (NSCA) recommends RIs of at least 30 seconds for muscular endurance and a range between 30 to 90 seconds for muscular hypertrophy. In addition, the NSCA recommends a RI between two and five minutes for muscular strength and power (Haff \& Triplett, 2016). Corroborating research also suggests, for 
optimal performance during resistance training, the use of short RIs (30s - 2-min) during muscular endurance and hypertrophy training (the ability to perform more training volume over a shorter amount of time) and long RIs (2-min - 5-min) during muscular power and strength training (strenuous activity requires greater recovery time to replenish energy systems) (Donnelly et al., 2009; Kraemer \& Fleck, 2007). Resistance training, with the goal of muscular strength, requires longer resting periods to resynthesize the depleted energy substrates, adenosine triphosphate (ATP) and phosphocreatine (PCr) (Willardson \& Burkett, 2008). The energy required for muscular strength training is provided from the hydrolysis (breakdown) of ATP; ATP reserves are limited and must be resynthesized for high-tension muscle contractions to continue (Haff \& Triplett, 2016; Weiss, 1991). ATP resynthesis is achieved through the hydrolysis of PCr and is known as the phosphagen energy system (Kenney et al., 2012; Robergs, Ghiasvand, \& Parker, 2004; Weiss, 1991). Muscular strength training primarily relies on the phosphagen energy system and depletes concentrations of PCr drastically to equate ATP concentrations (Baechle \& Earle, 2016; Robergs et al., 2004). After high-intensity exercise, ATP concentrations deplete between $50 \%$ to $60 \%$ and PCr concentrations are nearly eliminated. A comprehensive review of rest duration effects on muscular strength (Weiss, 1991) suggests, the depletion of ATP and PCr concentrations contribute to the fatigue experienced during physical activity. ATP concentrations completely resynthesize between three to five minutes, and $\mathrm{PCr}$ concentrations completely resynthesize within eight minutes following high-intensity exercise (Haff \& Triplett, 2016; Harris et al., 1976).

The length of the RI also affects the removal of proton accumulation caused by high levels of ATP hydrolysis and glycolysis during high-intensity exercise (Mirzaei, Arazi, \& Saberi, 2008; Robergs et al., 2004; Weiss, 1991). A high-intensity resistance exercise, such as a bench press, a squat, or a deadlift requires the body to rely mainly on fast-twitch muscle fibers for energy production. Fast-twitch muscle fibers rely heavily on anaerobic glycolysis and accumulate high levels of hydrogen ions during low-to-moderate intensity resistance performed to failure (Larson \& Potteiger, 1997). The inability to buffer or remove the accumulation of hydrogen ions has been shown to lower intracellular $\mathrm{pH}$, which results in metabolic acidosis and muscle fatigue (Robergs et al., 2004). At low pH values (muscle acidosis), muscle contraction shortening-velocity and the peak isometric force decreases significantly (Larson \& Potteiger, 1997). Other research also suggests that increased hydrogen ion concentration may be the main contributor to reduced force production, which is necessary for eccentric and concentric muscle contraction to continue during high-intensity exercise (Kramer \& Fleck, 2007; Larson \& Potteiger, 1997; Robergs et al., 2004).

The purpose of this investigation (1) was to summarize studies describing RIs effect on the maximum number and sustainability of repetitions, training volume and overall strength gains and (2) to propose that the application of longer RIs between intense exercise bouts may decrease muscle fatigue, and potentially improve the resistive exercise training responses.

\section{METHOD}

\section{Literature Search}

Relevant research was selected using Pubmed, Sports medicine research electronic database (SPORTDiscus), Medicine \& Science in Sports \& Exercise (MSSE) and Journal of Strength and Conditioning Research (JSCR), searching journal articles and reference lists, and World Wide Web searches using Google Research engine identifying pertinent databases and online journals. Of the thirty-five original studies, two abstracts, and three textbooks were initially focused on the effect of between-set RIs during resistance training, specifically using the following terms: fitness testing, rest interval, rest period, recovery, recover-time, training volume, and strength training. Fifteen original studies and three textbooks were fully reviewed. Table 1 to Table 4 summarize studies describing RIs effect on the maximum number and sustainability of repetitions, training volume and overall strength gains.

\section{RESULTS}

\section{Maximal Number and Sustainability of Repetitions}

The ability to sustain repetitions throughout sets increases the maximum number of repetitions performed during a bout of exercise (Willardson and Burkett, 2005). Greater sums of repetitions acutely increase training volume (repetitions $\times$ sets $\times$ load) and chronically increase muscular strength (Kraemer, 1997). Heavy training loads place a greater metabolic demand on the body and negatively affect repetition performance (Mirzaei et al., 2008; Willardson \& Burkett, 2008). Increasing the training load decreases energy substrates (ATP and PCR) and increases metabolic waste $\left(\mathrm{H}^{+}\right)$; thus, impeding necessary chemical reaction pathways that assist in the transformation of chemical energy into mechanical energy (Kraemer \& Fleck, 2007). Previous RI research was primarily concerned with the effect of heavier training loads on repetition performance; specifically, how age, training status, RI method, or exercise type are affected by between-set RI manipulation.

A study by Faigenbaum et al. (2008) was the first to research the effects of age and RI duration on lifting performance in a group of resistance trained males that consisted of: 12 boys, 13 teens, and 17 men. The study used a randomized crossover design to test the effects of one, two, and three-minute RIs on the number and sustainability of repetitions completed during three sets of bench pressing using a ten-repetition maximum (RM) load. The findings indicated that for all ages and all intervals, repetitions completed during each set significantly decreased as sets progressed; however, boys and teens had a less pronounced decrease in lifting performance (due to their ability to resist fatigue) compared to men (Table 1). Men's lifting performance declined significantly from an average of ten repetitions 
during the first set, to an average six repetitions during the third set. This study concluded that men would benefit the most from longer RIs and a minimum of three minutes of rest between sets may be needed to sustain repetitions.

Table 1. Repetition Sustainability Throughout Sets Using Various Rest Intervals

\begin{tabular}{|c|c|c|c|c|c|c|c|}
\hline Study & Load & $\begin{array}{l}\text { Exercise \& } \\
\text { Rest Intervals }\end{array}$ & Set 1 & Set 2 & Set 3 & Set 4 & Set 5 \\
\hline Faigenbaum et al. (2008) & $75 \%$ of $1 \mathrm{RM}$ & Bench Press & & & & & \\
\hline \multirow[t]{3}{*}{ Men's Values } & & $1 \mathrm{~min}$ & $10.0 \pm 0.0^{2,3}$ & $5.7 \pm 2.4^{3}$ & $2.7 \pm 1.5$ & & \\
\hline & & $2 \min$ & $10.0 \pm 0.0^{2,3}$ & $7.2 \pm 2.2$ & $4.2 \pm 2.2$ & & \\
\hline & & $3 \mathrm{~min}$ & $10.0 \pm 0.0^{3}$ & $7.9 \pm 2.7$ & $6.0 \pm 2.8$ & & \\
\hline \multirow{3}{*}{ Teens' Values } & & $1 \mathrm{~min}$ & $10.0 \pm 0.0^{3}$ & $9.5 \pm 1.4^{3}$ & $7.4 \pm 2.6$ & & \\
\hline & & $2 \min$ & $10.0 \pm 0.0^{3}$ & $9.3 \pm 1.4$ & $8.5 \pm 2.2$ & & \\
\hline & & $3 \mathrm{~min}$ & $10.0 \pm 0.0$ & $9.8 \pm 0.8$ & $9.1 \pm 1.8$ & & \\
\hline \multirow[t]{3}{*}{ Boys' Values } & & $1 \mathrm{~min}$ & $10.0 \pm 0.0^{3}$ & $9.2 \pm 1.4$ & $8.7 \pm 2.1$ & & \\
\hline & & $2 \min$ & $10.0 \pm 0.0$ & $10.0 \pm 0.0$ & $9.6 \pm 1.0$ & & \\
\hline & & $3 \min$ & $10.0 \pm 0.0$ & $10.0 \pm 0.0$ & $10 . \overline{0} \pm 0.0$ & & \\
\hline \multirow[t]{3}{*}{ Evangelista et al. (2011) } & $40 \%$ of $M V C$ & Bicep curl & & & & & \\
\hline & & $1 \min$ & $20.0 \pm 1.5^{2,3}$ & $9.0 \pm 0.7^{3}$ & $7.0 \pm 1.3$ & & \\
\hline & & $3 \mathrm{~min}$ & $24.0 \pm 1.7^{2,3}$ & $14.0 \pm 1.1^{3}$ & $10.0 \pm 0.7$ & & \\
\hline \multirow[t]{16}{*}{ Miranda et al. (2009) } & 8RM & Barbell bench press & & & & & \\
\hline & & $1 \mathrm{~min}$ & $8.4 \pm 0.2^{2,3}$ & $6.4 \pm 0.5^{3}$ & $4.2 \pm 0.6$ & & \\
\hline & & $3 \min$ & $8.3 \pm 0.2^{3}$ & $7.3 \pm 0.5$ & $5.9 \pm 1.0$ & & \\
\hline & & Inclined bench press & & & & & \\
\hline & & $1 \mathrm{~min}$ & $5.0 \pm 0.7^{3}$ & $3.9 \pm 0.7$ & $3.3 \pm 0.5$ & & \\
\hline & & $3 \min$ & $7.3 \pm 0.5^{3}$ & $6.6 \pm 0.5$ & $6.1 \pm 0.7$ & & \\
\hline & & Peck deck fly & & & & & \\
\hline & & $1 \mathrm{~min}$ & $4.6 \pm 0.8$ & $3.8 \pm 0.7$ & $3.3 \pm 0.8$ & & \\
\hline & & $3 \mathrm{~min}$ & $6.8 \pm 0.4$ & $5.9 \pm 0.7$ & $5.3 \pm 0.8$ & & \\
\hline & & Barbell lying triceps & & & & & \\
\hline & & extension & & & & & \\
\hline & & $1 \mathrm{~min}$ & $6.5 \pm 0.9^{2,3}$ & $4.9 \pm 0.9$ & $3.4 \pm 1.0$ & & \\
\hline & & $3 \mathrm{~min}$ & $7.3 \pm 0.7^{3}$ & $6.6 \pm 0.7$ & $6.0 \pm 0.7$ & & \\
\hline & & Triceps pushdown & & & & & \\
\hline & & $1 \mathrm{~min}$ & $4.6 \pm 0.6^{2,3}$ & $3.1 \pm 0.8^{3}$ & $2.0 \pm 0.7$ & & \\
\hline & & $3 \mathrm{~min}$ & $6.1 \pm 0.7^{3}$ & $5.3 \pm 0.7$ & $4.9 \pm 0.6$ & & \\
\hline \multirow[t]{17}{*}{ Rodrigues et al. (2012) } & $80 \%$ of $1 R M$ & Barbell bench press & & & & & \\
\hline & & $1 \mathrm{~min}$ & $5.8 \pm 2.3^{2,3}$ & $3.6 \pm 1.5$ & $2.8 \pm 1.2$ & & \\
\hline & & $3 \mathrm{~min}$ & $6.9 \pm 2.5^{2,3}$ & $4.7 \pm 1.7$ & $4.1 \pm 1.8$ & & \\
\hline & & $\begin{array}{l}\text { Machine lat pull } \\
\text { down }\end{array}$ & & & & & \\
\hline & & $1 \mathrm{~min}$ & $6.9 \pm 2.0^{2,3}$ & $3.6 \pm 1.1$ & $2.9 \pm 1.0$ & & \\
\hline & & $3 \mathrm{~min}$ & $7.4 \pm 1.9^{2,3}$ & $6.2 \pm 1.3^{3}$ & $4.4 \pm 1.5$ & & \\
\hline & & Seated machine & & & & & \\
\hline & & shoulder press & & & & & \\
\hline & & $1 \mathrm{~min}$ & $3.7 \pm 1.9^{2,3}$ & $2.1 \pm 1.6$ & $1.3 \pm 1.1$ & & \\
\hline & & $3 \mathrm{~min}$ & $4.5 \pm 2.7^{2,3}$ & $2.7 \pm 1.8$ & $2.3 \pm 1.7$ & & \\
\hline & & Machine triceps & & & & & \\
\hline & & extension & & & & & \\
\hline & & $1 \mathrm{~min}$ & $8.3 \pm 2.9^{2,3}$ & $5.3 \pm 1.5^{3}$ & $3.8 \pm 1.0$ & & \\
\hline & & $3 \mathrm{~min}$ & $9.9 \pm 2.7^{2,3}$ & $7.6 \pm 2.5$ & $6.4 \pm 2.6$ & & \\
\hline & & $\begin{array}{l}\text { Free weight standing } \\
\text { bicep curl }\end{array}$ & & & & & \\
\hline & & $1 \mathrm{~min}$ & $5.2 \pm 1.7^{2,3}$ & $2.5 \pm 1.0$ & $1.9 \pm 0.9$ & & \\
\hline & & $3 \mathrm{~min}$ & $5.6 \pm 1.6^{2,3}$ & $4.4 \pm 1.2^{3}$ & $3.1 \pm 1.1$ & & \\
\hline
\end{tabular}

Note. The superscript numbers designate significant difference in relation to the indicated set $(\mathbf{P}<0.05)$. $\mathbf{H R}=$ Heart rate. $\mathbf{M V C}=$ maximum velocity contraction. $\mathbf{R M}$ = Repetition maximum. 
Table 1. Repetition Sustainability Throughout Sets Using Various Rest Intervals (continued)

\begin{tabular}{|c|c|c|c|c|c|c|c|}
\hline Study & Load & $\begin{array}{l}\text { Exercise \& } \\
\text { Rest Intervals }\end{array}$ & Set 1 & Set 2 & Set 3 & Set 4 & Set 5 \\
\hline \multirow[t]{12}{*}{ Monteiro et al. (2013) } & $80 \%$ of $1 R M$ & Bench press & & & & & \\
\hline & & Ratio $1: 3$ & $12.9 \pm 3.6^{2,3,4,5}$ & $10.2 \pm 3.8^{3,4,5}$ & $6.3 \pm 3.1^{4,5}$ & $4.6 \pm 2.6$ & $3.8 \pm 2.2$ \\
\hline & & Ratio 1:5 & $12.3 \pm 4.0^{2,3,4,5}$ & $9.9 \pm 3.6^{3,4,5}$ & $7.6 \pm 3.6^{4,5}$ & $5.9 \pm 3.1$ & $4.6 \pm 2.6$ \\
\hline & & Ratio 1:7 & $12.4 \pm 3.7^{2,3,4,5}$ & $10 . \overline{9} \pm 3.7^{3,4,5}$ & $8.6 \pm 3.4^{4,5}$ & $6.7 \pm 3.0$ & $5.6 \pm 2.6$ \\
\hline & & $\begin{array}{l}\text { Progressive: } \\
1: 3-1: 5-1: 7-1: 9\end{array}$ & $12.5 \pm 4.0^{2,3,4,5}$ & $10.2 \pm 4.0^{3,4,5}$ & $7.9 \pm 3.5^{5}$ & $6.9 \pm 3.1$ & $6.2 \pm 2.6$ \\
\hline & & Fixed: 2 min & $13.5 \pm 4.1^{2,3,4,5}$ & $11.1 \pm 4.5^{3,4,5}$ & $8.7 \pm 4.2^{5}$ & $7.3 \pm 3.4$ & $6.0 \pm 2.7$ \\
\hline & & Triceps extension & & & & & \\
\hline & & Ratio $1: 3$ & $12.6 \pm 2.9^{2,3,4,5}$ & $9.9 \pm 1.8^{3,4,5}$ & $7.3 \pm 2.1^{4,5}$ & $5.7 \pm 1.8$ & $4.4 \pm 1.6$ \\
\hline & & Ratio 1:5 & $12.1 \pm 3.9^{2,3,4,5}$ & $10.6 \pm 3.3^{3,4,5}$ & $8.5 \pm 2.4^{5}$ & $7.2 \pm 2.3^{5}$ & $5.6 \pm 2.0$ \\
\hline & & Ratio 1:7 & $12.9 \pm 3.9^{3,4,5}$ & $11.8 \pm 3.2^{3,4,5}$ & $9.6 \pm 3.2^{4,5}$ & $8.1 \pm 2.8^{5}$ & $6.2 \pm 2.3$ \\
\hline & & $\begin{array}{l}\text { Progressive: } \\
\text { 1:3-1:5-1:7-1:9 }\end{array}$ & $13.2 \pm 3.1^{2,3,4,5}$ & $11.1 \pm 3.8^{3,4,5}$ & $9.1 \pm 3.3^{5}$ & $8.9 \pm 2.9^{5}$ & $8.1 \pm 2.7$ \\
\hline & & Fixed: 2 min & $12.4 \pm 3.7^{2,3,4,5}$ & $10.8 \pm 3.5^{3,4,5}$ & $9.1 \pm 3.4^{4,5}$ & $7.7 \pm 2.8$ & $6.7 \pm 2.1$ \\
\hline \multirow[t]{4}{*}{ Larson \& Potteiger (1997) } & $85 \%$ of $10 \mathrm{RM}$ & Squat & & & & & \\
\hline & & Post HR & $15.7 \pm 0.7^{2,3,4}$ & $10.6 \pm 0.5^{3,4}$ & $8.8 \pm 0.4^{4}$ & $7.9 \pm 0.6$ & \\
\hline & & $3 \mathrm{~min}$ & $15.5 \pm 0.6^{2,3,4}$ & $10.7 \pm 0.7^{3,4}$ & $8.1 \pm 0.4^{4}$ & $6.5 \pm 0.5$ & \\
\hline & & Ratio 1:3 & $15.6 \pm 0.7^{2,3,4}$ & $10.9 \pm 0.8^{3,4}$ & $8.3 \pm 0.6^{4}$ & $6.8 \pm 0.6$ & \\
\hline \multirow[t]{4}{*}{ Richmond \& Godard (2004) } & $75 \%$ of $1 R M$ & Bench press & & & & & \\
\hline & & $1 \mathrm{~min}$ & $11.9 \pm 2.5^{2}$ & $5.5 \pm 2.2$ & & & \\
\hline & & $3 \mathrm{~min}$ & $11.5 \pm 2.2^{2}$ & $8.3 \pm 2.6$ & & & \\
\hline & & $5 \mathrm{~min}$ & $11.5 \pm 2.3^{2}$ & $9.7 \pm 2.4$ & & & \\
\hline \multirow[t]{4}{*}{ Mirzaeli, Arazi, \& Saberi (2008) } & $90 \%$ of $1 R M$ & Bench press & & & & & \\
\hline & & $1.5 \mathrm{~min}$ & $4.4 \pm 0.7^{2,3,4}$ & $3.2 \pm 0.6^{3,4}$ & $2.2 \pm 0.6^{4}$ & $1.4 \pm 0.6$ & \\
\hline & & $2.5 \mathrm{~min}$ & $4.5 \pm 0.7^{2,3,4}$ & $3.8 \pm 0.9^{3,4}$ & $3.1 \pm 0.7^{4}$ & $2.5 \pm 0.8$ & \\
\hline & & $4 \mathrm{~min}$ & $4.5 \pm 0.7^{2,3,4}$ & $4.4 \pm 0.6^{3,4}$ & $3.8 \pm 0.9^{4}$ & $3.4 \pm 0.6$ & \\
\hline
\end{tabular}

Note. The superscript numbers designate significant difference in relation to the indicated set $(\mathrm{P}<0.05)$. $\mathbf{H R}=$ Heart rate. $\mathbf{M V C}=$ maximum velocity contraction. $\mathbf{R M}$ = Repetition maximum.

Research conducted by Evangelista, Pereira, Hackney, and Machado (2011) used 28 healthy untrained-men to test the effects of one and three-minute RI on the number of repetitions performed during three sets of a bicep curl. The bicep curl load was determined using $40 \%$ of the subject's maximal voluntary isometric contraction strength (MVC) measured by electromyography (EMG). The results indicated that neither RI was successful at sustaining repetitions throughout sets (Table 1). A similar study used twenty untrained-male subjects with one and three-minute RIs between sets but tested five upper-body exercises using $80 \%$ of subject's $1 \mathrm{RM}$ load. The results showed a significant reduction in repetitions for both RI groups, particularly when comparing the first and third set of all exercises (Table 1). In addition, a greater number of repetitions were performed in each set for all exercises using a three-minute RI (Table 2) (Rodrigues, Rodrigues, Sandy, Filho \& Dantas, 2012). A possible limitation in the previous studies was the use of untrained subjects; current research suggests that resistance-trained men may benefit the most from longer RIs because they require a longer recovery period to prevent a decrease in the number of repetitions performed (Richmond \& Godard, 2004).

Miranda et al. (2009) included 12 healthy men with at least two years of recreational resistance training experience. The subjects performed five different upper-body resistance training exercises using an 8RM load (80\% of 1RM) with either a one or three-minute RI between sets. The results showed significant differences in the repetitions completed during each exercise set for both RIs; however, the three-minute RI allowed for the greatest consistency in repetitions throughout all three sets (Table 1). Furthermore, significant differences were found in the number of repetitions completed during most exercise sets between both rest conditions (Table 2). The researchers concluded that instituting a longer RI (e.g., three-minutes) allowed for a greater amount and sustainability of repetitions compared to a shorter RI (e.g., one-minute).

Another possible limitation of all the aforementioned studies was the use of only fixed RIs between sets. Monteiro, Venturim, Perez, and Farinatti (2013) compared the effects of between set RIs using different methods of recovery. These methods included exerciserecovery ratios (1:3, 1:5, and 1:7), progressive intervals in each subsequent set (1:3-1:5-1:7-1:9), and a 2-minute fixed interval. The subjects included 16 men with at least one year of resistance training experience. All subjects performed five sets of the bench press and triceps extension using $80 \%$ of their 1RM load. The results showed that the shortest rest ratio $(1: 3)$ had the greatest decrease in the number of repetitions completed; although, all other strategies were also unable to sustain repetitions within multiple sets (Table 1). A similar study by Larson \& Potteiger (1997) also investigated the effects of different methods of recovery on the number of squat repetitions performed over four sets using $85 \%$ of subject's 10RM. RIs included a post-exercise heart rate of $60 \%$ age-predicted maximum heart rate, three-minute fixed interval, and a 1:3 rest ratio. No significant differences were found in the repetitions performed to exhaustion between 
all rest conditions (Table 2); however, no RI allowed for complete sustainability of repetitions throughout the consecutive sets (Table 1). Both studies concluded that the duration of the RI may be more influential than the strategy used to determine it.

Table 2. Maximum Repetitions Performed Each Set Using Various Rest Intervals

\begin{tabular}{|c|c|c|c|c|c|c|}
\hline Study & Load & $\begin{array}{l}\text { Exercises \& } \\
\text { Rest Intervals }\end{array}$ & Set 1 & Set 2 & Set 3 & Set 4 \\
\hline \multirow[t]{5}{*}{ Rodrigues et al. (2012) } & $80 \%$ of $1 R M$ & $\begin{array}{l}\text { Barbell bench press } \\
1 \mathrm{~min} \\
3 \mathrm{~min}\end{array}$ & $\begin{array}{l}5.8 \pm 2.3 \\
6.9 \pm 2.5 \\
\end{array}$ & $\begin{array}{l}3.6 \pm 1.5 \\
4.7 \pm 1.7^{*}\end{array}$ & $\begin{array}{l}2.8 \pm 1.2 \\
4.1 \pm 1.8^{*}\end{array}$ & \\
\hline & & $\begin{array}{l}\text { Machine lat pull down } \\
1 \mathrm{~min} \\
3 \mathrm{~min}\end{array}$ & $\begin{array}{l}6.9 \pm 2.0 \\
7.4 \pm 1.9\end{array}$ & $\begin{array}{l}3.6 \pm 1.1 \\
6.2 \pm 1.3^{*}\end{array}$ & $\begin{array}{l}2.9 \pm 1.0 \\
4.4 \pm 1.5^{*}\end{array}$ & \\
\hline & & $\begin{array}{l}\text { Seated machine shoulder } \\
\text { press } \\
1 \mathrm{~min} \\
3 \mathrm{~min}\end{array}$ & $\begin{array}{l}3.7 \pm 1.9 \\
4.5 \pm 2.7^{*}\end{array}$ & $\begin{array}{l}2.1 \pm 1.6 \\
2.7 \pm 1.8\end{array}$ & $\begin{array}{l}1.3 \pm 1.1 \\
2.3 \pm 1.7^{*}\end{array}$ & \\
\hline & & $\begin{array}{l}\text { Machine triceps extension } \\
1 \mathrm{~min} \\
3 \mathrm{~min}\end{array}$ & $\begin{array}{l}8.3 \pm 2.9 \\
9.9 \pm 2.7^{*}\end{array}$ & $\begin{array}{l}5.3 \pm 1.5 \\
7.6 \pm 2.5^{*}\end{array}$ & $\begin{array}{l}3.8 \pm 1.0 \\
6.4 \pm 2.6^{*}\end{array}$ & \\
\hline & & $\begin{array}{l}\text { Free weight standing bicep } \\
\text { curl with straight bar } \\
1 \mathrm{~min} \\
3 \mathrm{~min}\end{array}$ & $\begin{array}{l}5.2 \pm 1.7 \\
5.6 \pm 1.6 \\
\end{array}$ & $\begin{array}{l}2.5 \pm 1.0 \\
4.4 \pm 1.2^{*}\end{array}$ & $\begin{array}{l}1.9 \pm 0.9 \\
3.1 \pm 1.1^{*}\end{array}$ & \\
\hline \multirow[t]{5}{*}{ Miranda et al. (2009) } & 8RM & $\begin{array}{l}\text { Barbell bench press } \\
1 \mathrm{~min} \\
3 \mathrm{~min}\end{array}$ & $\begin{array}{l}8.4 \pm 0.2 \\
8.3 \pm 0.2\end{array}$ & $\begin{array}{l}6.4 \pm 0.5 \\
7.3 \pm 0.5\end{array}$ & $\begin{array}{l}4.2 \pm 0.5 \\
5.9 \pm 1.0^{*}\end{array}$ & \\
\hline & & $\begin{array}{l}\text { Inclined bench press } \\
1 \mathrm{~min} \\
3 \mathrm{~min}\end{array}$ & $\begin{array}{l}5.0 \pm 0.7 \\
7.3 \pm 0.5^{*}\end{array}$ & $\begin{array}{l}3.9 \pm 0.7 \\
6.6 \pm 0.5^{*}\end{array}$ & $\begin{array}{l}3.3 \pm 0.5 \\
6.1 \pm 0.7^{*}\end{array}$ & \\
\hline & & $\begin{array}{l}\text { Peck deck fly } \\
1 \mathrm{~min} \\
3 \mathrm{~min}\end{array}$ & $\begin{array}{l}4.6 \pm 0.8 \\
6.8 \pm 0.4^{*}\end{array}$ & $\begin{array}{l}3.8 \pm 0.7 \\
5.9 \pm 0.7^{*}\end{array}$ & $\begin{array}{l}3.3 \pm 0.8 \\
5.3 \pm 0.8^{*}\end{array}$ & \\
\hline & & $\begin{array}{l}\text { Barbell lying triceps extension } \\
1 \mathrm{~min} \\
3 \mathrm{~min}\end{array}$ & $\begin{array}{l}6.5 \pm 0.91 \\
7.3 \pm 0.65\end{array}$ & $\begin{array}{l}4.9 \pm 0.9 \\
6.6 \pm 0.7\end{array}$ & $\begin{array}{l}3.4 \pm 1.0 \\
6.0 \pm 0.7^{*}\end{array}$ & \\
\hline & & $\begin{array}{l}\text { Triceps pushdown } \\
1 \mathrm{~min} \\
3 \mathrm{~min} \\
\end{array}$ & $\begin{array}{l}4.8 \pm 0.6 \\
6.1 \pm 0.7 \\
\end{array}$ & $\begin{array}{l}3.1 \pm 0.8 \\
5.3 \pm 0.7^{*}\end{array}$ & $\begin{array}{l}2.0 \pm 0.7 \\
4.9 \pm 0.6^{*}\end{array}$ & \\
\hline Larson \& Potteiger (1997) & $85 \%$ of $10 R M$ & $\begin{array}{l}\text { Squat } \\
\text { Post HR } \\
3 \text { min } \\
\text { Ratio 1:3 }\end{array}$ & $\begin{array}{l}15.7 \pm 0.7 \\
15.5 \pm 0.6 \\
15.6 \pm 0.7\end{array}$ & $\begin{array}{l}10.6 \pm 0.5 \\
10.7 \pm 0.7 \\
10.9 \pm 0.8\end{array}$ & $\begin{array}{l}8.8 \pm 0.4 \\
8.1 \pm 0.4 \\
8.3 \pm 0.6\end{array}$ & $\begin{array}{l}7.9 \pm 0.6 \\
6.5 \pm 0.5 \\
6.8 \pm 0.6\end{array}$ \\
\hline \multirow[t]{2}{*}{ Dias et al. (2014) } & 10RM & $\begin{array}{l}\text { Peck deck fly } \\
1 \mathrm{~min} \\
2 \mathrm{~min}\end{array}$ & $\begin{array}{l}10.0 \pm 0.0 \\
10.0 \pm 0.0\end{array}$ & $\begin{array}{l}7.9 \pm 2.1 \\
8.4 \pm 2.1\end{array}$ & $\begin{array}{l}4.9 \pm 1.9 \\
6.4 \pm 1.8\end{array}$ & \\
\hline & & $\begin{array}{l}\text { Bench press } \\
1 \mathrm{~min} \\
2 \mathrm{~min} \\
\end{array}$ & $\begin{array}{l}10.5 \pm 1.1 \\
11.2 \pm 1.5 \\
\end{array}$ & $\begin{array}{l}5.7 \pm 2.8 \\
7.9 \pm 2.4^{*} \\
\end{array}$ & $\begin{array}{l}3.3 \pm 2.2 \\
5.2 \pm 2.9^{*} \\
\end{array}$ & \\
\hline Richmond \& Godard (2004) & $75 \%$ of $1 R M$ & $\begin{array}{l}\text { Bench press } \\
1 \mathrm{~min} \\
3 \mathrm{~min} \\
5 \mathrm{~min}\end{array}$ & $\begin{array}{l}11.9 \pm 2.5 \\
11.5 \pm 2.2 \\
11.5 \pm 2.3\end{array}$ & $\begin{array}{l}5.5 \pm 2.2 \\
8.3 \pm 2.6^{*} \\
9.7 \pm 2.4^{*}\end{array}$ & & \\
\hline
\end{tabular}

Note ${ }^{*}=$ set significantly different between all rest intervals.

Dias et al. (2014) used a different approach to test the effects of RI duration during upper-body resistance training. The purpose of the study was to compare the differences in the number of repetitions completed during a uni-joint (peck deck fly) or multi-joint (bench press) exercise. This randomized study included 18 healthy resistance-trained men ( $23.4 \pm 3.5 \mathrm{yrs})$ who performed three sets of a $10 \mathrm{RM}$ load using either a one-minute or two-minute RI between sets for both exercises. The results showed a greater number of repetitions performed during the third set of the peck deck fly exercise when using a two-minute RI compared to a one-minute RI (Table 2). Similarly, a two- 
minute RI allowed for a significantly greater number of repetitions performed during the second and third set of the bench press exercise (Table 2). The study concluded multi-joint exercises, such as the bench press, may benefit the most from longer RIs in regard to the maximum number of repetitions performed during each set.

Corroborating research conducted by Richmond \& Godard (2004), investigated the effects of three different between-set RIs (1-min vs 3-min vs 5-min) on multi-joint resistance training performance. Subjects were comprised of 28 healthy resistance-trained males who performed two sets of the bench press exercise using $75 \%$ of their $1 \mathrm{RM}$ load. The results indicated that repetitions significantly decreased between the first and second set for all resting periods (Table 1). In addition, the repetitions performed during the second set for all rest conditions were significantly different between groups (Table 2). The study concluded that the prescribed recovery between sets did not prevent a decrease in the number of repetitions; however, the three and five-minute RIs allowed for a greater sustainability of repetitions as sets progressed. The longer RIs were determined to be the most beneficial because they allowed targeted muscle groups a longer recovery period to resynthesize energy substrates (Harris et al., 1979; Richmond \& Godard, 2004).

Finally, research performed by Mirzaei et al. (2008) investigated the effects of different RIs on the sustainability of repetitions when using either a heavy or light resistance load. The study included 17 resistance-trained men who performed four consecutive sets of a bench press using two different loads (60\% vs $90 \%$ of $1 \mathrm{RM}$ ) and three different RIs (1.5-min vs 2.5-min vs 4-min). The results of the study demonstrated that the longest RI (4-min) resulted in a greater sustainability of repetitions when compared to the shorter RIs (1.5-min vs 2.5-min) for both training loads (Table 1). Furthermore, sustainability of repetitions over four consecutive sets were significantly greater for the heavier training load (90\%). This study concluded that longer RIs highly influence the number of repetitions performed, particularly during upper-body resistance training with heavy loads.

\section{Training Volume}

As previously mentioned, a longer RI has the greatest effect on the number and sustainability of repetitions over consecutive sets during a resistance training session. The sustainability of repetitions can allow for greater training volume (repetitions $\times$ sets $\times$ load), which prompts gains in muscular strength (Willardson \& Burkett, 2008). Prior investigations have suggested the use of a longer duration of rest between sets, particularly when the training goal requires a heavy training load and a large amount of training volume (Ratamess et al., 2007). A previously mentioned study by Dias et al. (2014) compared differences between the training volume completed during uni-joint (peck deck fly) and multi-joint (bench press) exercises using either a one or two-minute RI between sets of a 10RM load. The study reported longer RIs (2-min) allowed for a greater training volume completed for both the uni-joint and multi-joint exercises (Table 3). To contribute to the findings of Dias et al. (2014), a study performed by Willardson and Burkett (2005) investigated the effects of one, two, and fiveminute RIs on squat and bench press training volume. A group of 15 resistance-trained men performed four sets of a squat and bench press exercise using an $8 \mathrm{RM}$ load (85\% of $1 \mathrm{RM})$ and three different between-set RIs. The results showed that total training volume completed was significantly different between all RIs for both exercises, but the five-minute RI allowed for the greatest amount of volume to be completed (Table 3). Similar results were reported during a four-week study consisting of a 10RM bench press exercise using one, three, and five-minute RIs (Table 3) (Richmond \& Godard, 2004).

To determine an optimal resting duration, Ratamess et al. (2007) tested multiple RI lengths to examine and quantify the total training volume completed during the bench press exercise. This eight-week study included eight healthy resistance trained men. Subjects performed either a 10RM or 5RM load during the bench press exercise using five different RIs between sets (i.e., 30s, 1, 2, 3, 5-min). Training volume significantly decreased over four consecutive sets between all rest conditions except with the use of a five-minute RI (Table 3). A similar study investigated the total training volume completed during multiple upper-body resistance exercises using either a one or three-minute RI. The results also highlighted the linear relationship between RI duration and total training volume completed during an upper-body resistance training session (Table 3) (Miranda et al., 2009). The results of aforementioned studies determined longer RIs were the most beneficial to significantly increase training volume; however, a study conducted by Monteiro et al. (2013) found no significant differences in training volume after subjects rested between two and five-minutes between sets while performing both the triceps extension and bench press using $80 \%$ of subject's $1 \mathrm{RM}$ load (Table 3). A possible causation for conflicting results may be the duration of the experimental procedure. Reports of acute responses due to RI manipulations have been inconsistent due to varied methodologies; therefore, chronic response research might infer more conclusive results regarding the effects of RI duration on training volume.

De Souza Jr. et al. (2010) was the first study to compare the chronic effects of decreasing (2-min to 30s) and constant (2-min) RIs during an eight-week resistance training program. Twenty resistance trained males were equally divided into either a decreasing or constant RI group and performed two different training programs. During the first two weeks, three sets of 10-12RM load were performed for various upper-body and midsection exercises using two-minute RIs between sets. After the first two weeks, the constant RI group continued the same protocol while the descending RI group implemented decreasing RIs between sets (2min- 30secs). The results highlighted that the total training volume completed for both the squat and leg press were significantly greater in the constant RI group when compared to the descending RI group after the eight-week experimental treatment (Table 3).

Lastly, another study by Willardson and Burkett (2008) reported consistent results with De Souza Jr. et al. (2010). The researchers used four mesocycles (three-week periods) to compare training volume for 15 resistance trained men using both a heavy (70 - 90\% $1 \mathrm{RM})$ and light $(60 \% 1 \mathrm{RM})$ resistance load for the squat exercise. Subjects were prescribed two and four-minute RIs and asked to perform between five and eight sets for all exercises until exhaustion. The data indicated that a significantly greater training volume was completed during the heavy workouts (70-90\% of $1 \mathrm{RM}$ ) when a four-minute RI was used (Table 3). An investigation by De Salles et al. (2010) also suggested training volume was significantly greater when a longer RI was prescribed for both upper and lower-body exercises (Table 3). The major finding of all studies was training volume increased proportionally as the RI duration increased during resistance exercises using heavy loads. 
Table 3. Total Training Volume Completed Using Various Rest Intervals

\begin{tabular}{|c|c|c|c|c|c|}
\hline Study & Subjects & Duration & Intervention & Intervals & Results \\
\hline Dias et al. (2014) & $\begin{array}{l}18 \text { trained men } \\
(23.4 \pm 3.5 \text { yrs. })\end{array}$ & 2 weeks & $\begin{array}{l}2 \text { experimental sessions: } \\
\text { - } \quad \text { Bench press } \\
\text { - } \quad \text { Peck deck fly } \\
\text { - } \quad 3 \text { sets 10RM }\end{array}$ & $\begin{array}{l}1 \mathrm{~min} \\
2 \mathrm{~min}\end{array}$ & $\begin{array}{l}\text { Total training volume significantly } \\
\text { greater for both exercises using } 2 \\
\text { min rest interval }\end{array}$ \\
\hline $\begin{array}{l}\text { Willardson \& Burkett } \\
\text { (2005) }\end{array}$ & $\begin{array}{l}15 \text { trained men } \\
(20.7 \pm 2.6 \text { yrs. })\end{array}$ & $\sim 4$ weeks & \begin{tabular}{ll}
\multicolumn{2}{l}{3 experimental sessions } \\
- & Bench press \\
- & Squat \\
- & 4 sets 8RM
\end{tabular} & $\begin{array}{l}1 \mathrm{~min} \\
2 \min \\
5 \min \end{array}$ & $\begin{array}{l}\text { Total training volume significantly } \\
\text { different between all rest intervals } \\
\text { for both exercises }\end{array}$ \\
\hline $\begin{array}{l}\text { Richmond \& Godard } \\
\text { (2004) }\end{array}$ & $\begin{array}{l}28 \text { trained men } \\
(21.5 \pm 3.2 \mathrm{yrs} .)\end{array}$ & $\sim 4$ weeks & $\begin{array}{l}\text { 3 experimental sessions: } \\
\text { - } \quad \text { Bench press } \\
\text { - } \quad 75 \% \text { of } 1 \mathrm{RM}\end{array}$ & $\begin{array}{l}1 \mathrm{~min} \\
3 \mathrm{~min} \\
5 \mathrm{~min}\end{array}$ & $\begin{array}{l}\text { Training volume performed in } 2^{\text {nd }} \\
\text { set significantly different between } \\
\text { all rest intervals }\end{array}$ \\
\hline Ratamess et al. (2007) & $\begin{array}{l}8 \text { trained men } \\
(21.4 \pm 2.4 \text { yrs. })\end{array}$ & $\sim 8$ weeks & $\begin{array}{l}5 \text { experimental sessions per week } \\
\text { - } \quad \text { Bench press } \\
\text { Alternating: } \\
\text { - } \quad 75 \% \text { of } 1 \mathrm{RM} \\
\text { - } \quad 85 \% \text { of } 1 \mathrm{RM}\end{array}$ & $\begin{array}{l}30 \mathrm{sec} \\
1 \mathrm{~min} \\
2 \mathrm{~min} \\
3 \mathrm{~min} \\
5 \mathrm{~min}\end{array}$ & $\begin{array}{l}\text { Training volume significantly } \\
\text { decreased as sets progressed for all } \\
\text { rest intervals except } 5 \text { min interval }\end{array}$ \\
\hline Miranda et al. (2009) & $\begin{array}{l}12 \text { trained men } \\
(23.6 \pm 2.5 \text { yrs. })\end{array}$ & $\sim 4$ weeks & $\begin{array}{l}2 \text { experimental sessions: } \\
\text { - } \quad \text { Barbell bench press } \\
\text { - } \quad 3 \text { sets 8RM }\end{array}$ & $\begin{array}{l}1 \mathrm{~min} \\
3 \mathrm{~min}\end{array}$ & $\begin{array}{l}\text { Significantly greater training } \\
\text { volume completed for exercises } \\
\text { using } 3 \text { min rest interval }\end{array}$ \\
\hline Monteiro et al. (2013) & $\begin{array}{l}16 \text { trained men } \\
(25.0 \pm 2.5 \text { yrs. })\end{array}$ & $\sim 4$ weeks & \begin{tabular}{ll}
\multicolumn{2}{l}{5 experimental sessions: } \\
- & Bench press \\
- & Triceps extension \\
- & 5 sets $80 \% 1 \mathrm{RM}$
\end{tabular} & $\begin{array}{l}\text { Ratio 1:3 } \\
\text { Ratio 1:5 } \\
\text { Ratio 1:7 } \\
\text { IP } 2 \text { min }\end{array}$ & $\begin{array}{l}\text { No significant differences in } \\
\text { training volume between rest } \\
\text { intervals }\end{array}$ \\
\hline $\begin{array}{l}\text { De Souza et al. } \\
(2010)\end{array}$ & $\begin{array}{l}20 \text { trained men } \\
\text { CI: } 2 \text { min } \\
(20.5 \pm 1.0 \text { yrs. }) \\
\text { DI: } 2 \text { min }-30 \mathrm{~s} \\
(22.0 \pm 4.8 \text { yrs. })\end{array}$ & 8 weeks & $\begin{array}{l}\text { 6 experimental sessions per week } \\
\text { alternating between: } \\
\text { - } \quad \text { Program A } \\
\text { - } \\
\text { - } \\
\text { - } \\
\text { 10-12RM } \\
8-10 \mathrm{RM}\end{array}$ & $\begin{array}{l}\text { CI: } 2 \text { min } \\
\text { DI: } 2 \text { min } \\
-30 \mathrm{sec}\end{array}$ & $\begin{array}{l}\text { Total training volume significantly } \\
\text { greater for CI group compared to } \\
\text { DI group for both bench press and } \\
\text { squat exercises }\end{array}$ \\
\hline $\begin{array}{l}\text { Willardson \& Burkett } \\
\text { (2008) }\end{array}$ & $\begin{array}{l}15 \text { trained men } \\
2 \text { min } \\
(20.7 \pm 1.4 \text { yrs. }) \\
4 \text { min } \\
(22.6 \pm 4.6 \text { yrs. })\end{array}$ & $\sim 16$ weeks & $\begin{array}{ll}3 \text { mesocycles (4 weeks): } \\
\text { - } \quad \text { Squat } \\
\text { Alternating: } \\
\begin{array}{l}\text { Heavy workouts } \\
\text { (70\% - } 90 \% \text { of } 1 \mathrm{RM})\end{array} \\
\begin{array}{l}\text { Light workouts } \\
(60 \% \text { of } 1 \mathrm{RM})\end{array}\end{array}$ & $\begin{array}{l}2 \mathrm{~min} \\
4 \mathrm{~min}\end{array}$ & $\begin{array}{l}\text { Total training volume completed } \\
\text { significantly different between 2- } \\
\text { and 4-min rest interval }\end{array}$ \\
\hline De Salles et al. (2010) & $\begin{array}{l}\text { 36 trained men } \\
\text { 1-min: } \\
(22.4 \pm 1.3 \text { yrs. }) \\
\text { 3-min: } \\
(22.3 \pm 1.0 \text { yrs. }) \\
\text { 5-min: } \\
(22.3 \pm 1.0 \text { yrs. })\end{array}$ & 16 weeks & 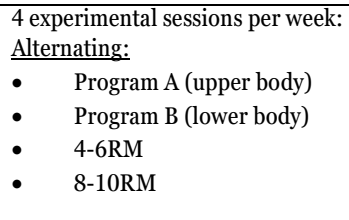 & $\begin{array}{l}1 \mathrm{~min} \\
3 \mathrm{~min} \\
5 \mathrm{~min}\end{array}$ & $\begin{array}{l}\text { Total training volume significantly } \\
\text { greater for groups using } 3 \text { min and } \\
5 \text { min rest intervals compared to } 1 \\
\text { min rest interval (bench press plus } \\
\text { leg press) }\end{array}$ \\
\hline
\end{tabular}

Note $. \mathrm{RM}=$ Repetition Maximum. $\mathrm{IP}=$ Progressive Interval. $\mathrm{CI}=$ Constant Rest Interval. $\mathrm{DI}=$ Decreasing Rest Interval.

\section{Strength Gains}

Prior research suggests a greater number repetitions and a greater amount of training volume lead to increases in muscular strength; however, contradictory research indicates that the duration of the RI may not affect overall strength (Willardson \& Burkett, 2008). Such results were found in the study conducted by Gentil et al (2010). The researchers performed a longitudinal study to investigate the chronic effects of two different between-set rest ratios (1:3 vs 1:6) on muscle strength (Final 1RM load) in 32 non-resistance trained young men. The subjects were prescribed a 12-week whole-body resistance training program comprised of two upper body exercises, two lower body exercises, and one midsection exercise. All exercises included either rest ratio (1:3 vs 1:6) between sets with an 8-12RM load. The results 
showed that the 1RM load significantly increased from pre-treatment to post-treatment following the 12-week resistance training intervention regardless of the rest ratio employed (Table 4).

Table 4. Strength Increases Using Various Rest Intervals

\begin{tabular}{|c|c|c|c|c|c|}
\hline Study & Subjects & Duration & Intervention & Intervals & Results \\
\hline Gentil et al. (2010) & $\begin{array}{l}32 \text { untrained men } \\
\text { Long rest }(1: 6) \\
(22.4 \pm 2.6 \text { yrs.) } \\
\text { Short rest }(1: 3) \\
(21.4 \pm 3.2 \text { yrs.) }\end{array}$ & $\sim 16$ weeks & $\begin{array}{l}3 \text { programs (12weeks) } \\
-\quad 2 \text { upper body exercises } \\
\text { - } \quad 2 \text { lower body exercises } \\
\text { - } \quad 1 \text { midsection exercise } \\
\quad 2 \text { sets } 8-12 \mathrm{RM}\end{array}$ & $\begin{array}{l}1: 3 \\
1: 6\end{array}$ & $\begin{array}{l}\text { Similar and significant increases in } \\
\text { upper and lower body strength no } \\
\text { matter what rest ratio was used }\end{array}$ \\
\hline $\begin{array}{l}\text { Buresh, Berg, \& French } \\
\text { (2009) }\end{array}$ & $\begin{array}{l}12 \text { untrained men } \\
(24.8+5.9 \text { yrs. })\end{array}$ & 10 weeks & $\begin{array}{l}\text { 4 experimental sessions per week: } \\
-\quad \text { Bench Press } \\
\text { - Squat } \\
\text { Alternating: } \\
\text { - Session } 1 \text { (lower body) } \\
\text { Session } 2 \text { (upper body) }\end{array}$ & $\begin{array}{l}1 \mathrm{~min} \\
2.5 \mathrm{~min}\end{array}$ & $\begin{array}{l}\text { There was no difference between } \\
\text { groups in relative strength increase } \\
\text { in either the squat or bench press. }\end{array}$ \\
\hline De Salles et al. (2010) & $\begin{array}{l}36 \text { trained men } \\
1 \text {-min: } \\
(22.4 \pm 1.3 \text { yrs. }) \\
3 \text {-min: } \\
(22.3 \pm 1.0 \text { yrs. }) \\
5 \text {-min: } \\
(22.3 \pm 1.0 \text { yrs. })\end{array}$ & 16 weeks & $\begin{array}{l}\text { 4 experimental sessions } \\
\text { Alternating: } \\
\text { - } \quad \text { Program A (upper body) } \\
\text { - } \quad \text { Program B (lower body) } \\
\text { Alternating: } \\
\text { - } \quad \text { 4-6RM } \\
\text { - } \quad \text { 8-10RM }\end{array}$ & $\begin{array}{l}1 \mathrm{~min} \\
3 \mathrm{~min} \\
5 \mathrm{~min}\end{array}$ & $\begin{array}{l}\text { Bench press group that used } 5 \text { min } \\
\text { rest intervals were significantly } \\
\text { stronger when compared to the } 1 \\
\text { min group. }\end{array}$ \\
\hline $\begin{array}{l}\text { Willardson \& Burkett } \\
\text { (2008) }\end{array}$ & $\begin{array}{l}15 \text { trained men } \\
2 \text { min } \\
(20.7+1.4 \text { yrs. }) \\
4 \text { min } \\
(22.6+4.6 \text { yrs. })\end{array}$ & $\sim 16$ weeks & $\begin{array}{ll}3 \text { mesocycles (4 weeks): } \\
\text { - } & \text { Squat } \\
\text { Alternating: } \\
\text { - } & \text { Heavy workouts } \\
& \quad(70 \%-90 \% \text { of } 1 \mathrm{RM}) \\
\text { - } & \text { Light workouts } \\
& (60 \% \text { of } 1 \mathrm{RM})\end{array}$ & $\begin{array}{l}2 \min \\
4 \text { min }\end{array}$ & $\begin{array}{l}\text { No significant difference in squat } \\
\text { strength gains between groups that } \\
\text { used 2- and 4-min rest intervals }\end{array}$ \\
\hline
\end{tabular}

Note. $\mathrm{RM}=$ Repetition Maximum

A similar study by Buresh, Berg, and French (2009) compared the effects of two different RIs (1 vs 2.5-min) on strength gains obtained from a whole-body resistance training program. Twelve untrained men were randomly divided into two separate groups (short rest vs. long rest). Subjects participated in four training sessions per week, for ten weeks, of an alternating upper and lower-body training program. Subject's baseline and post-training 1RM values were used to determine strength increases. No significant differences were found between groups in relative strength in either the squat or bench press exercise (Table 4). A possible limitation from the previously mentioned studies was the use of non-resistance trained individuals. Untrained subjects acquire strength increases no matter what type of RI was used due to no previous neuromuscular adaptations (Baechle \& Earle, 2016).

De Salles et al. (2010) performed a longitudinal study to determine the influence of different RIs on upper-body strength increases in 36 resistance trained men during a 16-week exercise regimen. The subjects prescribed either a 1-min, 3-min, or 5-min RI treatment during a bench press exercise. The results indicated that the group that used a 5-min RI were significantly stronger when compared to the 1-min group (Table 4). The researchers concluded that longer RIs between sets may contribute to greater strength increases. Conversely, a similar longitudinal study using resistance trained men found no significant differences in squat strength gains between groups that used either two or four-minute RI between sets (Table 4) (Willardson \& Burkett, 2008). A consensus of previous research suggests muscular strength gains may not be affected by the duration of rest between sets.

\section{CONCLUSION}

The recommended rest duration between sets consists of using either a short ( $\sim 30 \mathrm{~s}-2$-min) or long ( 2 - 5-min) RI based on an individual's resistance training goal (Haff \& Triplett, 2016). Prior investigations in RI effects have suggested the use of longer RIs during training with a heavy load because they allowed for a greater amount of time to resynthesize energy substrates and remove metabolic waste (Kraemer \& Fleck, 2007; Harris et al, 1976). Furthermore, longer RIs were the most successful at sustaining and increasing the repetitions performed (Richmond \& Godard, 2004). The population most affected by longer RIs was resistance-trained men, specifically during multijoint exercises with a heavy training load (Dias et al., 2014; Faigenbaum et al., 2008; Mirzaei, Arazi, \& Saberi, 2008).

Increasing the maximum number of repetitions performed leads to a greater training volume completed during an exercise session. In prior research, subjects overall training volume was the most affected by longer RIs (Miranda et al., 2009). The most reliable results of the 
linear relationship between RI duration and training volume was found in studies that observed chronic effects with longer experimental treatments (De Souza Jr. et al., 2010; Willardson\& Burkett, 2008). The only inconclusive results of RI manipulation were studies that investigated muscular strength adaptations (Buresh, Berg, \& French, 2009). The results showed a possible link between longer rest between and strength gains, but a consensus from the literature suggests further longitudinal research may be needed (De Salles et al., 2010; Gentil et al, 2010; Willardson \& Burkett, 2008).

Despite certain findings, none of the RIs prescribed to subjects allowed for the complete maintenance of repetitions throughout sets, which ultimately affects the training volume completed (reps $\times$ sets $\times$ load). This lead the researchers in the aforementioned studies to conclude that further research is needed on RIs longer than five minutes, possibly eight minutes (Haff \& Triplett, 2016; Harris et al., 1976), to see if there are any further contributions to resistance training performance, specifically in repetition performance and the volume of training completed.

\section{REFERENCES}

American College of Sports Medicine (ACSM). Progression models in resistance training for healthy adults. (2009). Medicine \& Science in Sports \& Exercise, 41(3), 687-708. doi: 10.1249/mss.0b013e3181915670

Buresh, R., Berg, K., \& French, J. (2009). The effect of resistive exercise rest interval on hormonal response, strength, and hypertrophy with training. Journal of Strength and Conditioning Research, 23(1), 62-71. doi: 10.1519/jsc.0b013e318185f14a

Dias, M.R.C., de Matos, D.G., Mazini, Filho M.L., Moreira, O.C., Hickner, R.C., Cardozo, D., Alves, H.B., Reis, L.G., \& Aidar, F.J. (2014). Comparison of repetition number between uni-joint and multi-joint exercises with 1-min and 2-min rest intervals. $J$ Exerc Physiol Online, 17(4), 93-101. Retrieved from: https://www.asep.org/asep/asep/JEPonlineAUGUST2014_Matos.pdf

Donnelly, J. E., Blair, S. N., Jakicic, J. M., Manore, M. M., Rankin, J. W., \& Smith, B. K. (2009). Appropriate physical activity intervention strategies for weight loss and prevention of weight regain for adults. Medicine \& Science in Sports \& Exercise, 41(2), 459-471. doi: 10.1249/mss.0b013e3181949333

Evangelista, R., Pereira, R., Hackney, A. C., \& Machado, M. (2011). Rest interval between resistance exercise sets: Length affects volume but not creatine kinase activity or muscle soreness. International Journal of Sports Physiology and Performance, 6(1), 118-127. doi: 10.1123/ijspp.6.1.118

Faigenbaum, A. D., Ratamess, N. A., Mcfarland, J., Kaczmarek, J., Coraggio, M. J., Kang, J., \& Hoffman, J. R. (2008). Effect of rest interval length on bench press performance in boys, teens, and men. Pediatric Exercise Science, 20(4), 457-469. doi: 10.1123/pes.20.4.457

Gentil, P., Bottaro, M., Oliveira, E., Veloso, J., Amorim, N., Saiuri, A., \& Wagner, D. R. (2010). Chronic effects of different between-set rest durations on muscle strength in nonresistance trained young men. Journal of Strength and Conditioning Research, 24(1), 3742. doi: 10.1519/jsc.0b013e3181b2965c

Haff, G., \& Triplett, N. T. (2016). Essentials of strength training and conditioning (4th ed.). Champaign, IL: Human Kinetics.

Harris, R. C., Edwards, R. H. T., Hultman, E., Nordesjö, L. O., Nylind, B., \& Sahlin, K. (1976). The time course of phosphorylcreatine resynthesis during recovery of the quadriceps muscle in man. Pflugers Archiv, 367(2), 137-142. https://doi.org/10.1007/bf00585149

Jan, M.H., Lin, J.J., Liau, J.J., Lin, Y.F., \& Lin, D.H. (2008). Investigation of clinical effects of high- and low-resistance training for patients with knee osteoarthritis: A randomized controlled trial. Physical Therapy, 88(4), 427-436. doi: 10.2522/ptj.20060300

Kenney, W. L., Wilmore, J. H., \& Costill, D. L. (2015). Physiology of sport and exercise. Champaign, IL: Human Kinetics.

Kraemer, W. J. (1997). A series of studies: The physiological basis for strength training in American football. Journal of Strength and Conditioning Research, 11(3), 131-142. doi: 10.1519/00124278-199708000-00001

Kraemer, W, \& Fleck, S. (2007). Optimizing strength training: Designing nonlinear periodization workouts. Champaign, IL: Human Kinetics.

Larson, G. D., \& Potteiger, J. A. (1997). A comparison of three different rest intervals between multiple squat bouts. Journal of Strength and Conditioning Research, 11(2), 115-118. doi: 10.1519/00124278-199705000-00011

Miranda, H., Simão, R., Moreira, L.M., de Souza, R.A., de Souza, J.A., de Salles, B.F., \& Willardson, J. M. (2009). Effect of rest interval length on the volume completed during upper body resistance exercise. J Sports Sci Med, 1(8): 388-392, 2009. Retrieved from: https://www.ncbi.nlm.nih.gov/pubmed/24150002

Mirzaei, B., Arazi, H., \& Saberi, Y. (2008). The effect of different rest intervals on sustainability of bench press repetitions with heavy vs light loads. International journal of fitness, 4(2): 9-16.

Monteiro, W. D., Venturim, F. O., Perez, A. J., \& Farinatti, P. T. (2013). Work volume in strength training is not affected by rest interval strategy. The Journal of sports medicine and physical fitness, 53(3), 312-318. Retrieved from: https://www.minervamedica.it/en/journals/sports-med-physical-fitness/article.php?cod=R40Y2013N03A0312\&acquista=1

Progression Models in Resistance Training for Healthy Adults. (2002). Medicine and Science in Sports and Exercise, 34(2), 364-380. doi: 10.1097/00005768-200202000-00027

Ratamess, N. A., Falvo, M. J., Mangine, G. T., Hoffman, J. R., Faigenbaum, A. D., \& Kang, J. (2007). The effect of rest interval length on metabolic responses to the bench press exercise. European Journal of Applied Physiology, 100(1), 1-17. https://doi.org/10.1007/s00421-007-0394-y

Richmond, S. R., \& Godard, M. P. (2004). The effects of varied rest periods between sets to failure using the bench press in recreationally trained men. Journal of Strength and Conditioning Research, 18(4), 846-849. doi: 10.1519/00124278-200411000-00028 
Robergs, R. A., Ghiasvand, F., \& Parker, D. (2004). Biochemistry of exercise-induced metabolic acidosis. American Journal of Physiology-Regulatory, Integrative and Comparative Physiology, 287(3), R502-R516. https://doi.org/10.1152/ajpregu.00114.2004

Rodrigues, B. M., Rodrigues, A. M., Sandy, D. D., Filho, M. M., \& Dantas, E. M. (2012). The effect of two different rest intervals on the number of repetitions in a training session. Serb $J$ Sports Sci, (1), 37-41.

Retrieved from: https://www.sjss.sportsacademy.edu.rs/archive/number/2012-1

Salles, B. F. D., Simão, R., Miranda, F., Novaes, J. D. S., Lemos, A., \& Willardson, J. M. (2009). Rest interval between sets in strength training. Sports Medicine, 39(9), 765-777. doi: 10.2165/11315230-000000000-00000

Souza, T. P. D., Fleck, S. J., Simão, R., Dubas, J. P., Pereira, B., Pacheco, E. M. D. B., ... Oliveira, P. R. D. (2010). Comparison between constant and decreasing rest intervals: Influence on maximal strength and hypertrophy. Journal of Strength and Conditioning Research, 24(7), 1843-1850. doi: 10.1519/jsc.0b013e3181ddae4a

Weiss, L. W. (1991). The obtuse nature of muscular strength: The contribution of rest to its development and expression. The Journal of Strength and Conditioning Research, 5(4), 219-227. doi: 10.1519/1533-4287(1991)005<0219:tonoms>2.3.c0;2

Willardson, J. M., \& Burkett, L. N. (2005). A comparison of 3 different rest intervals on the exercise volume completed during a workout. The Journal of Strength and Conditioning Research, 19(1), 23. doi: 10.1519/r-13853.1

Willardson, J. M. (2006). A brief review: Factors affecting the length of the rest interval between resistance exercise sets. The Journal of Strength and Conditioning Research, 20(4), 978. doi: 10.1519/r-17995.1

Willardson, J. M., \& Burkett, L. N. (2008). The effect of different rest intervals between sets on volume components and strength gains. Journal of Strength and Conditioning Research, 22(1), 146-152. doi: 10.1519/jsc.0b013e31815f912d

\section{Author Information}

Dennis J. Hernandez, DPT.

(D https://orcid.org/0000-0002-5429-7562

Department of Physical Therapy

D’Youville College, Buffalo, NY, USA

준 hernad09@dyc.edu
Young Sub Kwon, Ph.D., Corresponding Author (D https://orcid.org/0000-0001-8920-2757

Associate Professor \& Director of Human Performance Lab Department of Kinesiology and Recreation Administration College of Professional Studies

California Polytechnic University, Humboldt, Arcata, CA, USA

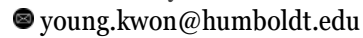

Conflict of Interest: The authors declare that the research was conducted in the absence of any commercial or financial relationship that could be constructed as a potential conflict of interest.

Publisher's Note: All claims expressed in this article are solely those of the authors and do not necessarily represent those of their affiliated organizations, or those of the publisher, the editors and reviewers. Any product that may be evaluated in this article, or claim that may be made by its manufacturer, is not guaranteed or endorsed by the publisher. 


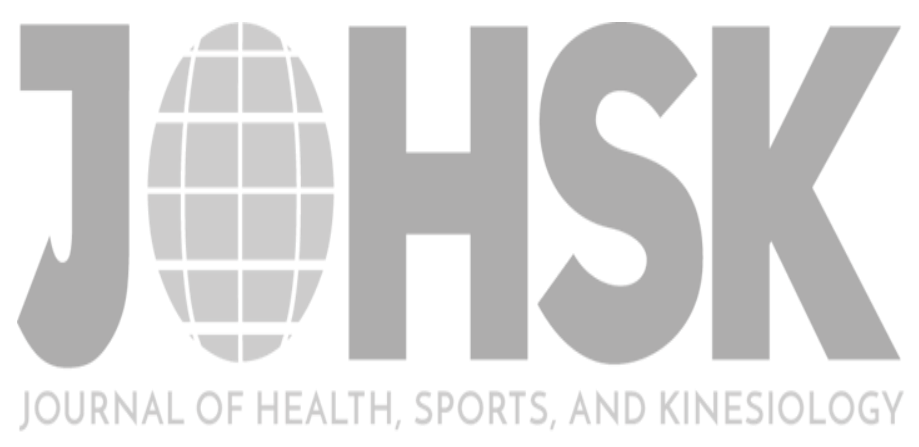

JOHSK ISSN

Volume URL

Volume DOI

Issue DOI
2692-9864 (Online) \& 2767-5874 (Print)

https://www.johsk.com/2021_vol2_issue4

https://doi.org/10.47544/johsk.2021.2.4.0146

https://doi.org/10.47544/jhsk.2021.12.31
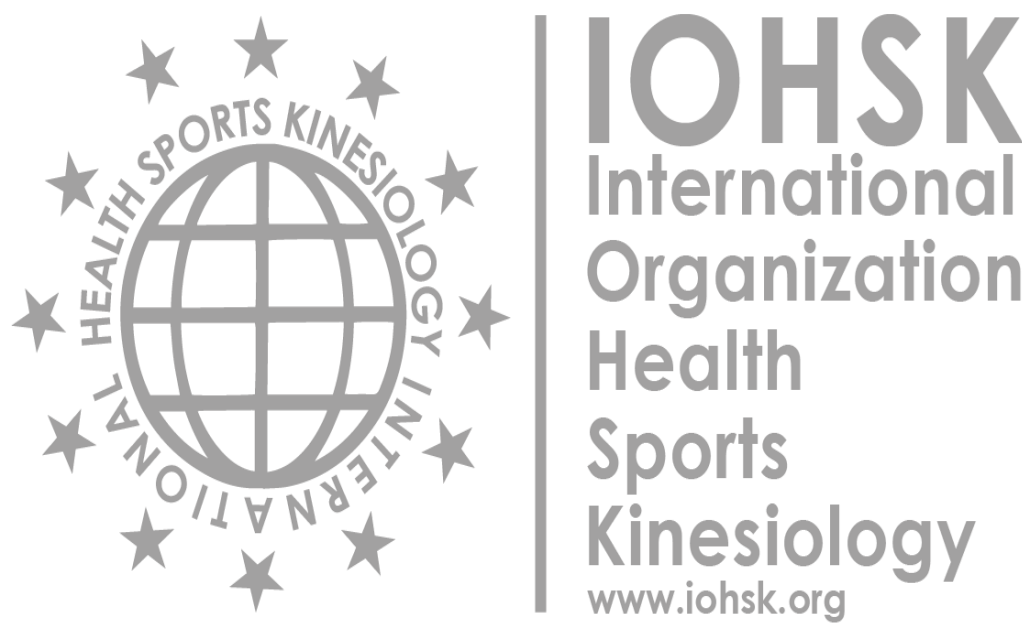

www.iohsk.org

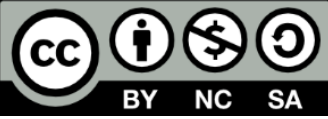

Copyright (C) 2020-2021. This work is licensed under a CC BY-NC-SA 4.0 International license. This is an open access article distributed under the Creative Commons Attribution License which permits unrestricted use, distribution, and reproduction in any medium, provided the original work is properly cited. 